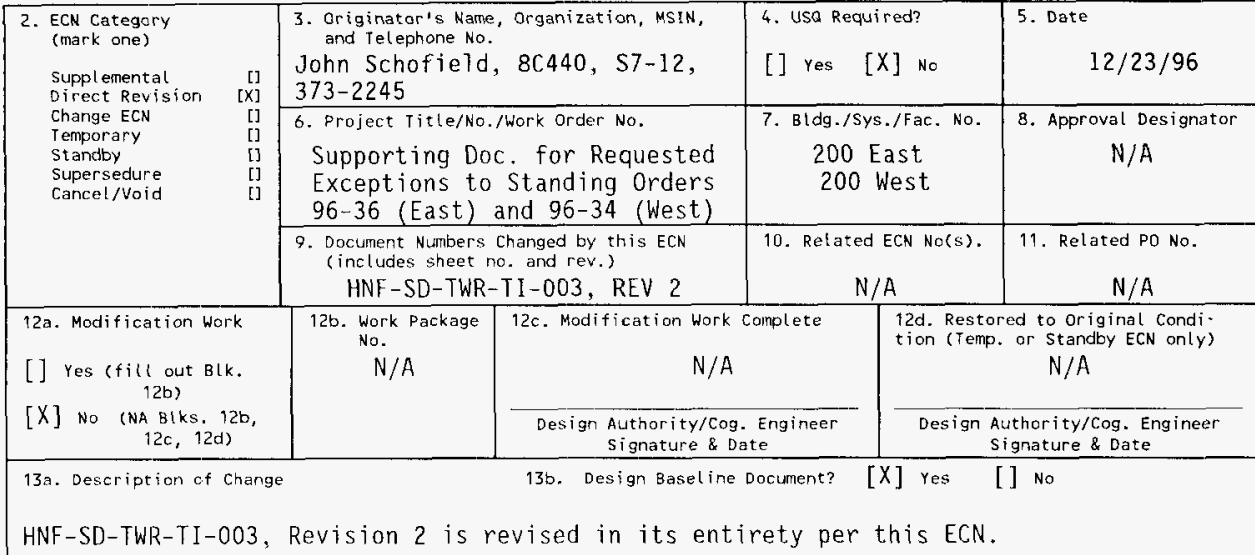

14a. Justification (mark one)

criteria change $[X]$ Design Improvement

As-Found

[]

Facilitate Const

[] Environmental

[]

Facility Deactivation

[]

Const. Error/Omission

Design Error/Omission

14b. Justification Details

HNF-SD-TWR-TI-003, Revision 2 is updated to incorporate comments following internal and DOE review.

15. Distribution (include name, MSIN, and no. of copies)

See Distribution Sheet.

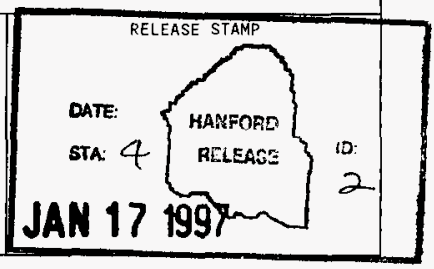




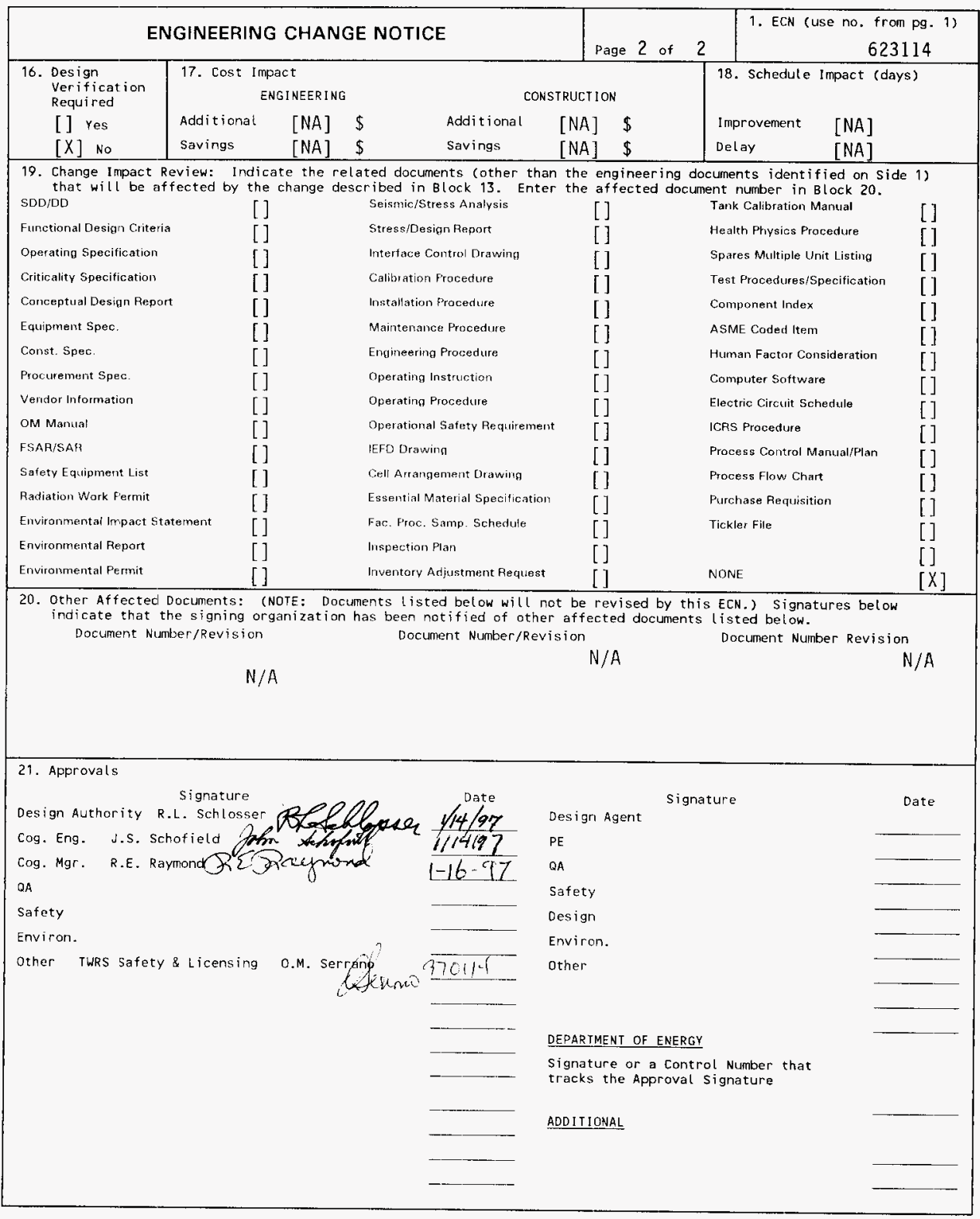




\title{
Supporting Documentation for Requested Exceptions to Standing Orders 96-36 (East) and 96-34 (West)
}

\author{
J.S. Schofield \\ NUMATEC, Richland, WA 99352 \\ U.S. Department of Energy Contract DE-AC06-87RL10930 \\ EDT/ECN: $\quad 623114$ \\ Org Code: $8 \mathrm{C} 440$ \\ UC: 2070 \\ Charge Code: N4J1A \\ BRR Code: EW3120074 \\ Total Pages: 81 \\ Key Words: Standing Order 96-36 (East) \\ Standing Order 96-34 (West)
}

Abstract:

Tefzel is at trademark of E.I. du Pont Nemours \& Co.

TFADEMARK DISCLAIMER. Reference herein to any specific comercial product, process, or service by trade name, trademark, manufacturer, or otherwise, does not necessarily constitute or imply its endorsement, recommendation, or favoring by the United States Government or any agency thereof or it:s contractors or subcontractors.

Printed in the United States of America. To obtain copies of this document, contact: WHC/BCS Document Control Services, P.O. Box 1970, Mailstop H6-08, Richland WA 99352, Phone (509) 372-2420; Fax (509) $376-4989$.
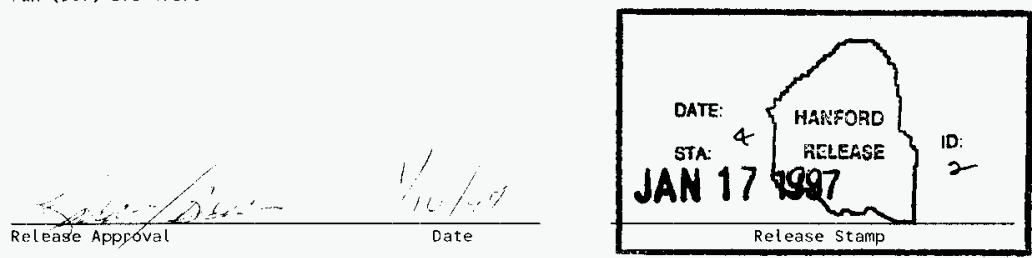

\section{Approved for Public Release}


(2) Title

SUPPORTING DOCUMENTATION FOR REQUESTED EXCEPTIONS TO STANDING ORDERS 96-36 (EAST) AND 96-34 (WEST)

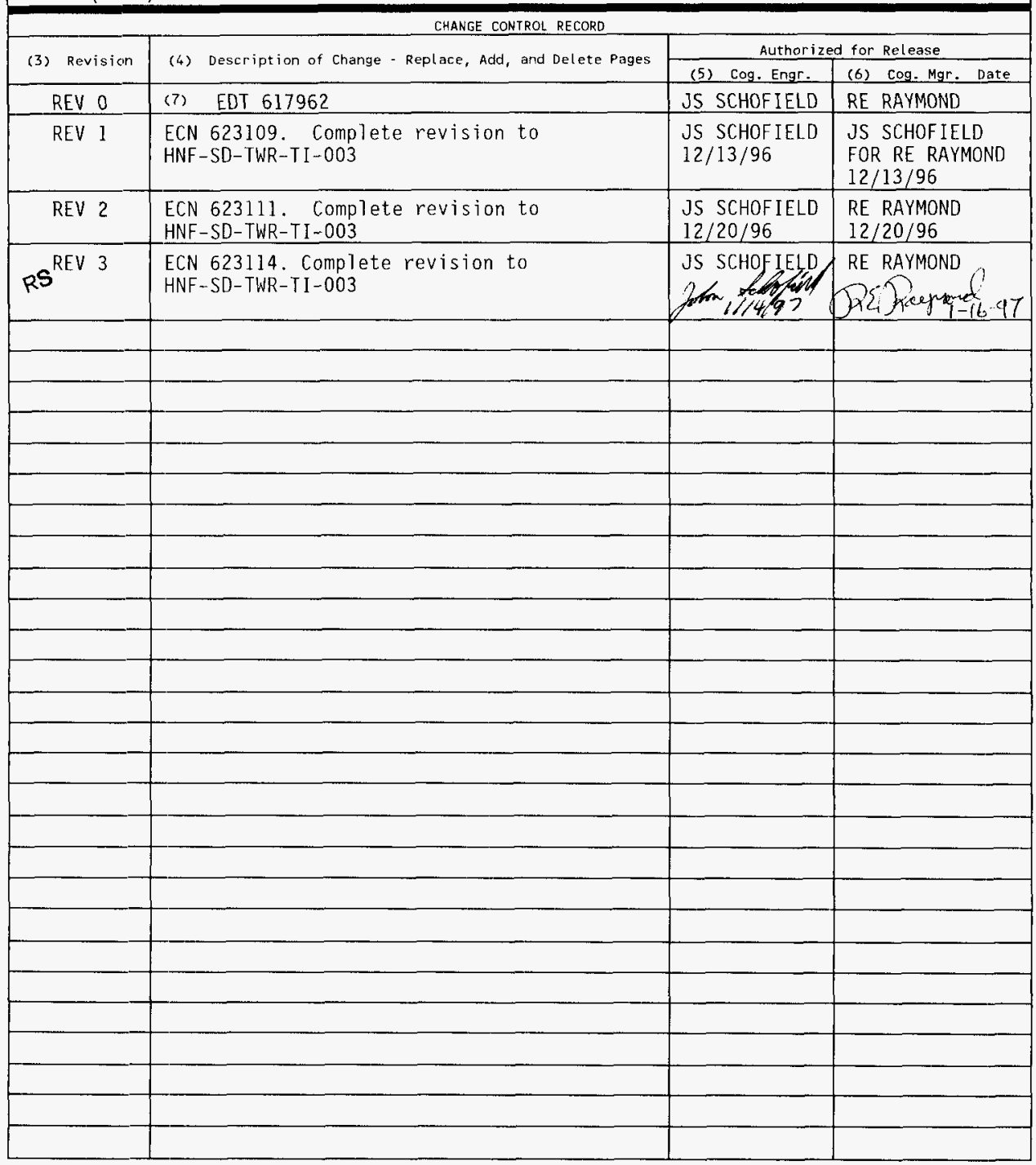


HNF-SD-TWR-TI-003, REV. 3

\title{
Supporting Documentation For Requested Exceptions to Standing orders 96-36 (East) and 96-34 (West)
}

J. S. Schofield

January 1997

the U.S. Department of Energy under Contract DE-AC06-96RL13200

\author{
Numatec Hanford Company \\ Lockheed Mart in Hanford Corporation \\ DE\&S Hanford, Inc. \\ Richland, Washington 99352
}




\section{SUMMARY}

On November 1, 1996 the U.S. Department of Energy (DOE), Richland Operations Office (RL) approved the Flammable Gas Unreviewed Safety Question (USQ) (Wagoner 1996). The Tank Waste Remediation System issued (Ha11 1996) two standing orders (96-36 East; and 96-34 West) to implement the requirements and authorization for continued operations included in the RL letter (Wagoner 1996). These standing orders included several requirements for the control of ignition sources (Appendix B, Section 7.0 "Ignition Source Controls") that include requirements for the design and operation of "...equipment and materials used in the conduct of work..." in Tank Farms.

A verbatim compliance review of these ignition source controls identified several pieces of equipment and materials which have been used routinely in Tanks Farms for many years in support of safe operation that either could not:

1. meet the equivalent design or safety provisions included in the standing orders (Hall 1996), or

2. be modified in a timely manner to meet safety and programmatic commitments.

When the standing order was prepared it was anticipated that there would be a need to approve temporary exceptions. Appendix B, Section 7.0 of the standing order (Hall 1996) reads in part as follows: "For activities where compliance will require modification to equipment or new materials, any temporary exceptions specifically allowed by RL until full compliance with the standing order is accomplished, are 1 isted in Table 3. "

This document provides a specific listing of the items of equipment or material that could not meet the above two criteria. Also included in a table for each item is the following information:

1. the applicable control in the standing orders that could not be met,

2. under what conditions (when) the control could not be met,

3. a discussion of the applicability of the standing order,

4. a discussion of the risk associated with continued use of the equipment or material, and

5. a discussion of the impact of not allowing continued use of the equipment or material.

The purpose of this supporting document is to provide a record of the information used to support a decision to grant temporary exceptions to the requirements in the standing order. 


\section{PROCESS FOR DEVELOPING THE LIST}

The cognizant engineers for East and West Tank Farms (which includes personnel assigned to special activities such as saltwell pumping) and Characterization Field Engineering were directed to perform an exhaustive review of the equipment and materials used routinely to support safe operations to meet programmatic requirements. Those items which could not be immediately modified or excluded without impacting safe (defined as required to meet Nuclear Safety, Environmental Safety, Radiological Safety, and Industrial Safety) operations were then compiled on a list and submitted to the Manager, Characterization Field Engineering. This list of equipment and materials was then submitted to the Flammable Gas Equipment Advisory Board (FGEAB) for review and acceptance if possible. See Appendix B, Section 7.0 of the standing order (Hall 1996) for the responsibilities of the FGEAB.

Those items that could not be accepted by the FGEAB (as providing an equivalence with the ignition source controls as stated in the standing orders) were then evaluated by the TWRS Design Authority (DA) and the Plant Review Committee (PRC). Al1 three of these groups (FGEAB, DA, and PRC) concluded that these items should be submitted to RL for approval of a temporary exception to the requirements of the standing order.

\section{ORGANIZATION OF THE LIST}

The list of equipment and materials has been organized based upon one of two judgements regarding risk.

1. The item is judged to pose a negligible risk from an ignition source standpoint. These items are termed de minimus.

De minimus items represent uncontrolled but negligible spark sources. Most are associated with manned work and work location monitoring requirements are in force. Several items are installed equipment and are therefore always present in the tanks and no monitoring controls or actions are appropriate, or

2. The item is judged to not pose a negligible risk from an ignition sources standpoint, but risk is judged to be acceptable for the time period covered by the standing order and in light of the importance of the waste management and safety related activities and operations that must utilize these items. These items are termed non-de minimus. Risk is managed with flammable gas monitoring.

Monitoring is designed to ensure, in the event an ignition source is inadvertently introduced into the area, flammable gases are below the level of concern for a fire, deflagration, or detonation. If increasing levels of flammable gases are detected, appropriate actions are taken. 


\section{ACRONYMS AND ABBREVIATIONS}

$\begin{array}{ll}\text { ALARA } & \text { As low as reasonably achievable } \\ \text { CGM } & \text { Continuous gas monitoring } \\ \text { DA } & \text { Design Authority } \\ \text { FG } & \text { Facility Group } \\ \text { FGEAB } & \text { Flammable Gas Equipment Advisory Board } \\ \text { GRE } & \text { Gas release event } \\ \text { GWD } & \text { Global waste disturbing activities } \\ \text { HPT } & \text { Health Physics Technician } \\ \text { ICS } & \text { Ignition Control Set } \\ \text { IMUST } & \text { Interim miscellaneous underground storage tank } \\ \text { ISVS } & \text { In situ vapor system } \\ \text { LFL } & \text { Lower flammability limit } \\ \text { LOW } & \text { Liquid Observation Wells } \\ \text { LWD } & \text { LocaT waste disturbing activities } \\ \text { NEC } & \text { National Electrical Code } \\ \text { NON } & \text { Non-waste disturbing activities } \\ \text { OSD } & \text { Operating System Document } \\ \text { OSR } & \text { Operating System Requirement } \\ \text { OVM } & \text { Organic Vapor Monitor } \\ \text { PADI } & \text { Pocket Alarming Dose Integrator } \\ \text { PAM } & \text { Portable Alpha Monitor } \\ \text { PAPR } & \text { Powered Air Purifying Respirators } \\ \text { PMCS } & \text { Push Mode Core Sampling } \\ \text { PPE } & \text { Personal Protection Equipment } \\ \text { PRC } & \text { Plant Review Committee } \\ \text { PVC } & \text { Poly Vinyl Chloride } \\ \text { RGS } & \text { Retained Gas Sampler } \\ \text { RH } & \text { Relative humidity } \\ \text { RL } & \text { U.S. Department of Energy, Richland Operations Office } \\ \text { RLU } & \text { Remote latch unit } \\ \text { RMCS } & \text { Rotary Mode Core Sampling } \\ \text { RWP } & \text { Radiation Work Permit } \\ \text { SHMS } & \text { Standard Hydrogen Monitoring System } \\ \text { TWRS } & \text { Tank Waste Remediation System } \\ \text { USQ } & \text { Unreviewed Safety Question } \\ & \\ & \\ & \end{array}$

\section{REFERENCES}

Wagoner, J. D., Letter to H. J. Hatch, President Fluor Daniel Hanford Inc, "Contract Number DE-AC06-96RL13200; The U.S. Department of Energy (DOE), Richland Operations Office (RL), Definition and Declaration of Flammable GaS Unreviewed Safety Question (USQ)," 96-WSD-283, November 1, 1996.

Hal1, L. E., Letter to Sal Marchetti, Project Director TWRS, Fluor Daniel Hanford, Inc., "Response to U.S. Department of Energy Richland Operations Office Declaration of Flammable Gas Unreviewed Safety Question," 9655505, November 8, 1996. 
HNF-SD-TWR-TI-003, REV. 3

\section{DE MINIMUS}




\title{
ITEIY CLASSIFICATION: DE MINIMUS
}

\author{
ITEM NUMBER: 1 (page 1 of 4 ) \\ EQUIPMENT: Rubber/plastic gloves, canvas gloves. Tyvek clothing, plastic clothing \\ CAYEGORY: Static Spark Potential
}

USE: :

Used for protecting personnel from contamination.

APPLI ICABLE CONTROL NOT MET:

ICS 2 \#' (ICS 1 \#3)

\author{
WHEN CONTROL NOT MET: \\ FG 1 Ex Tank (LWD, GWD) \\ FG 2 Ex Tank (GWD) \\ FG 1,2 Dome Intrusive (LWD, GWD) \\ FG 3 Dome Intrusive (LWD, GWD) \\ FG 1,2,3 Waste Intruding Equipment
}

\section{DISCUSSION OF STANDING ORDER APPLICABILITY:}

Surgeon's gloves, or other "rubber" gloves, are worn in radiation areas for personnel protection. Canvas gloves are coated with a vinyl covering when new, most of which eventually gets removed in the laundry. Gloves are worn in Ex Tank regions, but occasionally might be placed minimally inside a dome intrus ive area or waste intruding equipment. Tyvek clothing or plastic clothing is worn during operations with the potential for high personnel contamination. Tyvek clothing complies with the standing orders when grounded. This is not done at this $t$ ime, Plastic clothing does not comply with the standing orders. Use of either of those articles of protective clothing is a significant issue with respect to personnel contamination control. These are judged to have a negligible potential for creating sparks. Finger ring use (for radiologicat monitoring) meets equivalence with the standing orders, and so finger rings are not included in the above iteris.

\section{RISK ACCEPTANCE:}

This is an item where worker safety must be balanced with negligible ignition source risk. Gloves are used in Ex Tark locatiogs, but may be used in a minimally dome or waste intrusive location (e.g., at the entry of a riser or LOW). Tyvek and plastic clothing is only worn in an Ex Tank region. The risk of personnel contamination due to not using these gloves or clothing is unacceptable. The resulting delay to all sampling work, and most other tark intrusive work, the ability to obtain characterization data from waste tanks that is used both for helping to close safety issues and for design of privatization waste handling facilities must be balanced with the smalt risk of a $\mathrm{flammable} \mathrm{gas} \mathrm{ignition} \mathrm{event} \mathrm{due} \mathrm{to} \mathrm{a} \mathrm{spark} \mathrm{from} \mathrm{the} \mathrm{gloves} \mathrm{or} \mathrm{clothing.} \mathrm{The} \mathrm{risk} \mathrm{associated} \mathrm{with}$ continuing to use the gloves or clothing is managed by performing flammable gas monitoring, with safe shutdown controls, prior to and/or during use. This will include monitoring per method [A], [B], [C] or [D] as appropriate for the activity. See definition of monitoring methods at the end of this section. This manitoring is in full compliance with the monitoring requirements referenced by RL letter 96-WSD-283.

The persson performing the initial monitoring per [A] will be wearing rubber gloves, probably canvas gloves, and posisible Tyvek or plastic clothing. It is an acceptable risk to have him perform the monitoring while wearing these it:ems.

IMF'ACT OF NOT ACCEPTING RISK OF CONTINUED USE:

Facility Group 1 Tanks-Would stop all Ex Tank, dome intrusive work and waste intruding equipment work.

Facility Group 2 Tanks-Would stop all dome intrusive and waste intruding equipment, and some Ex Tank work.

Facility Group 3 or other Tanks-Would stop all waste disturbing dome intrusive, and waste intruding equipment work.

REGIUESTED APPROVAL FROM DOE:

Cortinued use whep performing flammable gas monitoring controls [A], [B], [C] or [D] for rubber gloves, canvas gloves, and Tyvek or plastic clothing in:

1) FG i EX Tank regions

2) FG 1,2 tanks during Dome Intrusive activities.

3) FG 1,2,3 tanks in waste intruding equipment.

4) FG 2 EX Tank region during global waste disturbing activities

5) FG 3 tanks for Dome Intrusive regions during local or global waste disturbing activities. 


\section{ITEM CLASSIFICATION: DE MINIMUS}

ITEM NUMBER: 1 (page 2 of 4)

EQUIPMENT: Air respirators, air fed hoods, and breathing air hoses

CATEGORY: Static Spark Potential

USE:

Used for providing adequate breathing air.

APFLICABLE CONTROL NOT MET:

ICs $2 \# 1$
WHEN CONTROL NOT MET:

FG 1 Ex Tank

FG 2 Ex Tank (GWD)

DISCUSSION OF STANDING ORDER APPLICABILITY:

Air respirators are made from rubber and plastic. Breathing air hoses are made from rubber. These are judged to have a regligible potential for creating sparks.

\section{RISK ACCEPTANCE:}

This is an item where worker safety must be balanced with negligible ignition source risk. The risk of internal contamination or inhalation of potentially toxic vapors due to not using respirators or breathing air when needed is unacceptable. The resulting delay to sampling work, and most other tank intrusive work, the ability to obtain characterization data from waste tanks that is used both for helping to close safety issues and for design of privatization waste handling facilities must be balanced with the small risk of a flammable gas ignition event due to a spark from the respirators or hoses. The risk associated with continuing their use is managed by performing flammable gas monitoring, with safe shutdown controls, prior to and/or during use. This will include monitoring per method [A] for the activity. See definition of monitoring methods at the end of this section. This monitoring is in full compliance with the monitoring requirements referenced by RL letter 96-WSD-283.

The person performing the initial monitoring per [A] may be wearing a respirator or an air hose. It is an acceptable risk to have him perform the monitoring while wearing these items.

IMPACT OF NOT ACCEPTING RISK OF CONTINUED USE:

Facility Group 1 Tanks-Would stop alt Ex Tank, and by default, most dome intrusive work and waste intruding equipinent work.

Facility Group 2 Tanks-Would stop all Ex Tank, and by default, most dome intrusive work and waste intruding equipment work during global waste disturbing activities.

Facility Group 3 or other Tanks-No Impact.

REQUESTED APPROVAL FROM DOE:

Continued use when performing $f$ lammable gas monitoring control [A] for respirators and breathing air hoses in:

1) FG 1 Ex Tank regions

2) FG 2 Ex Tank regions during global waste disturbing activities 
ITEM CLASSIFICATION: DE MINIMUS

\author{
ITEM NUMBER: 1 (page 3 of 4 ) \\ EQUIPMENT: Rubber/plastic footwear \\ CATEGORY : Static Spark Potential
}

USE :

Used for protecting feet from contamination.

APPLICABLE CONTROL NOT MET:

ICS 2 \#1
WHEN CONTROL NOT MET:

FG 1 Ex Tank

FG 2 Ex Tank (GWD)

DISCUSSION OF STANDING ORDER APPLICABILITY:

Rubber boots are worn in radiation areas for personnel protection. Rubber boots are judged to have a negligible potential for creating sparks.

\title{
RISK ACCIEPTANCE :
}

This is an iten where worker safety must be batanced with negligible ignition source risk. The risk of personnel contamination and loss of contamination control due to not using boots is unacceptable. The resulting delay to sampling work, and most other tank intrusive work, the ability to obtain characterization data from waste tanks that is used both for helping to close safety issues and for design of privatization waste handi ing facilities must: be balanced with the small risk of a flammable gas ignition event due to a spark from the boots. The risk assuciated with continuing to use the boots is managed by performing flammable gas monitoring, with safe shutdown controls, prior to and/or during use. This will include monitoring per method [A] for the activity. See definition of monitoring methods at the end of this section. This monitoring is in full compliance with the monitoring requirements referenced by RL Letter 96-WSD-283.

The person performing the initial monitoring per [A] will be wearing rubber boots. It is an acceptable risk to have him perform the monitoring while wearing the boots.

IMPACT OF NOT ACCEPTING RISK OF CONTINUED USE:

Facility Group 1 Tanks-Would stop all Ex Tank, and by default, most dome intrusive work and waste intruding equipment work.

Facility Group 2 Tanks-Would stop all Ex Tank, and by default, most dome intrusive work and waste intruding equipment work during global waste disturbing activities.

Facility Group 3 or other Ianks-No Impact.

REQUESTED APPROVAL FROM DOE:

Continued use when performing flamable gas monitoring control [A] for rubber boots in:

1) FG 1 Ex Tank regions

2) FG 2 Ex Tank regions during global waste disturbing activities 


\title{
ITEM CLASSIFICATION: DE MINIMUS
}

\author{
ITEM NUMBER: 1 (page 4 of 4 ) \\ EQUIPMENI : Installation, removal or use of masking tape \\ CATEGORY: static spark Potential
}

USE :

Used for taping up protective clothing.

APPLICAELE CONTROL NOT MEI:

ICS 2 \#
WHEN CONTROL NOT MET:

FG 1 Ex Tank

FG 2 EX Tank (GWD)

\section{DISCUSSION OF STANDING ORDER APPLICABILITY:}

Masking tape is used for taping personal protective clothing, therefore, is present in Ex Tank regions. The primary spark potential is when applying or removing the tape. Applying or removing masking tape could form small static sparks under certain conditions. Taping is not normally done in an Ex Tank area, but may be necessary in certain circumstances. Masking tape is judged to have a negligible potential for creating sparks.

\section{RISK ACCEPTANCE:}

This is an item where worker safety must be balanced with negligible ignition source risk. The risk of contamination due to not using masking tape is unacceptable. The resulting delay to sampling work, and most other tank intrusive work, the ability to obtain characterization data from waste tanks that is used both for helping to close safety issues and for design of privatization waste handling facilities must be balanced with the small risk of a $f$ lammable gas ignition event due to a spark from the tape. The risk associated with continuing the tape use is managed by performing flamable gas monitoring, with safe shutdown controls, prior to and/or during use. This will include monitoring per method [A] for the activity. See definition of monitoring methods at the end of this section. This monitoring is in full compliance with the monitoring requirements referenced by RL letter 96-WSD-283.

The person performing the initial monitoring per [A] will be wearing masking tape. It is an acceptabie risk to have him perform the monitoring while wearing the tape.

IMPACT OF NOT ACCEPTING RISK OF CONTINUED USE:

Facility Group 1 Tanks-Would stop all Ex Tank, and by default, most dome intrusive work and waste intruding equipment: work.

Facility Group 2 Tanks-Would stop all Ex Tank, and by default, most dome intrusive work and waste intruding equipment: work during global waste disturbing activities.

Facility Group 3 or other Tanks-No Impact.

REQUESTED APPROVAL FROM DOE:

Continued use when performing flammable gas monitoring control [A] for masking tape in:

1) FG 1 Ex Tank regions

2) FG 2 EX Tank regions during global waste disturbing activities 


\title{
ITEM CLASSIFICATION: DE MINIMUS
}

\author{
ITEM MUMBER: 2 \\ EOUIPMENT: Wearing of plastic badges, badge holders, and dosimeters. \\ CATEGORY: Static Spark potential
}

USE: :

Used for security and dosimetry.

APPLICAELE CONTROL NOT MET:

$\operatorname{lcs} 2 \# 1$
WHEN CONTROL. NOT MET:

FG 1 Ex Tank

FG 2 Ex Tank (GWD)

\section{DISCUSSION OF STANDING ORDER APPLICABILITY:}

Badges and dosimeters are small, plastic items which all personnel are required to carry for security and exposure monitoring. Risk of a static spark in the above listed Ex Tank regions from these $i$ tems should be small, especially if they are inside another pair of protective clothing. Badges, badge holders, and dosimeters are judged to have a negligible potential for causing flamable gas ignition under the applied conditions.

\section{RISK ACCEPTANCE:}

This is an item where worker safety must be balanced with negligible ignition source risk. The risk of overexposure due to not using dosimetry, and the violation of security requirements is unacceptable. The resulting delay to sampling work, and most other tank intrusive work, the ability to obtain characterization data from waste tanks that is used both for helping to close safety issues and for design of privatization waste handling facilities must be balanced with the small risk of a flamable gas ignition event due to a spark from the items. The risk associated with continuing their use is managed by performing flammable gas monitoring, with safe shutdown controls, prior to and/or during use. This will include monitoring per method [A] for the activity. See definition of monitoring methods at the end of this section. This monitoring is in full compl $i$ ance with the monitoring requirements referenced by RL letter 96-WSD-283.

The person performing the initial monitoring per [A] will be wearing a badge, badge holder, and dosimetry. It is an acceptable risk to have him perform the monitoring while wearing these items.

IMPACT OF NOT ACCEPTING RISK OF CONTINUED USE:

Facility Group 1 Tanks-Would stop all Ex Tank, and by default, most dome intrusive work and waste intruding equipment work.

Facility Group 2 Tanks-Would stop all Ex Tank, and by default, most dome intrusive work and waste intruding equipment work during global waste disturbing activities.

Facil lity Group 3 or other Tanks-No Impact.

REQUESTEL APPROVAL FROM DOE:

Continued use when performing flammable gas monitoring control [A] for badges, badge holders and dosimeters in:

1) FG 1 EX Tank work

2) FG 2 EX Tank regions during global waste disturbing activities 
HNF-SD-TWR-TI-003, REV. 3

\section{ITEM CLASSIFICATION: DE MINIMUS}

\section{ITEM NUMBER: 3}

EQUIPMENT: Installation of, removal of, working on, or extended presence of nonconductive lead blankets

CATEGOR'Y: static Spark Potential

USE: :

Used for portable shielding.

APPLICABLE CONTROL NOT MET:

ICs 2 \#1

WHEN CONTROL NOT MET:

FG 1 EX Tank

FG 2 Ex Tank (GWD)

\section{DISCUSSION OF STANDING ORDER APPLICABILITY:}

The lead blankets currently in use are constructed of a nonconductive polymer jacket surrounding a lead wool blanket. The blankets are used for shielding in the work area. This equipment may be in or outside of an ExTank exclusion zone. There is no ignition source issue with the lead; the verbatim compliance issue is due to the plastic coating. Lead blankets are judged to have a negligible potential for creating sparks.

\section{RISGK ACLEPTANCE :}

This is an item where worker safery must be balanced with negligible ignition source risk. Lead blankets are not arranged in a manner which could trap flammable gases. These blankets are normally installed and removed when Ex Tank regions are not present (i.e. before a riser is opened or after it is closed). During limited instances it may be necessary to move these blankets in one of the above listed Ex Tank areas. Removal is normally done after a riser is sealed. The risk of not using lead blankets would lead to higher personnel exposure if the items cannot be relocated. Failure to approve use of the lead blankets will result in considerable costs. This would restrict some work in the above listed Ex Tank regions until suitable replacements, if available, were obtained. The resulting delay to sampling work and most other tank intrusive work, and the ability to obtain characterization data from waste tanks that is used both for helping to close safety issues and for design of privatization waste handing facilities must be balanced with the small risk of a flamable gas ignition event due to a spark from the blankets. The risk associated with continuing their use is managed by performing flammable gas monitoring, with safe shutdown controls, prior to and/or during use. This will include monitoring per method [A] for the activity. See definition of monitoring methods at the end of this section. This monitoring is in full compliance with the monitoring requirements referenced by RL letter 96-WSD-283.

\section{IMF'ACT OF NOT ACCEPIING RISK OF CONTINUED USE:}

Facility Group 1 Tanks-Would stop some of Ex Tank, and by default some dome intrusive work and waste intruding equipment work.

Faciility Group 2 Tanks-Would stop some Ex Tank, and by default most dome intrusive work and waste intruding equipment work during global waste disturbing activities.

Facility Group 3 or other Tanks-No Impact.

REGIUESTED APPROVAL FROM DOE:

Coritinued use when performing flammable gas monitoring control [A] for lead blankets in:

1) FG ' Ex Tank regions

2) FG 2 EX Tank regions during global waste disturbing activities 
HNF-SD-TWR-TI-003, REV. 3

\section{ITEIM CLASSIFICATION: DE MINIMUS}

\section{ITEM NUMBER: 4}

EQUIPNENT: Installation, removal, or extended presence of nonconductive adhesive tape

CATEGOR': Static Spark Potential

USE:

Used for taping plastics and other miscellaneous items.

APF'LICABLE CONTROL NOT MET:

WHEN CONTROL NOT MET:

ICS $2 \# 1$, ICS $1 \# 3$

FG 1 EX Tank (LWD, GWD)

FG 2 EX Tank (GWD)

FG 1,2 Dome Intrus ive (LWD, GHD)

FG 3 Dome Intrusive (LWD, GWD)

FG $1,2,3$ waste Intruding Equipment

\section{DISCUSSION OF STANDING ORDER APPLICABILITY:}

Nonconductive achesive tape is used routinely in Ex Tank regions. Because of the nature of its use portions of tape will occasionally be exposed to tank vapors during sleeving, bagout or other activities, and as a result it is also included as a dome intrusive and waste intruding equipment item.

\section{RISK ACCEPTANCE:}

The minimal risk is primarily associated with tape application and removal, thus the time at risk is small. Tape is used in Ex Tank locations, but may be used in a minimally dome or waste intrusive location. 1t is used primarily for taping down plastics for contamination control. Depending upon the location, the work to be done, and the contamination level, tape may on occasion be placed around the edge of or just inside a dome intrusive region or $i$ tem of waste intruding equipment. Tape is also used when "horsetailing" out contaminated equipment from a tank. The contaminated item is brought up into a plastic sleeve, the plastic twisted around under the object, and tape wrapped around the twist. The taped area is then cut through and the waste item removed. should the taped joint come apart, the edge of the tape could be exposed to the tank vapors. Tape is also used to seal sleeves around items such as cameras which are lowered into tank vapor spaces. In such cases the tape is in the tank dome for anywhere from a few minutes to a few days. Not using tape would lead to ceasing most activities in the above areas. The resulting delay to sampling work, and most other tank intrusive work, the ability to obtain characterization data from waste tanks that is used both for helping to close safety issues and for design of privatization waste handling facilities must be balanced with the small risk of a flammable gas ignition event due to a spark from the tape. The risk associated with continuing its use is managed by performing flammable gas monitoring, with safe shutdown controls, prior to and/or during use. This will include monitoring per method $[A],[B],[C]$ or $[D]$ as applicable for the activity. See definition of monitoring methods at the end of this section. This monitoring is in full compliance with the monitoring requirements referenced by RL letter 96-WSD-283.

\section{IMFACT OF NOT ACCEPTING RISK OF CONTINUED USE:}

Facility Group 1 Tanks-Would stop all sampling related activities, and most other tank intrusive work.

Facility Group 2 Tanks-Would stop all sampl ing related activities, and most other tank intrusive work.

Facility Group 3 or other Tanks-Would stop all core sampling, and other tank activities with waste intruding equipment.

REQUESTED APPROVAL FROM DOE:

Cont inued use when performing $f$ lammable gas monitoring control [A], [B], [C] or [D] as appropriate for use of green tape in:

1) FG I EX Tank regions

2) FG ? tanks for Ex Tank regions during global waste disturbing activities

3) FG 1,2 Done Intrusive regions

4) FG 3 tanks for Dome Intrusive regions during local and global waste disturbing activities

5) $F G ~ 1,2,3$ tank Waste Intruding Equipment 
HNF-SD-TWR-TI-003, REV. 3

\section{ITEM CLASSIFICATION: 'DE MINIMUS}

\section{ITEM NUMBER: 5}

EQUIPMENT: Portable Alpha Monitor (PAM)

CATEGORY: Electrical Spark Potential

USE :

Used for monitoring for alpha contamination

APPLICABLE CONTROL NOT MET:

ICs 2 \#?

ICS $1 \#$
WHEN CONTROL NOT MET:

FG 1 Ex Tank (LWD, GWD)

FG 2 EX Tank (GWD)

FG 1,2 Dome Intrusive (LWD, GWD)

FG 3 Dome Intrusive (LWD, GWD)

FG $1,2,3$ Waste Intruding Equipment

\section{DISCUSSION OF STANDING ORDER APPLICABILITY:}

The PAM is battery powered. The unit is judged not in verbatim compliance with the standing orders. Per ICS \#2: "As; a minimum the equipment is non-sparking under normal operation...". While the PAM normally meets this requirement, the probe source is eas $i l y$ damaged and a postulated spark could occur if internat electronics were shorted out. The PAM is usually used for determining alpha contamination on smears rather than near a $r i s e r$ or in a waste intruding equipment item. However, sometimes it is necessary to use the PAM to determine cortamination levels (fixed or smearable) on the equipment. PAMs are judged to have a negligible potential for causing flammable gas ignition.

\section{RISK ACLEPTANCE:}

This is an iten where worker safety must be balanced with negligible ignition source risk. The PAM is used in Ex Tank locations, but may be used in a minimally dome or waste intrusive location (e.g., at the entry of a riser or LOW). The PAM is needed for monitoring for alpha contamination. The potential problems arising from an alpha contamination spread are more severe than from a beta gama spread. Monitoring for alpha contamination is required by the RWPs for most waste intruding or dome intrusive activities on tanks which have shown a potential for alpha contamination problems. The requirement for using alpha monitors comes in part from letter $333 \mathrm{BO}$-950.0 JUSTIFICATION FOR DUAL SURVEY EXEMPTION IN 200 EAST TANK FARMS, 8/8/95. Per discussion with a vendor, there are no known battery powered, intrinsically safe, alternatives available for the PAMs. Furthermore, switching to a different monitor could not be made without significant delays due to required testing. PAMs are inspected frequently and checked prior to use, which minimizes the possibility of using a monitor with a failed window. The risk associated with continuing to use the PAM is managed by performing flammable gas monitoring, with safe shutdown controls, prior to and/or during use of the PAM. This will include monitoring per method [A], [B], [C] or [D] as appropriate for the activity. See definition of monitoring methods at the end of this section. This monitoring is in full compliance with the monitoring requirements referenced by RL letter 96-WSD-283.

\section{IMPACT OF NOT ACCEPTING RISK OF CONTINUED USE:}

Facility Group 1 Tanks-Restricts HPT flexibility to monitor riser area for alpha contamination and results in lowering of radiological control and contamination problems. Failure to accept the risk of continuing to use the PAM will: shut down or restrict most waste intrusive work.

Facility Group 2 Tanks-Same as above.

Facility Group 3 or other Tanks-Same as above, for local or global waste disturbing activities.

\section{REQUESTED APPROVAL FROM DOE:}

Continued use when performing flammable gas monitoring controls [A], [B] [C] or [D] as appropriate for PAMs in:

1) Ex Tank regions in FG 1 tanks.

2) Dome Intrusive regions in FG 1,2 tanks.

3) Wast:e Intruding Equipment in $\mathrm{FG}^{2}, 2,3$ tanks.

4) Dome Intrusive regions (LWD, GWD) for FG 3 tanks

5) Ex Tank regions in FG 2 tanks (GWD) 
HNF-SD-TWR-TI-003, REV. 3

\title{
ITEM CLASSIFICATION: DE MINIMUS
}

\author{
ITEM NUMBER: 6 \\ EQUIPMENT: Nonconductive poly bottle
}

CATEGORY: Static Spark Potential

USE: :

Used for contamination control

APPLICABLE CONTROL NOT MET:

ICS $2 \# 1$, ICS $1 \# 3$
WHEN CONTROL NOT MET :

FG 1 Ex Tank

FG 1,2 Dome Intrusive

FG 2 EX Tank (GWD)

\section{DISCUSSION OF STANDING ORDER APPLICABILITY:}

Nonconductive poly bottles are used in Ex Tank regions, but may be used in a minimally intrusive region for washing off some equipment items by pouring the solution inside the bottle over the item and down a $r$ iser. Glass bot:tles could be used as a substitute, but poly bottles have been used because they are safer (non-breakable). Poly bottles are judged to have a negl igible potential for creating sparks.

\section{RISK ACCEPTANCE:}

These bottles are normally used in Ex Tank locations, but may be used in a minimally dome intrusive region when pouring the liquid down a riser. The amount of liquid used is small, nominally $\leq 1$ liter. The velocity of the poured liquid is limited to gravity flow and the wetting action of the liquid on the bottle will minimize static buildup. The potential safety concern associated with breakage of a glass bottle is a greater concern than the small risk of a flammable gas ignition event due to a spark from the plastic bottle. The risk associated with continuing use of the poly bottle is managed by performing flammable gas monitoring, with safe shutdown controls, prior to and/or during use. This will include monitoring per method [H]. See definition of monitoring methods at the end of this section. This monitoring is in full compliance with the monitoring requirements referenced by RL letter 96-WSD-283.

IMPACT OF NOT ACCEPTING RISK OF CONTINUED USE:

Facility Group 1 Tanks-Small impact. Would switch to glass or other container meeting standing order requirernents. Will be a slight increase in the personnel risk for cuts in radiation zones.

Facility Group 2 Tanks-Small impact. Would switch to glass or other container meeting standing order requirements. Will be a slight increase in the personnel risk for euts in radiation zones.

Facility Group 3 or other Tanks-No impact, except when using around/in waste intruding equipment. Would switch to glass or other container meeting standing order requirements. Will be a slight increase in the personnel risk for cuts in radiation zones.

REGIUESTED APPROVAL FRON DOE:

Continued use when performing $\mathrm{flammable} \mathrm{gas} \mathrm{monitoring} \mathrm{control} \mathrm{[H]} \mathrm{for} \mathrm{use} \mathrm{of} \mathrm{nonconductive} \mathrm{poly} \mathrm{bottles} \mathrm{in:}$

1) FG I EX Tank regions

2) FG 1,2 Dome Intrusive regions

3) FG ?'Ex Tank regions during global waste disturbing activities 
HNF-SD-TWR-TI-003, REV. 3

\section{ITEIM CLASSIFICATION: DE MINIMUS}

ITEM NUMBER : 7

EQUIPMENT: Zip cords

CATEGORY: Static Spark Potential

USE: :

Used for taking waste level measurements.

APPLICABLE CONTROL NOT MET:

WHEN CONTROL NOT MET:

ICS $2 \#$, ICS $1 \# 3$

FG 1 EX Tank

FG 1,2 Dome Intrusive

FG 1,2,3 Waste Intrusive

\section{DISCUSSION OF STANDING ORDER APPLICABILITY:}

A zip cord is an insulated wire that is inserted into a riser and lowered down to the waste surface. Waste intruding equipment is included in this evaluation because on rare occasions it may be necessary to use a zip cord in a failed LOW or drill string. The electrical spark produced by the zip cord's contact with the waste or the metal riser is similar to that for manual tapes, which has been analyzed in WHC-SD-WM-ES-176, and is 1 inited by the portable ohm meter used to take the reading. The current level and voltage values are orders of magnitude below the ignition curve in UL 913. Bonding of zip cords is impractical since this would interfere with their operation. Coating of the zip cords with a static reducing compound would provide little reduction in the static discharge risk, and could increase the potential for contamination or waste disposal problems. Zip cords are judged t:o have a negligible potential for creating sparks.

RISK ACCEPTANCE:

See risk acceptance starting on next page.

IMF'ACT OF NOT ACCEPTING RISK OF CONTINUED USE:

Facility Graup 1 Tanks-Would shut down most sanpling activities until an alternate was available, or run the risk of error's in sampling and resulting questions with TCRs.

Facility Group 2 Tanks-Would shut down most sampling activities until an alternate was available, or run the risk of errors in sampling and resulting questions with TCRs.

Facility Group 3 or other Tanks-No impact, except when needed for waste intruding equipment.

REGUESTED APPROVAL FROM DOE:

Continued use when performing flamable gas monitoring control $[H]$ for use of nonconductive coated zip cords in:

1) FG I EX Tank regions

1) FG 1,2 Dome Intrusive regions

2) Wast:e intruding equipment (such as failed LOWs) in FG 1,2,3 tanks 
Risk Acceptance for Zip cords.

The distance between a specific riser and the waste surface is required for many waste intrusive jobs such as leak detection, sampl ing, level gauge installations/repairs or tank equipment installations. Zip cords have been shown to be an inexpensive and easy means of detecting the waste level in tanks. Alternate non tank intrusive measurement systems have been evaluated and determined to be cost prohibitive and substiantially more complex.

The relative humidity (RH) has been measured at $>50 \%$ in $95 \%$ of the non-exhausted tanks sampled. The remaining $5 \%$ of the non exhausted tanks all measured between $40-50 \% \mathrm{RH}$. The SX Farm exhausted tanks measured between $20-40 \% \mathrm{RH}$, except one tank which was $65 \% \mathrm{RH}$. 241-C-105 measured between 40-60\% RH, and 241- $[$; -106 measured between $50-100 \%$ RH. Therefore, for non-exhausted tanks, plastic coated zip cords in dome intrusive regions are expected to be in compl $i$ ance with the standing orders about $95 \%$ of the time. For exhausted tanks, $241-\mathrm{C}-105$ and $24 \uparrow-\mathrm{C}-106$ are approximately $50 \% \mathrm{RH}$. Most double shell tanks would be expected t:o be the same due to the liquid or moist solid surfaces. For waste intruding equipment, waste gases; will, be at $100 \% \mathrm{RH}$ because the gases come from waste pockets surrounded by liquid waste. In such pockets the water vapor in the gas would be at equilibrium with the water in the liquid. The gas in waste intruding equipment may be partially mixed with tank vapors depending upon the work being done but, as most tank vapors have a high $\mathrm{RH}$, the RH of the mixed vapors in waste intruding equipment is expected to be $>50 \%$.

Most sampling would have to be shut down without the use of zip cords. The resulting delay to sampling work, and some other tank intrusive work, the ability to double check questionable ENRAF, manual tape or FIC readings, and the ability to obtain characterization data from waste tanks that is used both for helping to close safety issues and for design of privatization waste handing facilities must be balanced with the small risk of a flammable gas ignition event due to a spark from the zip cord. The risk associated with cont inuing use of the zip cords is managed by performing flamable gas monitoring, with safe shutdown controls, prior to and/or during use. This will include monitoring per method [H]. See definition of monitoring methods at the end of this section. This monitoring is in full compliance with the monitoring requirements referenced by DOE/RL letter 96-WSD-283. 
HNF-SD-TWR-TI-003, REV. 3

\section{ITEM CLASSIFICATION: DE MINIMUS}

\section{ITEM NUMBER: 8}

EQUIPMENT: Nonconduct ive plastic ropes

CATEGORY: Static Spark Potential

USE:

Used for tieing tools used around open risers or miscellaneous purposes.

\begin{tabular}{l|l}
\hline APPLICAIBLE CONTROL NOT MET: & WHEN CONTROL NOT MET: \\
ICS $2 \#, 1$, ICS $1 \# 3$ & FG 1 EX Tank \\
FG 2 EX Tank (GWD)
\end{tabular}

DISCUSSION OF STANDING ORDER APPLICABILITY:

Nonconductive plastic rope is used as lanyards for tools around open risers and other miscellaneous needs. $\mathrm{Plastic}$ rope is judged to have a negligible potential for causing flamable gas ignition under the applied conditions.

\section{RISK ACIEPTANCE:}

Nonconductive plastic rope is used for a variety of applications in addition to restraining tools. If nonconductive plastic rope cannot be used, mani la rope can be used as an alternative. However, manila rope is not: as istrong and can weaken with time when exposed to the elements. Contaminated plastic rope can be wiped down easier. Plastic rope has proven to be more effective and less expensive for general use in tank farms and is used in Ex Tank regions. Normal use of nonconductive plastic ropes does not involve activities that would build up a significant static charge.

The use of plastic rope is advantageous for operations. The inability to use this rope is a significant concern due to increased personnel and clothing contamination potential than the minimal risk of a flammable gas ignition event due to a spark from the plastic rope. The risk associated with continuing use of the rope is managed by performing flammable gas monitoring, with safe shutdown controls, prior to and/or during use. This will include monitoring per method [A]. See definition of monitoring methods at the end of this section. This monitoring is in full compliance with the monitoring requi rements referenced by RL letter 96-WSD-283.

IMPACT OF NOT ACCEPTING RISK OF CONTINUED USE:

Facility Group 1 Tanks-Minor impact, would switch to manila or similar rope, would increase potential for personnel contamination.

Facility Group 2 Tanks-Minor impact, would switch to manila or similar rope, would increase potential for personnel contamination.

Facility Group 3 or other Tanks-No impact, except when using around/in waste intruding equipment, would switch to manila or similar rope, would increase potential for personnel contamination.

\section{REQUESTIED APPROVAL FROM DOE:}

Cont inued use when performing flammable gas monitoring control [A] for use of nonconductive plastic rope in:

1) FG 'I EX Tank regions

2) FG ? EX Tank regions during global waste disturbing activities 
HNF-SD-TWR-TI-003, REV. 3

\section{ITEIM CLASSIFICATION: DE MINIMUS}

ITE:M NUMBER: 9

EQUIPMENT: Nonconductive plastic tubing

CATEGORY: Static Spark Potential

USE: :

Used for purge lines or miscellaneous purposes.

APPLICABLE CONTROL NOT MET:

ICS $2 \# 1$, ICS $1 \# 3$
WHEN CONTROL NOT MET:

FG $\uparrow$ Ex Tank

FG 1,2 Dome Intrusive

FG 2 Ex Tank (GWD)

\section{DISCUSSION OF STANDING ORDER APPLICABILITY:}

Nonconductive plastic tubing is used for miscellaneous needs, including temporary gas purge lines, vent and balance testing and aerosol testing of filters, temporary drain lines and temporary instrument lines during calibration or operation. Nonconductive plastic tubing is judged to have a negligible potential for causing $\mathrm{flammable}$ gas ignition under the applied conditions. Nonconductive plastic tubing shall not be used below the plane of a riser.

\section{RISK ACCEPTANCE:}

Nonconductive plastic tubing is used as described above in Ex Tank areas. The nonconductive plastic tubing is alsio considered to be used in Dome Intrusive activities because it is connected to fittings which are in conmunication with the dome vapor space. During use, it is normally immobile. Static charge due to friction is minimized during insertion or removal. If nonconductive plastic tubing cannot be used, the onty alternatives are rigid tubing or the wire wrapped tubing used during CGM sampling. Rigid tubing use is undesirable due to the extra cost and time for installation and waste disposal. Wire wrapped tubing is more expensive than nonconductive plastic tubing and is primarily available in a few specific lengths. The costs associated with these al ternatives are a greater concern than the small risk of a flammable gas ignition event due to a spark from the plastic tubing. The risk associated with continuing to use this tubing is managed by performing $f$ ammable gas monitoring, with safe shutdown controls, prior to and/or during use. This will include monitoring per method [A], [B], or [C] as applicable for the activity at the time the tubing is used. See definition of monitoring methods at the end of this section. This monitoring is in full compliance with the monitoring requirernents referenced by RL letter 96-WSD-283.

IMPACT OF NOT ACCEPTING RISK OF CONTINUED USE:

Fac:ility Group 1 Tanks-Moderate impact due to occasional work delays. Would switch to alternate higher cost (in both time and money) tubing now available.

facility Group 2 Tanks-Moderate impact due to occasional work delays. Would switch to alternate higher cost (in both time and money) tubing now available.

Facility Group 3 or other Tanks-No impact.

REGUESTED APPROVAL FROM DOE:

Continued use when performing flammable gas monitoring control [A], [B], or [C] as appropriate for nonconductive plastic tubing in:

1) FG I Ex Tank regions

2) FG 1,2 Dome Intrusive regions

3) FG 2 EX Tank regions during global waste disturbing activities 
HNF-SD-TWR-TI-003, REV. 3

\section{ITEM CLASSIFICATION: DE MINIMUS}

ITEM NUMBER: 10

EQUIPMENT: Installation and removal of Garlock gaskets

CATEGORY: Static Spark Potential

USE: :

Used for sealing riser flanges to risers.

APF'LICABLE CONTROL NOT MET:

ICs 2 \#1
WHEN CONTROL NOT MET:

FG 1 EX Tank

\section{DISCUSSION OF STANDING ORDER APPLICABILITY:}

Garlock gaskets are used for seal ing riser $f$ langes to risers. Garlock gaskets are a replacement for asbestos gasikets, which are no longer used for reasons related to worker safety and asbestos abatement. Ex Tank use for gaskets in Facility Group 1 tanks is included to avoid confusion because the gaskets are handled in an Ex Tank area prior to installation. Garlock gasket installation and removal is judged to have a negligible potential for causing flammable gas ignition under the applied conditions.

\section{RISK ACCEPTANCE:}

Garlock gaskets are a replacement for asbestos gaskets, which are no longer used for reasons related to worker safety and asbestos abatement. They have been installed on hundreds of risers in recent years. The barrier provided by the gaskets is needed to seal the risers. Using other materials is undesirable from an environmental standpoint. The gaskets are sandwiched between two steel flanges during use, with only a small portion of the gasket illess than $1 / 8$ inch) open to the vapor space. There is no process which would be expected to build up a static charge on the gaskets. The installed orientation of the gasket and flanges is such that a static charge would not be retained. Therefore, the risk associated with Garlock gaskets is strictly confined to installation and removal. Since instaltation and removal tasks are of a short duration, the actual time at risk is small.

The problems with using alternative gaskets are a more significant concern than the low risk of a flammable gas ignition event due to a spark from a gasket. The risk associated with continuing use of the gaskets is managed by performing flamable gas monitoring, with safe shutdown controls, prior to and/or during installation. This will include monitoring per method $[B]$. See definition of monitoring methods at the end of this section. This monitoring is in full compliance with the monitoring requirements referenced by RL letter 96-WSD-283.

IMPACT OF NOT ACCEPTING RISK OF CONTINUED USE:

Facility Group 1 Tanks-There is no reasonably available gasket material which has equivalent performance for worker safety and contamination control.

Facility Group 2 Tanks-No Impact.

Facil lity Group 3 or other Tanks-No Impact.

REQUESTED APPROVAL FROM DOE :

Cont inued use when performing $f$ lammable gas monitoring control [B] for installation and removal of Garlock gaskets in tanks without flammable gas monitoring or response actions in:

1) FG I EX Tank regions 
HNF-SD-TWR-TI-003, REV. 3

\section{ITEM CLASSIFICATION: DE MINIMUS}

ITEM NUMBER: 11

EQLIPMENT: Nonconductive plastic garden type sprayer

CATEGORY': Static Spark Potential

USE:

Used for contamination control.

APF'LICAELE CONTROL NOT MET:

WHEN CONTROL NOT MET:

ICS $2 \#$

FG 1 EX Tank

FG 2 EX Tank (GWD)

DISCUSSION OF STANDING ORDER APPLICABILITY:

The garden sprayer is a comercial unit containing less than 5 galtons of liquid. It is hand pumped and is used in Tank Farms for localized wetting and contamination control. The non-sparking brass end may enter dome intrusive regions, but the container and wand are located outside, or in Ex Tank regions only. The garden type sprayer is judged to have a negligible potential for causing flamable gas ignition under the applied conditions.

\section{RISK ACCEPTANCE:}

The sprayer has proven to be an inexpensive, easy to use, flexible tool for use in tank farms. Static buildup on the sprayer tip from the water spray is believed to be minimal. The nozzle velocity is $t$ imited by the air pressure that can be generated by hand pumping. The sprayer is used for less than a minute at a time. The risk associated with continued use of the sprayer is managed by performing flamable gas monitoring, with safe shutdown controls, prior to and/or during use. This will include monitoring per method [A]. See definition of monitoring methods at the end of this section. This monitoring is in full compliance with the rmonitoring requirernents referenced by RL letter 96-WSD-283.

IMF'ACT OF NOT ACCEPTING RISK OF CONTINUED USE :

Facility Group 1 Tanks-Minor impact, would switch to stainless steel sprayer.

Facijlity Group 2 Tanks-Negligible impact.

Facility Group 3 or other Tanks-No impact.

REQUESTED APPROVAL FROM DOE:

Cont inued use when performing flamable gas monitoring control [A] for use of nonconductive plastic sprayer in:

1) FG I EX Tank regions

2) FG ? EX Tank regions during global waste disturbing activities 
HNF-SD-TWR-TI-003, REV. 3

\section{ITEM CLASSIFICATION: DE MINIMUS}

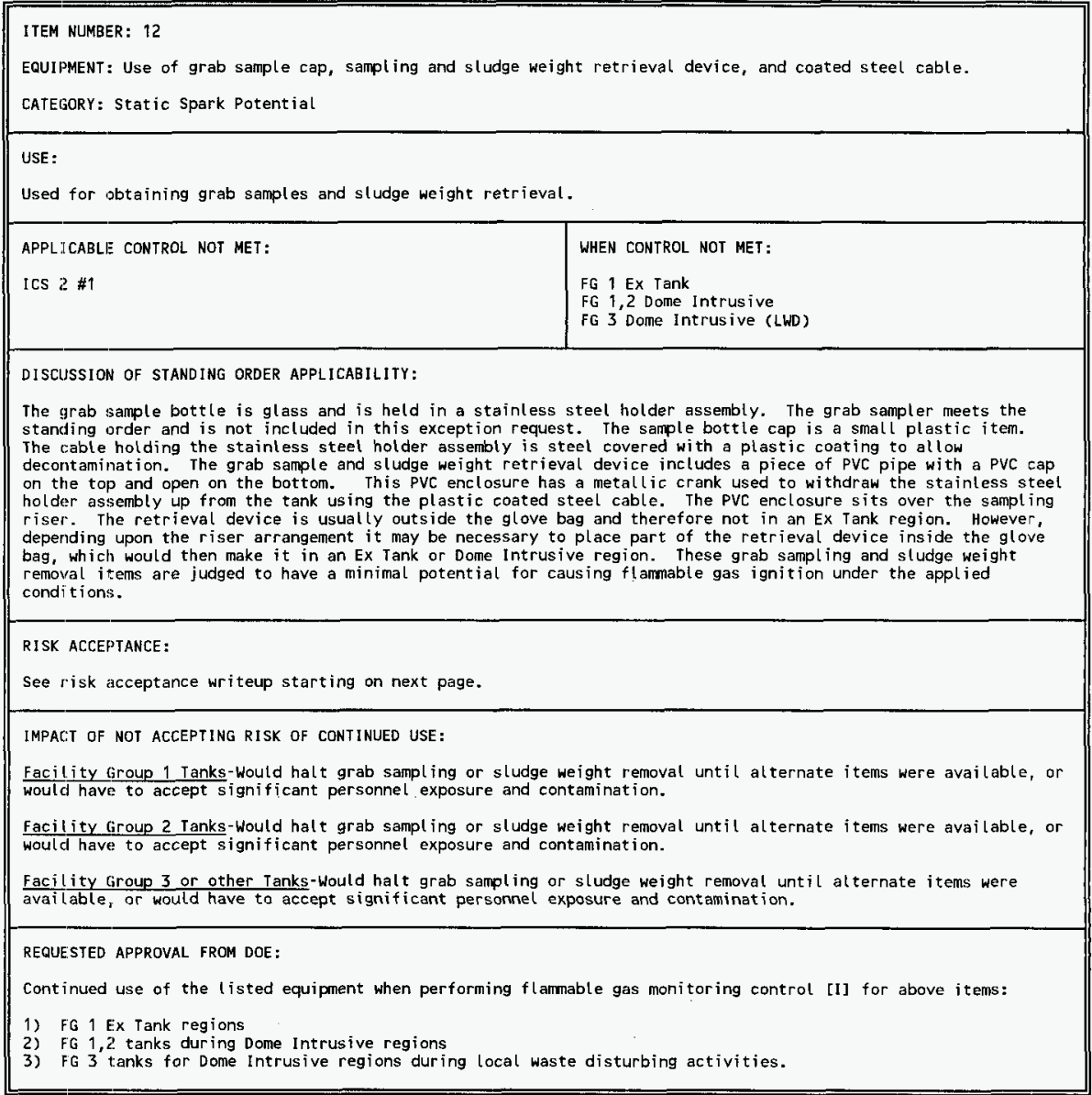


HNF-SD-TWR-TI-003, REV. 3

Risk Acceptance for Grab Samole Items.

The cap is a negligible source of static discharge. The relative humidity ( $\mathrm{RH}$ ) has been measured at $>50 \%$ in 95\% of the non-exhausted tanks sampled. The remaining $5 \%$ of the non-exhausted tanks all measured between 40-50\% RH. The SX Farm exhausted tanks measured between 20-40\% RH, except one tank which was $65 \%$ RH. $241-\mathrm{C}-105$ measured between $40-60 \% \mathrm{RH}$, and $241-\mathrm{C}-106$ measured between $50-100 \% \mathrm{RH}$. Therefore, for nonexhausted tanks, use of the cable and enclosure in dome intrusive regions is expected to be in comptiance with the standing orders about $95 \%$ of the time. For exhausted tanks, $241-\mathrm{E}-105$ and $241-\mathrm{c}-106$ are approximately $50 \%$ RH. Most double-shell tanks would be expected to be the same due to the liquid or moist solid surfaces.

Not using the coated cable would lead to a significant increase in personnel exposure and contamination. The static buildup resulting from the cable rubbing against the inside of the PVC riser adapter is judged to have minimal risk for causing flamable gas ignition under the applied conditions. Not only is the humidity above $50 \%$ much of the time, the cable is inserted/retrieved slowly and the whole insertion or removal step only takes a few minutes. Not using the retrieval device would result in more personnel exposure. The impact of halting waste transfers and characterization from halting grab sampling must be balanced against the low risk of a flammable gas ignition event due to a spark from these $i$ tens. The risk associated with cont inued use of the items is managed by perforning flammable gas monitoring, with safe shutdown controls, prior to and/or during use. This will include monitoring per method [I]. See definition of monitoring methods at the end of this section. This monitoring is in full compliance with the monitoring requirements referenced by RL letter 96-WSD-283. 


\title{
ITEM CLASSIFICATION: DE MINIMUS
}

\author{
ITEM NUMBER : 13,14 \\ EQUIPMENT: Installation, removal, and presence of PVC Liners for manual tapes and FICs
}

CATEGORY: static Spark Potential

USE :

Used for keeping metal tapes from grounding out against the insides of risers.

\begin{tabular}{||l|l}
\hline APPLICABLE CONTROL NOT MET: & WHEN CONTROL NOT MET: \\
ICS $2 \# 1$ & FG $1,2,3$ Dome Intrusive
\end{tabular}

DISCUSSION OF STANDING ORDER APPLICABILITY:

The PVC liners are present on most single-shell and double-shell tanks with manual tapes or FICs, to prevent the metall tapes from making contact with the riser wall. Removal and replacement of these liners is done

occasionally. Approximately four times in the past, a manual tape or fic has been removed to permit sampling when another riser was not available. To date, this has been done to allow push mode core sampling, which would result in a steel pipe being inserted into the riser. Grab sampling has been done at least once in the last three years through a tiner.

\section{RISK ACCEPTANCE :}

The relative humidity (RH) has been measured at $>50 \%$ in $95 \%$ of the non-exhausted tanks sampled. The remaining $5 \%$ of the non-exhausted tanks all measured between $40-50 \%$ RH. The SX Farm exhausted tanks measured between $20-40 \%$ $\mathrm{RH}$, except one tank which was $65 \% \mathrm{RH}$. 241-C-105 measured between 40-60\% RH, and 241-C-106 measured between 50 $100 \% \mathrm{RH}$. Therefore, for non-exhausted tanks, use of the cable and enclosure in dome intrusive regions is expected to be in compl iance with the standing orders about $95 \%$ of the time. For exhausted tanks, 241-C-105 and 241-Ci-106 are approximately 50\% RH. Most double-shell tanks would be expected to be the same due to the liquid or moist solid surfaces.

The FVC liners are already installed in the tanks. The cost in labor, time, waste disposal, and personnel exposure to remove them is a more significant concern than the small risk of a flammable gas ignition event due to a spark from a liner. The risk associated with continued use of the liners is managed by performing $f$ larmable gas monitoring, with safe shutdown controls, prior to and/or during installation. This will include monitoring per method $[B]$. See definition of monitoring methods at the end of this section. This monitoring is in full compliance with the monitoring requirements referenced by RL letter 96-WSB-283.

Core sampling is seldom performed through a riser liner, and rarely for grab sampling. During grab sampling, the plastic coated steel cable would be raised and lowered while in occasional contact with the riser liner. This does not pose a significant static buildup hazard. Flamable gas monitoring is done while taking the sample and the discusision above on the tank humidity levels applies.

No monitoring for flammable gas is done for the routine presence of the PVC liners in a tank vapor space. It is an acceptable risk to have the liners installed in the tanks without monitoring for flamable gases during their presence.

IMPACT OF NOT ACCEPIING RISK OF CONIINUED USE:

Facility Group 1 Janks-Almost all the tanks would be out of compliance, and the risk of removing the liners is far greater from cost and ALARA standpoints, than the risk involved with leaving them in place.

Facility Group? Ianks-Same as for FG 1 tanks.

Facility Group 3 or other Tanks-Same as for FG 1 tanks.

REQUESTED APPROVAL FROM DOE:

Continued use when performing $f$ lammable gas monitoring control [H] for installation or removal of PVC riser liners, and their extended presence in tanks without flammable gas monitoring in:

1) FG $1,2,3$ Dome Intrusive regions 
HNF-SD-TWR-TI-003, REV . 3

\title{
ITEM CLASSIFICATION: DE MINIMUS
}

\author{
ITEM NUMBER : 15,16 \\ EQUIPMENT: Manual Tapes \\ CATEGORY: Static Spark Potential
}

USE :

Used for ineasuring waste level surfaces.

APPLICABLE CONTROL NOT MET:

WHEN CONTROL NOT MET:

ICS ? \#2

FG 1,2,3 Done Intrusive

\section{DISCUSSION OF STANDING ORDER APPLICABILITY:}

The electrical spark produced by the manual tape contact with the waste has been evaluated in WHC-SD-WM-ES-176, and is liunited by the portable ohm meter used to take the reading. The current and voltage values are orders of magnitude below the ignition curve in UL 913. The manual tapes are not bonded to the tank, which could be interpreted as being required by the 1 CS 2 control \$2 in the standing orders. These tapes will not function if bonded to the tank. Manual tapes are judged to have a negligible potential for causing flamable gas ignition under the applied conditions.

\section{RISK ACCEPTANCE:}

The netal tapes used for the manual tape level gauges represent a small potential static discharge source. If the manual tape acquired a static charge, it would dissipate over time. If a portable ohm meter is connected to the manual tape when it held a charge, it would be dissipated through the meter circuitry to ground. Any spark at the time of connection would be outside the controlled area. The loss of manual tapes for determining waste levels to detect leaks to the environment is greater than the small $r$ isk of a flammable gas ignition event due to a spark from a tape. The $r i s k$ associated with continuing use of the tapes is managed by performing $f$ lammable gas monitoring, with safe shutdown controls, prior to and/or during installation and removal. This includes

monitoring per method [B]. See definition of monitoring methods at the end of this section. This monitoring is in full compliance with the monitoring requirements referenced by RL letter 96-WSD-283.

Monitoring is not an appropriate control for the presence of the manual tapes in a tank vapor space as no response actions are available. Per the above discussion, it is an acceptable risk to have the manual tapes installed in the tanks without monitoring for flamable gases during their presence.

IMPACT OF NOT ACCEPTING RISK OF CONTINUED USE:

Facility group 1 Tanks-All tanks would be out of compliance and the risk of removing the tapes is far greater from cost, ALARA, and lack of level monitoring standpoints, than the risk involved with leaving them in place.

Facility Group 2 Tanks-Almost all tanks would be out of compliance and the risk of removing the tapes is far greater from cost, ALARA, and lack of level monitoring standpoints than the risk involved with leaving them in place.

Facility Group 3 or other Tanks-Same as for FG 2 tanks.

REQUESTED APPROVAL FROM DOE:

Continued use when performing flamable gas monitoring control [H] for instaltation or removal of manual tapes in:

1) FG 1,2 Dome Intrusive regions

Continued extended presence of manual tapes without flammable gas monitoping in:

2) FG 1,2,3 Done Intrusive regions 


\section{ITEM CLASSIFICATION: DE MINIMUS}

\section{ITEM NUMBER: 17}

EQUIPMENT: Core Sampling Equipment-Installation, use, removal, or extended presence of Pipe Wiper, (Frisbee) Rainer Rubber \#R2325 (Truck 1), H-2-821457 (Trucks 2 and 3)

CATESORY: Static Spark Potential

USE :

Used for sealing around drill string during core sampling.

APPLICABLE CONTROL NOT MET:

ICS $2 \# 1$
WHEN CONTROL NOT MET :

FG 1,2 Dome Intrusive

FG 3 Dome intrusive (LWD)

\section{DISCUSSION OF STANDING ORDER APPLICABILITY:}

The firisbiee is a rubber disc approximately nine inches in diameter and is located at the top of a riser during core sampling. It is used to provide a seal around the drill string between the tank vapor space and the area outside the tank. About a two inch annular area of the frisbee is exposed to the tank vapor space. Frisbees have a negligible potential for causing a flammable gas ignition under the applied conditions. The FGEAB reviewed the use of the frisbee and determined that the frisbee met equivalence with the standing orders because of the lubricant used to wet it down prior to insertion of the drill string. The frisbee is still included in this exception because it cannot be guaranteed that the lubricant will remain present should the drill string be in place for an extended period of time with no sampling activity ongoing.

\section{RISK ACCEPTANCE:}

WHC-SD-WM-SAD-035 Rev 0a for rotary mode core sampling (RMCS) in flammable gas single-shell tanks concluded the use of the frisbee was acceptable for RMCS in flammable gas tanks. The conclusion from this document cannot be directly applied to push mode core sampling (PMCS). However, the continued risk of using the frisbee is low. Not using the current frisbee would cease all PMCS and retained gas sampling.

The frisbee design cannot be readily changed. The frisbee was tested at the Bureau of Mines and must stay the same configuration for RMCS unless a new design is tested. The resulting delay to sampling work and the ability to obtain characterization data from waste tanks that is used for both helping to close safety issues and for desicn of privatization waste handing facilities must be balanced with the small risk of a flammable gas ignition event due to a spark from the frisbee. The risk associated with continuing its use is managed by performing flamable gas monitoring, with safe shutdown controls, prior to and/or during use. This will include monitoring per method $[A]$, $[B]$, or $[C]$ as applicable for the core sampling step being performed. See definition of manitoring methods at the end of this section. This monitoring is in full compliance with the monitoring requi rements referenced by RL letter $96-$ WSD -283 .

IMPACT OF NOT ACCEPTING RISK OF CONTINUED USE:

Facility Group 1 Tanks-Would stop all PMCS and retained gas sampling.

Facility troup 2 Tanks-Would stop all PMCS and retained gas sampling.

Facility Group 3 or other Tanks-Would stop all PMCS and retained gas sampling.

REQUESTED APPROVAL FROM DOE:

Continued use when performing flammable gas monitoring control [A], [B] or [C] as appropriate for use of the core sampling frisbee in:

1) FG 1,2 Dome Intrusive regions

2) FG 3 tanks for Dome Intrusive regions during local waste disturbing core sampling 


\section{ITEM CLASSIFICATION: DE MINIMUS}

ITEM NUMBER: 18

EQUIPMENT: Core Sampling Equipment-Installation, removal, and use of Plastic Kamlock Caps.

CATESORY: Static Spark Potential

USE :

Used for capping the quill rod when disconnected from the drill string

APPLICABLE CONTROL NOT MET:

ICS $? \#$

WHEN CONTROL NOT MET:

FG 1,2 Dome Intrusive

DISCUSSION OF STANDING ORDER APPLICABILITY:

Kamlock caps are placed on the bottom of the quill rod when it is disconnected from the drill string for contamination control. The Kamlock caps in use are constructed of nonconductive polymer material. The quill rod is not comnected to the tank when the Kamlock cap is in place, but the quill rod could be vented back to the tank vapor space. Based upon the definitions in the standing order, this could be interpreted as dome intrusive work. Plastic Kamlock caps are judged to have a negligible potential for causing a flammable gas ignition under the appl i ed conditions.

\section{RISK ACCEPTANCE:}

This is an item where worker safety must be balanced with negligible ignition source risk. Not using the caps would cease all push mode core sampling (PMCS) and retained gas sampling. Steel caps were previously used, but were el iminated because they were a personnel safety hazard. Installation and removal of the caps is normally done at arm's length to minimize personnel exposure or contamination. The cap is held out and slowly raised up onto the quill rod and the Kamlock handles on the adapter moved to hold the cap in place. Handl ing of the heavy steel caps was difficult at arm's length, so the plastic caps were implemented. This has improved operations arourd the truck. In use, the caps are motionless. Thus, there is no mechanism for static charge buildup. El imination of the plastic caps is not warranted from a cost, schedule, and worker safety standpoint, and is a more significant concern than the small risk of a flammable gas ignition event due to a spark from the plastic caps. The risk associated with continuing their use is managed by performing flammable gas monitoring, with safe shutclown controls, prior to and/or during use. This will include monitoring per method [A] or [B] as applicable for the core sampling step being performed. See definition of monitoring methods at the end of this section. This monitoring is in full compliance with the monitoring requirements referenced by RL letter 96-WSD-283.

IMPACT OF NOT ACCEPTING RISK OF CONTINUED USE:

Facility Group 1 Tanks-Would delay PMCS and retained gas sampling until different caps were obtained; increased personnel safety hazard.

Facility Group 2 Tanks-Would delay PMCS and retained gas sampling until different caps were obtained; increased personnel safety hazard.

Facility Group 3 or other Tanks-No Impact.

REQUESTED APPROVAL FROM DOE:

Cont inued use when performing flamable gas monitoring control [A] or [B] as appropriate for use of plastic Kamlock caps in:

1) FG 1,2 Dome Intrusive regions 
HNF-SD-TWR-TI-003, REV. 3

\section{ITEM CLASSIFICATION: DE MINIMUS}

\begin{tabular}{|c|c|}
\hline \multicolumn{2}{|c|}{$\begin{array}{l}\text { ITEM NUMBER: } 19 \\
\text { EQUIPMENT: Presence of extension cords } \\
\text { CATEGORY: Static Spark Potential }\end{array}$} \\
\hline \multicolumn{2}{|c|}{$\begin{array}{l}\text { USE: } \\
\text { Used for providing power to electrical equipment. }\end{array}$} \\
\hline $\begin{array}{l}\text { APPL I:CABLE CONTROL NOT MET: } \\
\text { ICS } 2: \# 2\end{array}$ & $\begin{array}{l}\text { WHEN CONTROL NOT MET: } \\
\text { FG } 1 \text { EX Tank } \\
\text { FG } 2 \text { EX Tank (GWD) }\end{array}$ \\
\hline \multicolumn{2}{|c|}{$\begin{array}{l}\text { DISCUSSION OF STANDING ORDER APPLICABILIIY: } \\
\text { ELectrical. Cords are used in some EX Iank regions. The cords meet equivalence with the standing orders from an } \\
\text { electrical spark potential as long as power connections or disconnections are accomplished outside the Ex Tank } \\
\text { area or when the Ex Tank area does not exist. There is a negligible risk of a static spark potential from the } \\
\text { plastic or rubber coated extension cords. }\end{array}$} \\
\hline \multicolumn{2}{|c|}{$\begin{array}{l}\text { RISK ACCEPTANCE: } \\
\text { Continued uSe of this equipment will permit activities to continue that require temporary service electrical } \\
\text { power to an Ex Tank region. Cal ibration or maintenance of Operating Safety Requirements and Operating Safety } \\
\text { Documents required instruments, Standard Hydrogen Monitoring System (SHMS) cabinets, leak detectors or other } \\
\text { instruments is a more significant concern than the negligible risk of a flammable gas ignition event due to a } \\
\text { static spark from one of these items. The risk associated with continuing to use the cords is managed by } \\
\text { performing flammable gas monitoring, with safe shutdown controls, prior to installation and during use when } \\
\text { personnel are present. This will include monitoring per method [A] - See definition of monitoring methods at the } \\
\text { end of this section. This monitoring is in full compliance with the monitoring requirements referenced by RL } \\
\text { letter } 96-w S D-283 \text {. }\end{array}$} \\
\hline \multicolumn{2}{|c|}{$\begin{array}{l}\text { IMPACT OF NOI ACCEPTING RISK OF CONTINUED USE: } \\
\text { Facility Group } 1 \text { Tanks-Will shut down a moderate amount of EX Tank region work. } \\
\text { Facility Group } 2 \text { Ianks-Same as above, except only during global waste disturbing activities. } \\
\text { Facility Group } 3 \text { or other Tanks-No Impact. }\end{array}$} \\
\hline \multicolumn{2}{|c|}{$\begin{array}{l}\text { REQUESTED APPROVAL FROM DOE: } \\
\text { Continued use when performing flammable gas monitoring controt [A] for the presence of electrical cords in: } \\
\text { 1) FG } 1 \text { EX Tank regions } \\
\text { 2) FG } 2 \text { EX Tank regions during global waste disturbing activities }\end{array}$} \\
\hline
\end{tabular}




\title{
ITEM CLASSIFICATION: DE MINIMUS
}

\author{
ITEM NUMBER: 20 \\ EQUIPMENT: Closed Pit Work Related Equipment-Installation, Use and Removal of Low and High Pressure Pit Spray \\ Whirlie and operation of Valve Handles
}

CATEGORY: Mechanical Spark Potential

USE :

Used for washing down pits and operating valves in pits.

APPL IICABLE CONTROL NOT MET:

WHEN CONTROL NOT MET:

ICS $2 \# 1$

FG 1 Ex Tank

FG 2 EX Tank (GWD)

FG 1 Dome Intrusive

FG 2,3 Dome Intrusive (LWD, GWD)

DISCUSSION OF STANDING ORDER APPLICABILITY:

The subject tools and equipment are normally made of carbon steel and were not procured to meet non-sparking criteria. The valve handle is used for operating valves in pits through holes in the cover blocks. The spray whirlie is inserted through an opening in the cover block and sprays solutions inside the pit for decontamination or temporarily fixing loose contamination. Most usage will be Ex Iank related, but it may be required to use a valve handle or the whirlie in a pit during a time when it is designated as Dome Intrusive.

\section{RISK ACCEPTANCE :}

Valve handle operation has been evaluated to be low risk with regards to spark initiation. This is due to the low energies and small ranges of motion involved. The whirlie operation creates a high humidity environment with in the pit which is not conducive to spark generation. Furthermore, these tools are either; a) not readily or economically available in a spark resistant version, or b) are only rarely used in areas requiring compliance with the standing order controls, hence, the time at risk is low. The need to use these tools is a more significant concern than the small risk of a flammable gas ignition event due to a spark from one of them. The risk associated with continuing to use these tools and equipment is managed by performing flammable gas monitoring, with safe shutdown controls, prior to and/or during the work. The monitoring includes method [A] or [B] as appropriate, or in certain instances [C] if waste intrusive work is occurring in the tank at the same time as working in a pit which is in communication with the tank vapor space. See definition of monitoring methods at the end of this section. This monitoring is in full compliance with the monitoring requirements referenced by RL letter 96-WSD-283.

IMPACT OF NOT ACCEPTING RISK OF CONTINUED USE:

Facility Group 1 Tanks-Will significantly increase contamination and exposure, and shut down all pit work and a minor amount of other Ex Tank work unt il alternate equipment or means of isolating from the tank can be established. Will halt installation of most new equipment items into the tank.

Facility Group 2 Tanks-Will significantly restrict or shut down pit work during dome intrusive activities until alternate tools or means of isolating from the tank can be established. Will halt installation of most new equipment items into the pit. Will affect most all transfers. Will significantly increase exposure and spread of contamination.

Facility Group 3 or other Tanks-will halt some transfers. Will significantly increase exposure and spread of contamination.

REQUESTED APPROVAL FROM DOE:

Continued use when performing $f$ lammable gas monitoring controls [A], [B], or [C] as appropriate for the above equipment :

1) FG 1 tank EX Tank regions.

2) FG 1 tank Dome Intrusive regions

3) FG 2 and 3 tanks Dome Intrusive regions during local and global waste disturbing activities.

4) FG 2 Ex Tank regions during global waste disturbing activities 
HNF-SD-TWR-TI-003, REV. 3

\section{NON-DE MINIMUS}

ND- $\mathbf{i}$ 


\section{ITEM CLASSIFICATION: NON-DE MINIMUS}

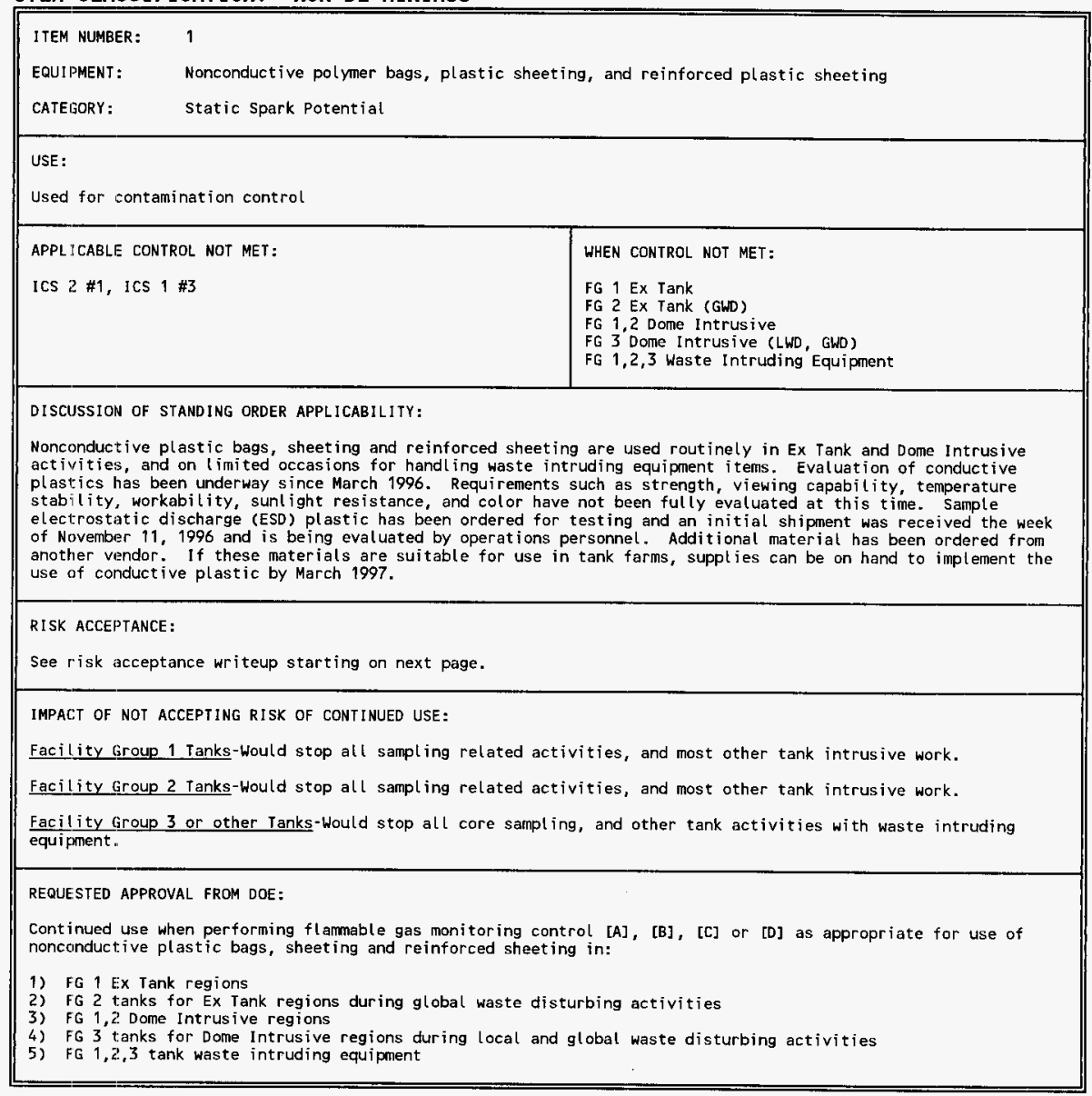


HNF-SD-TWR-TI-003, REV. 3

Risk Acceptance for nonconductive plastic bags, sheeting and reinforced sheeting-

This is an item where worker safety must be balanced with negligible ignition source risk. Use of plastic for contamination control is standard in the nuclear industry. At Hanford, the HANFORD SITE RADIOLOGICAL CONTROL MANJAL, HSRC-1, requires contamination control as one of its basic tenets. Section 125 of the manual is one of several sections requiring contamination control. Section $342 \# 3$ and \#4 strongly suggest the use of plastics for contamination control and section 413 \#4 requires it for waste packaging. Implementation of alternate contamination control materials could not be done without exhaustive testing and procedure changes.

Plastic sheeting is routinely placed around risers or other openings to protect the areas from becoming contaminated. It is also used for wrapping items or contaminated equipment. Plastic bags are usually used for containing tools or equipment, either to protect them from becoming contaminated, or to contain them if they are, or for holding contaminated waste. This usage can be either inside or outside an Ex Tank area, depending upon whether the associated riser (or breather filter valve) is open or not. Work is planned and conducted so that the Ex Tank area exists for the minimum time possible to perform the job. Work with nonconductive plastics in Dome Intrusive or Waste Intruding Equipment is infrequent. Plastic sheeting or bags would be exposed to Dome Intrusive or Waste Intruding Equipment regions if used to bag an open riser or cover an item such as the top of a drill string. For contamination control, it may be necessary to install plastic shesting just inside a dome intrusive area (e.g., a ventilation duct or a pit during saltwell pumping).

The plastic bags and sheeting do not experience significant movement during normal operations. Static buildup is a function of the relative humidity and physical factors that influence a charge such as mechanical friction. The potential for a static spark discharge is more likely during periods when the plastic is being installed at the start of a job, or at the end when the material is being removed.

Installation of plastics is normally done before opening a riser or other opening into tank dome space. Plastic removal is also normally done after the opening into the tank dome space is sealed. Therefore, the majority of the plastic handling and movement is not done in Ex Tank or Dome Intrusive regions. The major potential for static discharge will be during times when use of the nonconductive plastic meets the requirements in the standing orders. When working in Ex Tank Dome Intrusive areas, the plastic will be in place and stationary the majority of the time.

The relative humidity (RH) has been measured at $>50 \%$ in $95 \%$ of the non-exhausted tanks sampled (as of $7 / 96$ ). This is to be expected since the concentration of water in air in a sealed chamber will eventually reach saturation and be in equilibrium with the liquid phase. The remaining $5 \%$ of the non-exhausted tanks all were measured to be between $40-50 \% \mathrm{RH}$. The SX Farm exhausted tanks measured between $20-40 \%$ RH, except one tank which was $65 \%$ RH. 241-C-105 measured between 40-60\% RH, and 241-c-106 measured between 50-100\% RH. Therefore, for non-exhausted tanks, plastics in dome intrusive regions are expected to be in compliance with the standing orders about $95 \%$ of the time. For exhausted tanks, 241-c-105 and 241-c-106 are approximately $50 \%$ RH. Most double-shell tanks would be expected to be the same due to the liquid or moist solid surfaces. For facility group 1,2, and 3 tanks that are exhausted, no tank is known to have pressurized from a $\mathrm{flam}$ lable gas GRE. Therefore, air flow would be expected to be into any opening into a Dome Intrusive region, which would minimize contact of plastic in these areas with tank vapors. For waste intruding equipment, any concentrated (i.e., non diluted by tank air) waste gases will be at $100 \%$ relative humidity because the gases would come from waste pockets surrounded by liquid waste. In such pockets, the water vapor in the gas would be at equilibrium with the water in the liquid. The gas in waste intruding equipnent may be partially mixed with tank vapors depending upon the work being done, but as most tank vapors have a high RH, the RH in waste intruding equipment should be expected to be $>50 \%$.

Concern is when a spark occurs coincident with a flammable gas mixture $>100 \%$ lower flammability limit (LFL). Per Appendix A of WHC-SD-WM-JCO-007, Rev OA (Draft), vapor space sample results for single-shell tanks indicate that $70-90 \%$ of the tanks show negligible or nondetectable flammable gas levels during non waste intrusive work. The remaining $10-30 \%$ of the tanks average $1.2-1.5 \%$ of the LFL. The highest CGM measurement ( $7 \%$ ) recorded to date using the organic vapor monitor (OVM) equated to approximately $3.5 \%$ of the LFL. The highest vapor sample results obtained via Type B/Type 4 vapor sampling correlates to $2.51 \%$ of the LFL. One IMUST tank sampled showed no flamable gas present. The highest recorded organic concentration, $3.8 \%$ of the LFL, was found in 241-C-103. $241-\mathrm{C}-103$ is the only waste tank known to have a significant floating organic layer. Since July 1996, one tank has shown a $10 \%$ of the LFL CGM reading ( $5 \%$ of the LFL), and one showed a $13 \%$ LFL CGM reading (6.5\% LFL) prior to intrusive activities. Actively ventilated tanks would be expected to have low $f$ lammable gas levels because of the constant dilution air passing through the tanks. No actively ventilated single-shell tanks have shown flamable gas levels above minimum detectible levels in either the Type 3 or 4 vapor samples or in the special OVM samples taken in these tanks.

Theoretically, plastic sheets and bags could trap flamable gases if in place for sufficient time to allow gases from a GRE to accumulate inside the plastic. If practical, plastics should be installed to prevent the accumulation of flammable gases. The use of high point vents should be considered for plastic wrapped items attached to a tank dome space or item of waste intruding equipment (see sleeving and glove bags pages for high point vents related to sleeving or glove bag use) when; 1) an evaluation of the potential for accumulation of the flamable gas within the plastic shows it to be a concern, 2) the installation of high point vents and the handing of plastics with the vent installed will not cause significant contamination problems. 
The following can be summarized concerning the risk with using nonconductive plastic bags, sheeting and reinforced sheeting:

1) The majority of use of nonconductive plastics in Tank Farms currently is in compliance with the standing orders as the materials are used in regions where Ignition Control set 2 controls are not required.

The highest potential for a static spark from these materials is during installation or removal. The majority of the time installation and removal are performed in regions where Ignition control Sets 1 or 2 are not required, or before the region status is changed by removing a riser flange or performing some other activity. enough such that nonconductive plastic use in these areas is in compliance with the standing orders.

Flammable gas levels have not been seen in excess of the LFL in the tank dome for any tank except in pre-mitigated 241-sY-101 during one or more gas release events (GREs). In approximately $80 \%$ of the single-shell tanks that have been sampled, the flamable gas is below detectable levels. In the remaining $20 \%$ of the single-shell tanks the flammable gas is less than $2 \%$ of the LFL, except for $2-3$ specific readings which have ranged up to $6.5 \%$ of the LFL. The presence of flammable gases in actively ventilated single-shell and double-shell tanks would be expected to be low because of the constant dilution air. Although the presence of flammable gas concentrations in Ex Tank and Dome Intrusive areas above the LFL cannot be positively ruled out, they can be expected to be a rare occurrence.

Based upon the following, use of nonconductive plastics in Tank Farms poses a low risk of causing a flamable gas ignition event; a) consideration of the low percentage of the time nonconductive plastics will be used in a region where the standing order equivalence would not be met, b) consideration of the $(i m i t e d$ "static inducing" work done in regions where the standing order equivalence would not be met, c) the $l i m i t e d$ time in dome intrusive or waste intruding equipment regions when the relative humidity will be low enough that nonconductive plastic use would not meet the standing orders, d) the limited time in Ex Tank areas where plastics could come in contact with tank vapors containing a high flamable gas concentration and low relative hunidity, and e) the rare occasion that flammable gas levels might be above the LFL in a dome intrusive region.

The low risk associated with continuing use of nonconductive plastics is further reduced by performing flamabte gas monitoring of the work area prior to and during use. This will include monitoring per method $[A],[E],[C]$ or $[D]$ as applicable for the activity. See definition of monitoring methods at the end of this section. This monitoring is in compliance with the monitoring requirements referenced by RL letter 96-WSD-283.

When $f$ lammable gas levels reach $25 \%$ of the $L F L$, work ceases as required per the monitoring requirements referericed in section $\mathbf{8 . 0}$ of the standing orders. The National Fire Protection Association (NFPA 30, 1988) recommends that processes be controlled so that $\mathrm{flammable} \mathrm{gas} \mathrm{concentrations} \mathrm{are} \mathrm{<25} \mathrm{percent} \mathrm{of} \mathrm{the} \mathrm{lower}$ flamatility limit (LFL), when relying upon vapor space flamability levels to preclude the possibility of an ignition. DOE Order 5480.4 requires Hanford waste tanks to be operated within NFPA guidelines. Thus, a control of $425 \%$ of the LFL has been established for performing activities in and around Tank Farm facilities. Because of the unpredictable nature of GREs, it is not possible to ensure that $25 \%$ of the LFL is never exceeded. Procedures and controls are thus in place to minimize the potential for a tank to exceed $25 \%$ of the L.FL, and to cease work in areas common with the tank vapor space when the flammable gas concentration exceeds this value. This $25 \%$ limit is far below the actual limit at which flamability can occur, and is conservatively chosen to allow for potential measurement errors.

Monitoring is normally performed with a portable CGM. The CGM is calibrated with pentane and reads high by $100 \%$ when manitoring for hydrogen in air. For conservatism, no correction factor is applied in the field to the CGM reading when used for monitoring for personnel protection. Thus a $25 \%$ of the LFL reading on a CGM is actually $12.5 \%$ of the LFL for hydrogen in air, but is treated as if it were $25 \%$. Depending upon the concentration of the $f$ lammable gas constituent and oxidants (ammonia, methane, carbon monoxide, nitrous oxide) a $25 \%$ LFL CGM reading will be indicative of $12.5 \%$ to approximately $20 \%$ of the LFL. The response time of a CGM to an increase in flamable gas concentration is not instantaneous. The CGM starts responding to an increase in flammable gas concentrations almost immediately upon the gas reaching the cGM internals. The internal response time for a CGM to reach a $10 \%$ of the LFL indication ( $5 \%$ LFL actual for hydrogen in air) when exposed to a $23 \%$ of the LFL pentane mixture (equivalent to a $11.5 \%$ of the LFL hydrogen in air mixture) ranged from 7-12 seconds in a number of informal tests. Time to reach the full $23 \%$ test gas indication took 20-40 seconds.

If the CGM is drawing a sample out of a tank dome space, the time for the tank vapors to reach the CGM is approximately 26 seconds, based upon the $500 \mathrm{~cm}^{3} / \mathrm{min}$ CGM flow and the tubing currently used for flammable gas monitoring. Thus an instantaneous change from 0 to $12.5 \%$ of the LFL for hydrogen in air in a tank vapor space (an indicated $25 \%$ of the LFL) would not indicate any change at all on a CGM for about 26 seconds. At 26 seconds, the indicated LFL would begin to rise and 33-36 seconds after the step change the CGM would indicate about $10 \%$ of the LFL. The CGM would indicate $25 \%$ of the LFL approximately $45-65$ seconds after the step change. 
If the CGM were being used to sample the immediate work area, the 26 second delay would not apply. The CGM would start to rise immediately and a reading of $10 \%$ of the LFL would be noted $7-12$ seconds after sensing a $25 \%$ step increase in the LFL.

It is not realistic to have an instantaneous step change from $0 \%$ of the LFL to $100 \%$ of the LFL in an Ex Tank area. Therefore, a CGM is an acceptable instrument to use for flamable gas monitoring in these areas as long as work is hat ted upon significant increase in the indicated flammable gas levels. An instantaneous step increase in an entire tank dome vapor space concentration from 0 to $100 \%$ of the LFL is not realistic due to the large volume of gas which would be required to be released. However, local ized spots near the waste surface could show a quick step change to $>100 \%$ of the LFL from relatively small releases of gases from below the waste surface. The risk is very low that a gas stream would be released from the waste surface of a 75 foot diameter tank and enter a 4 inch diameter riser directly above without the gas being partially diffused by tank vapors. Since plastic sheeting, bags or reinforced sheeting are not routinely used near the waste surface where there could be quick localized step changes in the flammable gas concentration, the response time for CGMs is not a concern when monitoring prior to and during use of nonconductive plastics.

Switching to conductive or static dissipative plastics without testing by operations field personnel can tead to significant contamination problens. The material selected must be stable from a temperature and sunt ight exposure standpoint. The material also must be suitable from a workability standpoint. Field testing will be done on the new materials as they are available. New materials will not be selected as replacement for existing nonconductive plastics until it can be demonstrated that the new materials meet the same demand:s as the current plastics.

Using conductive plastics will require the implementation of new administrative controls to ensure nonconductive plastics are controlled or removed from supply and work areas so that nonconductive plastics are not: used at the wrong time. An immediate halt on the use of nonconductive plastics would lead to ceasing most activities in the Ex Tank, Dome Intrusive or Waste Intruding Equipment regions until suitable replacements are obtained. Use of nonconductive plastics is permissible where not restricted by the standing orders. The resulting delay to sampl ing work and most other tank intrusive work, the ability to obtain characterization data from waste tanks that is used for safety issue closure and for design of privatization waste handling facilities, must be balanced with the small risk of a flammable gas ignition event due to a spark from the plastic.

The use of nonconductive plastic bags, sheeting, and reinforced sheeting is acceptable until a suitable replacement is available in sufficient quantities. This will be no later than March 1, 1997, assuming that the replacement material currently being tested meets minimum acceptable standards for worker safety and contamination control. Nonconductive plastic sheeting and bags installed prior to March 1, 1997 may remain in place until there is an operational reason for their replacement. 


\section{ITEM CLASSIFICATION: NON-DE MINIMUS}

ITEM NUMBER : 2

EQUIPMENT: Nonconduct ive polymer steeving

CATEGORY: Static Spark Potential

USE :

Used for contamination control

APPLICABLE CONTROL NOT MET:

ICS $2 \# 1$, ICS $1 \# 3$

WHEN CONTROL NOT MET :

FG $\uparrow$ Ex Tank

FG 2 Ex Tank (GWD)

FG 1,2 Done Intrusive

FG 3 Dome Intrusive (LWD, GWD)

FG $1,2,3$ waste Intruding Equipment

DISCUSSION OF STANDING ORDER APPLICABILITY:

Nonconductive plastic sleeving is routinely used in Ex Tank and Dome Intrusive activities, and on some occasions for removing waste intruding equipment items. Evaluation of conductive plastics has been underway since March

1996. Requirements such as strength, viewing capability, temperature stability, workability, sunlight

resistance, and color have not been fully evaluated at this time. Sample electrostatic discharge (ESD) plastic has been ordered for testing and an initial shipment was received the week of November 11, 1996 and is being

evaluated by operations personnel. Additional material has been ordered from another vendor. If these materials are suitable for use in tank farms, supplies can be on hand to fully implement use of conductive plastic by March 1997.

\section{RISK ACCEPIANCE:}

See risk acceptance writeup starting on next page.

IMPACT OF NOT ACCEPTING RISK OF CONTINUED USE:

Facility Group 1 Tanks-Would stop all sampling related activities, and most other tank intrusive work.

Facility tiroup 2 Tanks-Would stop all sampling related activities, and most other tank intrusive work.

Facility Group 3 or other Tanks-Would stop all core sampling, and other tank activities with waste intruding equipment.

\section{REQUESTED APPROVAL FROM DOE:}

Cont inued use when performing flammable gas monitoring control [A], [B], [C] or [D] as appropriate for use of nonconductive plastic sleeving in:

1) FG $\uparrow$ Ex Tank regions

2) FG 2 tanks for Ex Tank regions during global waste disturbing activities

3) FG 1,2 Dome Intrusive regions

4) FG 3 tanks for Dome Intrusive regions during local and global waste disturbing activities

5) FG 1,2,3 tank waste Intruding Equipment 


\section{Risk Acceptance for nonconductive plastic sleeving.}

Use of plastic for contamination control is standard in the nuclear industry. At Hanford, the HANFORD SITE RADIOLOGICAL CONTROL MANUAL, HSRC-1, requires contamination control as one of its basic tenets. Section 125 of the manual is one of several sections requiring contamination control. Section $342 \# 3$ and \#4 strongly suggest the use of plastics for contamination control and section 413 \#4 requires it for waste packaging. Implementation of alternate contamination control materials could not be done without exhaustive testing and procedure changes.

Plastic sleeving is routinely used around risers or other openings when removing contaminated equipment. The equipment is brought up into the sleeving and taped seals are placed above and below the item. These taped seals are cut through to remove the item from the tank riser or opening while keeping both cut ends sealed for contamination control. This usage is therefore inside an Ex Tank area, and the inside of the plastic sleeving is common with tank dome vapors or the vapors inside waste intruding equipment when being removed. Sleeving is also used for protecting items such as video cameras and vapor sampling tubes which are inserted into tank vapor spaces for contamination control.

Static buildup is a function in part of the relative humidity and physical factors that influence a charge such as mechanical friction. Nonconductive plastic sleeving normally is not in place for an extended period of time. It normally is placed around an object and the object removed from the tank in anywhere from a few minutes to a few hours. The potential for a static spark discharge is more likely during periods when the plastic is being moved. The act of sleeving out an object from a tank riser requires sliding the item into the sleeving. This is done at a relatively slow pace, to avoid problems with contamination control. This activity would not induce a static charge to the extent that continually rubbing the plastic would, but it could theoretically induce a small charge.

The relative humidity (RH) has been measured at $>50 \%$ in $95 \%$ of the non-exhausted tanks sampled (as of $7 / 96$ ). This is to be expected since the concentration of water in air in a sealed chamber will eventually reach saturation, and be in equilibrium with the liquid phase. The remaining $5 \%$ of the non-exhausted tanks all were measured to have between $40-50 \%$ RH. The SX Farm exhausted tanks measured between $20-40 \%$ RH, except one tank which was 65\% RH. 241-C-105 measured between 40-60\% RH, and 241-C-106 measured between 50-100\% $\mathrm{RH}$. Therefore, for non-exhausted tanks, plastics in dome intrusive regions are expected to be in compliance with the stianding orders about 95\% of the time. For exhausted tanks, 241-c-105 and 241-c-106 are approximately $50 \%$ RH. Most double-shell tanks would be expected to be the same due to the liquid or moist solid surfaces. For waste intruding equipment, any concentrated ( $i . e .$, non diluted by tank air) waste gases will be at $100 \%$ $\mathrm{RH}$ beciause the gases would come from waste pockets surrounded by liquid waste. In such pockets the water vapor in the gas would be at equilibrium with the water in the liquid. The gas in waste intruding equipment may be partially mixed with tank vapors depending upon the work being done, but as most tank vapors have a high $\mathrm{RH}$, the $\mathrm{RH}$ in waste intruding equipment should be expected to be $>50 \%$.

Concern is when a spark occurs coincident with a flammable gas mixture $>100 \%$ lower flammability limit (LFL). Per Appendix A of WHC-SD-WM-JCO-007, Rev OA (Draft), vapor space sample results for single-shell tanks indicate that approximately $70-90$ percent of the tanks show negligible or nondetectable flammable gas levels during non waste intrusive work. The remaining 10-30 percent of the tanks average $1.2-1.5 \%$ of the LFL. The highest CGM measurement $(7 \%)$ recorded to date using the organic vapor monitor (OVM) samples equated to approximately $3.5 \%$ of the LFL. The highest vapor sample results obtained via Type B/Type 4 Vapor sampl ing correlates to $2.51 \%$ of the LFL. One IMUST tank sampled showed no flammable gas present. The highest recorded organic concentration, $3.8 \%$ of the LFL, was found in $\mathrm{C}-103$. C-103 is the only waste tank known to have a significant floating organic layer. Since July 1996, one tank has shown a 10\% of the LFL CGM reading ( $5 \%$ of the $L F L$ ), and one showed a $13 \%$ LFL CGM reading $(6.5 \%$ LFL) prior to intrusive activities. Actively vent ilated tanks would be expected to have low flammable gas levels because of the constant dilution air passing through the tanks. No actively ventilated single-shell tanks have shown flammable gas levels above minimum detectible levels in either the Type 3 or 4 vapors samples or in the special OVM samples taken in these tanks.

Theoretically, plastic sleeving could trap flamable gases if in place for sufficient time to allow gases from a GRE to accumulate inside the plastic. When removing contaminated items from a tank, sleeving cannot normally be installed in such a manner as to prevent the trapping of tank vapors. Trapping of gases is not a conciern when sleeving clean items into a tank because the top end of the sleeving is normally open. The use of high point vents should be considered for sleeving when; 1) an analysis of the gas potential accumulation shows it to be a realistic probability, 2) the high point vent can be shown to prevent the accumulation of flammable gases under the vent, and 3) the installation of high point vents and the handling of sleeving with them installed will not cause significant contamination problems. (e.g., repetitive sleeving out of drill string sections should not use high point vents because of the limited time available for gas accumulation, the extra exposure personnel will receive, and likely contamination problems with repeatedly installing the filters.

The following can be sumarized concerning the risk of using nonconductive plastic sleeving:

1) There is a small potential for static buildup and subsequent discharge due to the nature of the waste removal process from a tank. The potential is minimized by not performing operations in a manner that would enhance the static sparking potential of the material. sleeving is normally in place on a tank for a relatively short period of time ranging from a few minutes to a few hours. 
The relative humidity in passively ventilated tanks or waste intruding equipment is expected to be high enough so that the majority of nonconductive plastic use in these areas is in compliance with the standing orders. For actively ventilated tanks, the air flow is expected to be into the tank, which should minimize contact between tank dome space vapors and the plastic.

Wind exposure provides the only air flow to cause a potential static buildup. Potential for liquid flow across the plastic surface resulting in a static buildup is minimal.

Flammabte gas levels have not been seen in excess of the LFL in the tank dome space for any tank except in pre-mitigated 241-SY-101 during one or more GREs. In about $80 \%$ of the single-shell tanks that have been sampled, the LFL is below detectable. In the remaining $20 \%$ of the single-shell tanks, the LFL is less than $2 \%$, except for $2-3$ specific readings which have ranged up to $6.5 \%$. The presence of flammable gases in actively ventilated single-shell and double-shell tanks would be expected to be low most of the time because of the constant dilution air. Therefore, al though the presence of flammable gas concentrations in Dome Intrusive areas above the L.FL cannot be positively ruled out, they can be expected to be a rare occurrence.

Based upon the following, continued use of nonconductive plastic sleeving in Tank Farms poses a low risk of causing a flammable gas ignition event; a) consideration of the small amount of time sleeving is exposed to the tank vapors space, b) the low percentage of the time nonconductive plastics will be used in dome intrusive or waste intruding equipment regions when the relative humidity will be low enough that nonconductive plastic use would not meet the standing orders, c) the lack of static generating mechanisms outside of normal handling, and $d$ ) the small percent of the time that flammable gas levels might be above the LFI. .

The risk associated with continuing use of nonconductive plastics is further reduced by performing flammable gas monitoring of the work area prior to and during use. This will include monitoring per method [A], [B], $[C]$, or $[D]$, as applicable, for the activity. See definition of monitoring methods at the end of this section. This monitoring is in compliance with the monitoring requirenents referenced by $R L$ letter 96-WSD $* 283$.

When $f l$ anmable gas levels reach $25 \%$ of the LFL, work ceases as required per the monitoring requirements referenced in Section $\mathbf{8 . 0}$ of the standing orders. The National Fire Protection Association (NFPA 30, 1988) recommends that processes be controlled so that flammable gas concentrations are $<25$ percent of the lower flamability limit (LFL), when relying upon vapor space flamability levels to preclude the possibility of an ignition. DOE Order 5480.4 requires Hanford waste tanks to be operated within NFPA guidel ines. Thus, a control of $<25 \%$ of the LFL has been established for performing activities in and around Tank Farm

facilities. Because of the unpredictable nature of GREs, it is currently not possible to ensure that $25 \%$ of the LFL is never exceeded. Procedures and controls are thus in place to minimize the potential for a tank to exceed $25 \%$ of the LFL, and to cease work in areas common with the tank vapor space when the flammable gas concentration exceeds this value. This $25 \%$ limit is far below the actual limit at which flammability can occur, and is conservatively chosen to allow for potential measurement errors.

Monitoring is normally performed with a portable CGM. The CGM is calibrated with pentane and reads high by $100 \%$ when monitoring for hydrogen in air. For conservatism, no correction factor is applied in the field to the CGN reading when used for monitoring for personnel protection. Thus a $25 \%$ of the LFL reading on a CGM is actually $12.5 \%$ of the LFL for hydrogen in air, but is treated as if it were $25 \%$. Depending upon the concentration of the flammable gas constituent and oxidants (ammonia, methane, carbon monoxide, nitrous oxide) a $25 \%$ LFL CGM reading will be indicative of $12.5 \%$ to approximately $20 \%$ of the LFL. The response time of a CGM to an increase in flammable gas concentration is not instantaneous. The CGM starts responding to an increase in flarmable gas concentrations almost immediately upon the gas reaching the CGM internals. The internal response time for a CGM to reach a 10\% of the LFL indication ( $5 \%$ LFL actual for hydrogen in air) when exposed to a $23 \%$ of the LFL pentane mixture (equivalent to a $11.5 \%$ of the LFL hydrogen in air mixture) ranged from $7-12$ seconds in a number of informal tests. Time to reach the full $23 \%$ test gas indication took 20-40 seconds.

If the CGM is drawing a sample out of a tank doge space, the time for the tank vapors to reach the CGM is approximatel.y 26 seconds, based upon the $500 \mathrm{~cm}^{3} / \mathrm{min}$ CGM flow and the tubing currently used for flammable gas moritoring. Thus an instantaneous change from 0 to $12.5 \%$ of the LFL for hydrogen in air in a tank vapor space (an indicated $25 \%$ of the LFL) would not indicate any change on a CGM for about 26 seconds. At 26 seconds, the indicated LFL would begin to rise and 33-36 seconds after the step change the CGM would indicate about $10 \%$ of the LFL. The CGM would indicate $25 \%$ of the LFL approximately $45-65$ seconds after the step change.

If the CGM were being used to sample the immediate work area or inside of an adjacent sleeved item, the 26 second delay would not apply. The CGM would start to rise immediately and a reading of $10 \%$ of the LFL would be noted $7-12$ seconds after sensing a $25 \%$ step increase in the LFL. 
A CGM is an acceptable instrument to use for flamable gas monitoring in Dome intrusive and Waste Intruding Equipment regions as long as work is halted upon significant increase in the indicated 4 lammable gas levels. An instantaneous step increase in an entire tank dome vapor space concentration from 0 to $100 \%$ of the LFL is not realistic due to the large volume of gas which would be required to be released. However, localized spots near the waste surface could show a quick step change to $>100 \%$ of the LFL from relatively small releases of gases from below the waste surface. The risk is very low that a gas strean would be released from the waste surface of a 75 foot diameter tank and enter a 4 inch diameter riser directly above without the gas being partially diffused by tank vapors. Since plastic sleeving is not routinely used near the waste surface where there could be quick localized step changes in the flammable gas concentration, the response time for CGMs is not a significant concern when monitoring prior to or during use of nonconductive plastic sleeving.

Not using nonconductive sleeving would lead to ceasing most activities in the Ex Tank, Dome Intrusive or Waste Intruding Equipment regions until suitable replacements are obtained. The resulting delay to sampling work and most other tank intrusive work and the ability to obtain characterization data from waste tanks that is used both for safety issue closure and for design of privatization waste handl ing facilities must be balanced with the small risk of a flamable gas ignition event due to a spark from the plastic.

Another issue is cost. The yearly cost for plastic sleeving will almost triple due to the standing orders $(0.58 / \mathrm{ft}$ for the ESD material versus $0.20 / \mathrm{ft}$ for the nonconductive plastic material).

The use of nonconductive plastic sleeving is acceptable unt il a suitable replacenent is available in sufficient quantities. This wil! be no later than March 1, 1997, assuming that the replacenent material current: ly being tested meets minimum acceptable standards for worker safety and contamination control. plastic sleeving installed prior to March 1, 1997 may remain in place until there is an operational reason for its replacement. The conductive plastic sleeving currently being evaluated will be implemented for Type 4 vapor sampling following approval of this exception. Should the material prove unacceptable for use, the current nonconductive sleeving may be used until replacement material is available that meets minimum acceptable standards for worker safety and contamination control. 
HNF-SD-TWR-TI-003, REV. 3

\section{ITEM CLASSIFICATION: NON-DE MINIMUS}

ITEM NUMBER: 3

EQUIPMENT: Installation, removal, and use of nonconductive glove bags

CATEGORY: Static Spark Potential

USE:

Used for contamination control

APPLICABLE CONTROL NOT MET:

ICS $2 \# 1$

WHEN CONTROL NOT MET:

FG 1 Ex Tank

FG 1,2 Dome Intrusive

FG 3 Dome Intrusive (LWD)

DISCISSION OF STANDING ORDER APPLICABILITY:

Glove bags are installed on risers and are used for high contamination potential activities, such as grab sampling. Glove bags are used for contamination control. Development of a suitable alternate glove bag has been underway since March 1996. Requirements such as strength, viewing capability, temperature stability,

workability, sunlight resistance, and color have not been fully evaluated at this time. Sample plastic has been received from one vendor and has been sent to a testing laboratory to determine how close it comes to the current requirements for ESD plastic. Additional testing will be performed. If the mater iat meets ESD requirements, it is estimated that a glove bag supply can be on hand by March 1997, at though a limited number may be obtained $\mathrm{f} r \mathrm{om}$ the vendor for use by early February 1997. New conductive plastic glovebag will be phased into use. Until March 1997, nonconductive plastic glove bags will continue to be used, but will have a high point vent as a compensatory measure.

\section{RISK ACCEPTANCE:}

See risk acceptance writeup starting on next page.

IMPACT OF NOT ACCEPTING RISK OF CONTINUED USE:

Facility Group 1 Tanks-Would halt grab sampling and high contamination maintenance activities until alternate bag was available.

Facility Group 2 Tanks-Same as FG 1 tanks.

Facility Group 3 or other Tanks-Same as FG 1 tanks.

\section{REQUESTED APPROVAL FROM DOE:}

Continued use when performing flamable gas monitoring control [B] or [C] for nonconductive plastic glove bags in:

1) FG 1 Ex Tank regions

2) FG 1,2 tanks in Dome Intrusive regions

3) FG 3 tanks for Dome Intrusive regions during local waste disturbing activities. 


\section{Risk Acceptance for nonconduct ive glove bags.}

Use of plastic for contamination control is standard in the nuclear industry. At Hanford, the HANFORD SITE RADIOLOGICAL CONIROL MANUAL, HSRC-1, requires contamination control as one of its basic tenets. Section 125 is one of several sections requiring contamination control. Section $342 \# 3$ and \#4 strongly suggest the use of plastics for contamination control and section 413 \#4 requires it for waste packaging. Implementation of alternate contamination control materials could not be done without exhaustive testing and procedure changes.

Plastic glove bags are normally used for taking grab samples and for performing some higher contamination $r$ isk maintenance jobs. The glove bag provides a sealed enclosure for contamination purposes, al though most glove bags also have small cartridge filters attached to permit use on exhausted tanks and to permit ease of collapsing the bag when the work is complete. These filters can also act as high point vents. Glove bag usage is typically inside an Ex Tank area. The inside of the glove bag is common with tank dome vapors when the riser flange is removed, which is conservatively interpreted to be a dome intrusive region.

static buildup is a function of the relative humidity and physical factors that influence a charge such as mechanical friction. Nonconductive plastic glove bags normally are not in place for an extended period of time. They are placed around a riser and will normally remain there for durations of a shift, to a day or two. The riser flange is open only when samples are being obtained. The potential for a static spark discharge is more likely during periods when the plastic is being moved. Work in a glove bag involves extensive hand movements for short periods of time. These are done at a relatively slow pace to avoid contamination spread in the bag. This would not induce a static charge to the extent that continually rubbing the plastic would, but could theoretically induce a small charge. Air movement across the plastic will be due to wind. The plastic could become wet occasionally from rain or snow, but liquids are not forced across the surface in a manner that would cause a static charge buildup.

The relative humidity (RH) has been measured at $>50 \%$ in $95 \%$ of the non-exhausted tanks sampled (as of $7 / 96$ ). This is to be expected since the concentration of water in air in a sealed chamber will eventually reach saturation, and be in equilibrium with the liquid phase. The remaining $5 \%$ of the non-exhausted tanks al! measured berween 40-50\% RH. The SX Farm exhausted tanks measured between $20-40 \%$ RH, except one tank which was $65 \%$ RH. 241-C-105 measured between 40-60\% RH and 241-C-106 measured between 50-100\% RH. Therefore, for non-exhausted tanks, plastics in dome intrusive regions are expected to be in compliance with the standing orders about: $95 \%$ of the time. For exhausted tanks, $241-c-105$ and $241-c-106$ are approximately $50 \%$ RH. Most double-shell. tanks would be expected to be the sarne due to the liquid or moist solid surfaces.

Concern is when a spark occurs coincident with a flamable gas mixture $>100 \%$ lower flammability limit (LFL). Per Appendix A of WHC-SD-WM-JCO-007, Rev OA (Draft), vapor space sample results for single-shell tanks indicate that approximately $70-90 \%$ of the tanks show negligible or nondetectable flammable gas levels during non waste intrusive work. The remaining $10-30 \%$ of the tanks average $1.2-1.5 \%$ of the LFL. The highest CGM measurement ( $7 \%$ ) recorded to date using the organic vapor monitor (OVM) samples equated to approximately $3.5 \%$ of the LFL. The highest vapor sample results obtained via Type B/Type 4 sampl ing correlates to $2.51 \%$ of the LFL. One JMUST tank sampled showed no flammable gas present. The highest recorded organic concentration, $3.8 \%$ of the LFL, was found in 241-C-103. 241-C-103 is the only waste tank known to have a significant floating organic layer. Since July 1996 , one tank has shown a $10 \%$ of the LFL. CGM reading ( $5 \%$ of the $L F L$ ), and one showed a $13 \%$ LFL CGM reading $(6.5 \% \mathrm{LFL})$ prior to intrusive activities. Actively ventilated tanks would be expected to have low flammable gas levels because of the constant dilution air passing through the tanks. No actively ventilated single-shell tanks have shown flammable gas levels above minimum detectible levels in either the Type 3 or 4 vapors samples or in the special ovm samples taken in these tanks.

Plastic glove bags could theoretically trap flammable gases if in place for sufficient time to allow gases from a GRE to accumulate inside the bag. The fitters in place on most glove bags will act as a high point vent to allow some, if not the majority, of any flamable gases in the bag to be vented.

The followirg can be summarized concerning the actual risk with using nonconductive plastic glove bags:

1) There is a small potential for static buildup and subsequent discharge due to the nature of the glove bag operations. The potential is minimized by not performing operations in a manner that would enhance the static sparking potential of the materiat. Glove bags are in place on a tank and open to a tank vapor space for a relatively short period of time.

2) The relative humidity in passively ventilated tanks or waste intruding equipment is expected to be high enough such that use of nonconductive plastic use is often in compliance with the standing orders.

3) Flammable gas levels have not been seen in excess of the LFL in the tank dome for any tank except in pre-mitigated 241-sY-101 during one or more GRES. In about $80 \%$ of the single-shell tanks that have been sampled, the LFL is below detectable limits. In the renaining $20 \%$ of the single-shell tanks, the LFL is less than $2 \%$, except for $2-3$ specific readings which have ranged up to $6.5 \%$. The presence of $f$ lamable gases in actively ventilated single-shell and double-shell tanks would be expected to be low most of the time because of the constant dilution air. Therefore, although the presence of flammable gas concentrations in Dome Intrusive areas above the LFL cannot be positively ruled out, they can be expected to be a rare occurrence. 
HNF-SD-TWR-TI-003, REV. 3

Based upon the following, continued use of nonconductive plastic glave bags in Tank farms poses a low risk of causing a flammable gas ignition event; a) consideration of the small amount of time glove bags are exposed to the tank vapors space, b) the low percentage of the time a glove bag will be used in dome intrusive regions when the relative humidity will be law enough that nonconductive plastic glove bag use would not meet the standing orders, c) the lack of static generating mechanisms outside of normat handling, and d) the small percent of the time that flammable gas levels might be above the LFL.

The low risk with continuing use of nonconductive plastic glove bags is further reduced by performing flammable gas monitoring of the work area prior to and during use. This will include monitoring per method [B] or [C] as applicable for the activity. See definition of monitoring methods at the end of this section. This monitoring is in compliance with the monitoring requirements referenced by RL letter 96-WSD-283.

When $f$ lammable gas levels reach $25 \%$ of the $L F L$, work ceases as required per the monitoring requirements referenced in section 8.0 of the standing orders. The National Fire Protection Association (NFPA 30, 1988) recormends that processes be controlled so that $f$ lamable gas concentrations are <25 percent of the lower flammability limit (LFL), when relying upon vapor space flammability levels to preclude the possibility of an ignition. DOE Order 5480.4 requires Hanford waste tanks to be operated wi thin NFPA guidel ines. Thus, a control of $<25 \%$ of the LFL has been established for performing activities in and around Tank Farm

facilities. Because of the unpredictable nature of GREs, it is currently not possible to ensure that $25 \%$ of the LFI. is never exceeded. Procedures and controls are thus in place to minimize the potent ial for a tank to exceed $25 \%$ of the LFL, and to cease work in areas common with the tank vapor space when the flammable gas concentration exceeds this value. This $25 \% \mathrm{limit}$ is far below the actual limit at which flammability can occur, and is conservatively chosen to allow for potential measurement errors.

Monitoring is normally performed with a portable CGM. The CGM is calibrated with pentane and reads high by $100 \%$ when monitoring for hydrogen in air. For conservatism, no correction factor is applied in the field to the CGM reading when used for monitoring for personnel protection. Thus a $25 \%$ of the LFL reading on a CGM is actually $12.5 \%$ of the LFL for hydrogen in air, but is treated as if it were $25 \%$. The response time of a CGM to an increase in $\mathrm{flammable}$ gas concentration is not instantaneous. The CGM starts responding to an increase in flammable gas concentrations almost immediately upon the gas reaching the CGM internals. The internal response time for a CGM to reach a $10 \%$ of the LFL indication ( $5 \%$ LFL actual for hydrogen in air) when exposed to a $23 \%$ of the LFL pentane mixture (equivalent to a $11.5 \%$ of the LFL hydrogen in air mixture) ranged from $7-12$ seconds in a number of informal tests. Time to reach the full $23 \%$ test gas indication took $20-40$ seconds.

If the CGM is drawing a sample out of a tank dope space, the time for the tank vapors to reach the CGM is approximatel.y 26 seconds, based upon the $500 \mathrm{~cm}^{3} / \mathrm{min}$ CGM flow and the tubing currently used for flammable gas moritoring. Thus an instantaneous change from 0 to $12.5 \%$ of the LFL for hydrogen in air in a tank vapor space (an indicated $25 \%$ of the LFL) would not indicate any change at all on a CGM for about 26 seconds. At 26 seconds, the indicated LFL would begin to rise and 33-36 seconds after the step change the CGM would indicate about $10 \%$ of the LFL. The CGM would indicate $25 \%$ of the LFL approximately $45-65$ seconds after the step change.

If the CGM was being used to sample the immediate work area or inside of a glove bag the 26 second delay would not apply, the CGM would start to rise immediately and a reading of $10 \%$ of the LFL would be noted $7-12$ seconds after sensing a $25 \%$ step increase in the LFL.

A CGM is an acceptable instrument to use for flammable gas monitoring in Dome Intrusive regions (including gtove bags) as long as work is halted upon significant increase in the indicated flammable gas levels. An instantaneous step increase in an entire tank dome vapor space concentration from 0 to $100 \%$ of the LFL is not realistic due to the large volume of gas which would be required to be released, although localized spots near the waste surface could show a quick step change to $>100 \%$ of the LFL from relatively small releases of gases from below the waste surface. The risk is very low that a gas stream would be released from the waste surface of a 75 foot diameter tank and enter a 4 inch diameter riser directly above without the gas being partially diffused by tank vapors. Since plastic glove bags are located on risers and monitoring for flammable gases is done both in the tank dome space and the glove bag while sampling, the current response time for CGMs is not a significant concern.

Performance of grab sampling or higher contamination risk maintenance activities without glove bags would result in these activities taking place in the open air. This is unacceptable from a contamination control standpoint. Discontinuing use of nonconductive glove bags would lead to ceasing these activities until a suitable replacement glove bag is available. The resulting delay to sampling work (and some maintenance activities), the ability to obtain characterization data from waste tanks that is used for safety issue closure and for design of privatization waste hand ing facilities, and the halting of waste transfers dependent upon grab sampling is a more significant concern than the low risk of a flammable gas ignition event due to a spark from a nonconduct ive plastic glove bag.

The use of nonconductive plastic glove bags is acceptable through March 1 , 1997 until a suitable replacement is available in sufficient quantities, provided that high point venting is implemented as a compensatory measure. 
HNF-SD-TWR-TI-003, REV , 3

\section{ITEM CLASSIFICATION: NON-DE MINIMUS}

\begin{tabular}{|c|c|}
\hline $\begin{array}{ll}\text { ITEM NUMBER: } & 4 \\
\text { EQUIPMENT : } & \text { Use of Type } 4 \text { Vapor Sampling head } \\
\text { CATEISORY: } & \text { Static Spark Potential }\end{array}$ & \\
\hline $\begin{array}{l}\text { USE: } \\
\text { Used for obtaining Type } 4 \text { dome space vapor samples }\end{array}$ & \\
\hline $\begin{array}{l}\text { APPLICABLE CONTROL NOT MET: } \\
\text { ICS } 2 \# 1\end{array}$ & $\begin{array}{l}\text { WHEN CONTROL NOT MET: } \\
\text { FG } 1 \text { EX Tank } \\
\text { FG } 1,2 \text { Dome Intrusive }\end{array}$ \\
\hline \multicolumn{2}{|c|}{ 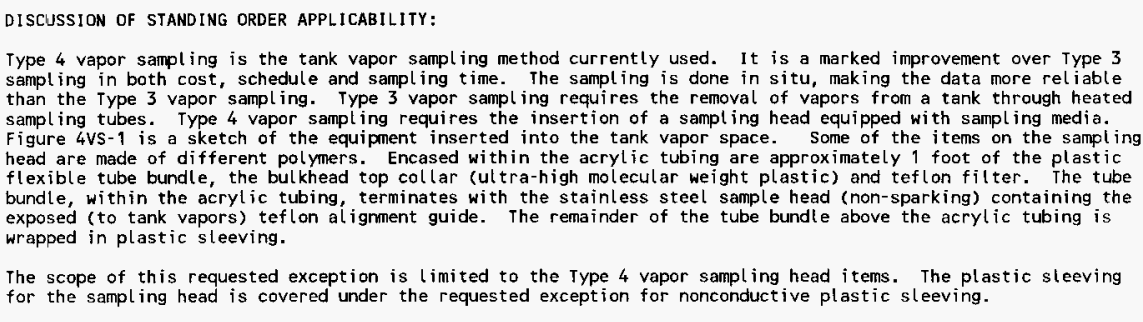 } \\
\hline \multicolumn{2}{|l|}{$\begin{array}{l}\text { RISK ACCEPIANCE: } \\
\text { See risk acceptance writeup starting on next page. }\end{array}$} \\
\hline \multicolumn{2}{|c|}{$\begin{array}{l}\text { IMPACT OF NOT ACCEPTING RISK OF CONTINUED USE: } \\
\text { Facility Group } 1 \text { Tanks-Would halt TYpe } 4 \text { vapor sampl ing unt il alternate items were available. } \\
\text { Facility Group } 2 \text { Tanks-Would halt Type } 4 \text { vapor sampling unt il alternate items were available. } \\
\text { Facility Group } 3 \text { or other Tanks-No Impact. }\end{array}$} \\
\hline \multicolumn{2}{|c|}{$\begin{array}{l}\text { REQUESIED APPROVAL FROM DOE: } \\
\text { Continued use when performing flammable gas monitoring control [B] for above polymeric items during Type } 4 \text { vapor } \\
\text { sampl ing in: } \\
\text { 1) FG } 1 \text { EX Tank regions } \\
\text { 2) FG } 1,2 \text { tanks during Dome Intrusive activities }\end{array}$} \\
\hline
\end{tabular}


The teflon and various plastic components in the Type 4 vapor sampling head were all specifically selected for use based upon their physical characteristics and because they were shown to cause minimal bias to the sampling operation from outgassing of organics. Alternate materials cannot be used for the Iype 4 vapor sampling head without going through extensive testing. The sampling method is sufficiently sensitive that during early sampling with the Type 4 vapor sampler, it was found that the results were being biased by outgassing from the plasticizer used in the tape that attached the plastic sleeve to the sample head. This required revising the taping method normally used for sleeving objects inserted into tank risers to the one shown in Figure 4VS-1 which maintains a barrier between the tape and the vapor sampling head inlet. The ends of the sampling tubes are tightly pressed into the teflon end piece. There is no flow of tank vapors into the acrylic housing as there is no driving force to cause vapors to pass by the seal.

Static buildup is a function of the relative humidity and physical factors that influence a charge such as mechanicat friction. The Type 4 vapor sampling head is only in a tank vapor space for a few hours. The unit is stationary at that time while the tank vapors flow through the tubes. There is no work done to induce a static charge.

The relative humidity has been measured at $>50 \%$ in $95 \%$ of the non-exhausted tanks sampled (as of $7 / 96$ ). This is to be expected since the concentration of water in air in a sealed chamber will eventually reach saturation, and be in equilibrium with the liquid phase. The remaining $5 \%$ of the non-exhausted tanks all measured approximately between $40-50 \% \mathrm{RH}$. The SX Farm exhausted tanks measured approximately between $20-40 \%$ RH, except one tank which was 65\% RH. 241-C- 105 measured 40-60\% RH, and 241-C-106 measured 50-100\% RH. Therefore, for non-exhausted tanks, plastics in dome intrusive regions are expected to be in compliance with the standing orders about $95 \%$ of the time. For exhausted tanks, 241-C-105 and 241-C-106 are approximately $50 \%$ RH. Most double-shell tanks would be expected to be the same due to the liquid or moist solid surfaces.

Concern is when a spark occurs coincident with a $\mathrm{flammable} \mathrm{gas} \mathrm{mixture}>100 \%$ lower flammability limit (LFL). Per Appendix A of WHC-SD-WM-JCO-007, Rev OA (Draft), vapor space sample results for single-shell tanks indicate that $70-90 \%$ of the tanks show negligible or nondetectable flammable gas levels during non waste intrusive work. The remaining $10-30 \%$ of the tanks average $1.2-1.5 \%$ of the LFL. The highest CGM measurement $(7 \%)$ recorded to date using the organic vapor monitor (OVM) samples equated to approximately $3.5 \%$ of the LFL. The highest vapor sample results obtained via Type B/Type 4 vapor sampling correlates to $2.51 \%$ of the LFL. One IMUST tank sampled showed no $\mathrm{flammable} \mathrm{gas} \mathrm{present.} \mathrm{The} \mathrm{highest} \mathrm{recorded} \mathrm{organic}$ concentration, $3.8 \%$ of the LFL, was found in 241-C-103. 241-c-103 is the only waste tank known to have a significant floating organic layer. Since July 1996, one tank has shown a $10 \%$ of the LFL CGM reading $(5 \%$ of the $L F L)$, and one showed a $13 \%$ LFL CGM reading ( $6.5 \%$ LFL) prior to intrusive activities. Actively ventilated tanks would be expected to have low flammable gas levels because of the constant dilution air passing through the tanks. No actively ventilated single-shelt tanks have shown flammable gas levels above minimum detectible levels in either the Type 3 or 4 vapors samples or in the special ovm samples taken in these tanks.

Trapping of gases is not a concern with the Type 4 vapor sampling head as the top end of the external sleeving is open. The following list summarizes the points to be considered when evaluating the risk assocjated with using the Type 4 vapor sampling head:

1) The air flow in the sampler tubing is insufficient to induce a static charge.

2) There is a low potential for static buildup and subsequent discharge with the unit. There are no moving parts and the head is in the tank vapor space for only a few hours.

3) The relative humidity in passively ventilated tanks or waste intruding equipment is expected to be high enough so that the majority of the time nonconductive plastic use in these areas is in compl iance with the standing orders.

5) Ftammable gas levels have not been seen in excess of the LFL in the tank dome space for any tank except in pre-mitigated 241-sY-101 during one or more GREs. In about $80 \%$ of the single-shell tanks that have been sampled the LFL is below detectable. In the remaining $20 \%$ of the single-shelL tanks the $L F L$ is less than $2 \%$, except for $2-3$ specific readings which have ranged up to $6.5 \%$. The presence of flamable gases in actively ventilated single-shel $L$ and double-shell tanks would be expected to be low most of the time because of the constant dilution air. Therefore, al though the presence of flammable gas concentrations in Dome Intrusive areas above the LFL cannot be positively ruled out, they can be expected to be a rare occurrence.

Based upon the following, continued use of the Type 4 vapor sampling head in Tank Farms poses a low $r$ isk of causing a flammable gas ignition event; a) consideration of the small amount of time the Type 4 vapor samoling head is exposed to the tank vapor space, b) the low percentage of the time the Type 4 vapor sampling head will be used in a dome intrusive regions when the relative humidity will be low enough that the head use would not meet the standing orders, c) the lack of any significant static generating mechanisms, and d) the small percent of the time that flammable gas levels might be above the LFL. 
HNF-SD-TWR-TI-003, REV. 3

The risk with continuing use of the Iype 4 vapor sampling head is further reduced by performing $f(a m m a b l e$ gas monitoring of the work area prior to and during use. This will include monitoring per method [B]. See definition of monitoring methods at the end of this section. This monitoring is in compliance with the monitoring requirements referenced by RL letter 96-WSD-283.

When flammable gas levels reach $25 \%$ of the $L F L$, work ceases as required per the monitoring requirements referenced in section 8.0 of the standing orders. The National Fire Protection Association (NFPA 30, 1988) recommends that processes be controlled so that flammable gas concentrations are < 25 percent of the lower flammalsility limit (LFL) when relying upon vapor space flammability levels to preclude the possibitity of an ignition. DOE Order 5480.4 requires Hanford waste tanks to be operated within NFPA guidelines. Thus, a control of $<25 \%$ of the LFL has been established for performing activities in and around Tank Farm

facilities. Because of the unpredictable nature of GREs, it is currently not possible to ensure that $25 \%$ of the LFL is never exceeded. Procedures and controls are thus in place to minimize the potential for a tank to exceed $25 \%$ of the LFL, and to cease work in areas common with the tank vapor space when the flammable gas concentration exceeds this value. This $25 \%$ limit is far below the actual limit at which flammability can occur, and is conservatively chosen to allow for potential measurement errors.

Monitoring is normally performed with a portable CGM. The CGM is calibrated with pentane and reads high by $100 \%$ when monitoring for hydrogen in air. For conservatism, no correction factor is applied in the field to the CGIM reading when used for monitoring for personnel protection. Thus a $25 \%$ of the LFL reading on a CGM is actually $12.5 \%$ of the LFL for hydrogen in air, but is treated as if it were $25 \%$. Depending upon the concentration of the flammable gas constituent and oxidants (ammonia, methane, carbon monoxide, nitrous oxide) a $25 \%$ LFL CGM reading will be indicative of $12.5 \%$ to approximately $20 \%$ of the LFL. The response time of a CGM to an increase in ftamable gas concentration is not instantaneous. The CGM starts responding to an increase in flammable gas concentrations almost immediately upon the gas reaching the CGM internals. The internal response time for a CGM to reach a $10 \%$ of the LFL indication ( $5 \%$ LFL actual for hydrogen in air) when exposed to a $23 \%$ of the LFL pentane mixture (equivalent to a $11.5 \%$ of the LFL hydrogen in air mixture) ranged from $7-12$ seconds in a number of informal tests. Time to reach the full $23 \%$ test gas indication took 20-40 seconds.

If the CGM is drawing a sample out of a tank dome space, the time for the tank vapors to reach the CGM is approximately 26 seconds, based upon the $500 \mathrm{~cm}^{3} / \mathrm{min}$ CGM flow and the tubing currently used for flammable gas monitoring. Thus an instantaneous change from 0 to $12.5 \%$ of the LFL for hydrogen in air in a tank vapor space (an indicated $25 \%$ of the LFL) would not indicate any change at alt on a CGM for about 26 seconds. At 26 seconds, the indicated LFL would begin to rise and 33-36 seconds after the step change the CGM would indicate about $10 \%$ of the LFL. The CGM would indicate $25 \%$ of the LFL approximately $45-65$ seconds after the step change.

A CGM is an acceptable instrument to use for flamable gas monitoring in Dome Intrusive regions as long as work is halted upon significant increase in the indicated flammable gas levels. An instantaneous step increase in an entire tank dome vapor space concentration from 0 to $100 \%$ of the LFL is not realistic due to the large volume of gas which would be required to be released, although localized spots near the waste surface could show a quick step change to $>100 \%$ of the LFL from relatively small releases of gases from below the waste surface. The risk is low that a gas stream would be released from the waste surface of a 75 foot diameter tank and enter the $2 \frac{1}{2}$ inch diameter sampling head directly above without the gas being partially diffused by tank vapors. The sampling head is not routinely used near the waste surface where there could be quick localized step changes in the flammable gas concentration. Were high gas concentrations present for a few seconds until noted by the CGM, there is still low risk of a static discharge as there are no moving parts to the Type 4 vapor sampling head and no major static discharge inducing activity.

The current polymeric materials used for vapor sampling were selected after a study which evaluated the effects of outgassing with a variety of compounds. Using other materials, even if they were available, would result in unnecessary expense and delays to the vapor sampling-program. The impact on resolution of tank safety issues by hatting Type 4 vapor sampling is a more significant concern than the low risk of a flammable gas ignition event due to a spark from these items. 


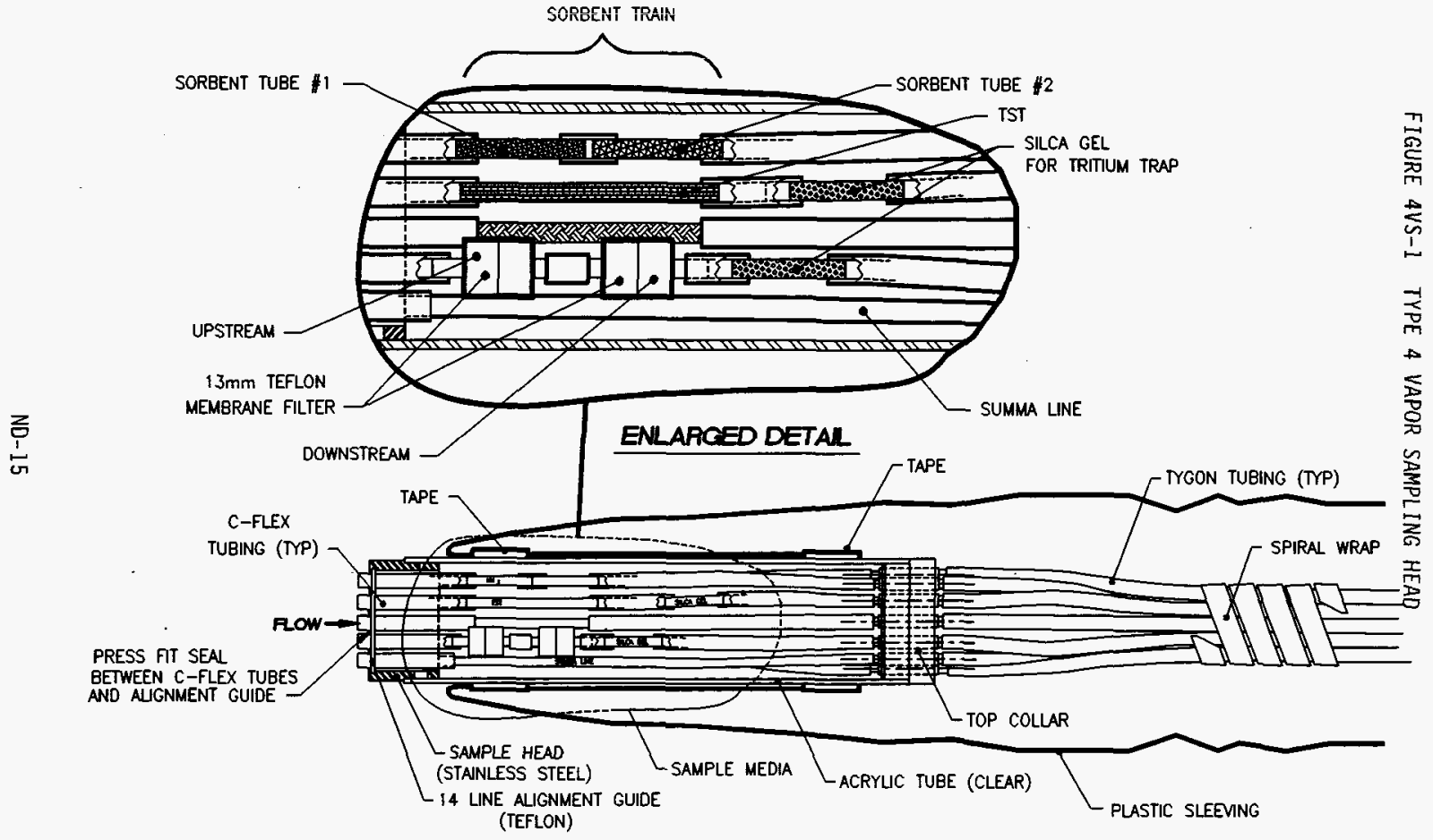

14 TUBE SAMPLE HEAD ASSEMBLY 


\section{ITEM CLASSIFICATION: NON-DE MINIMUS}

\begin{tabular}{|c|c|}
\hline \multicolumn{2}{|c|}{$\begin{array}{l}\text { ITEM NUMBER: } 5 \\
\text { EQUIPMENT: Electric Impact Wrench } \\
\text { CATEGORY: Electrical Spark Potential, Mechanical Spark Potentiat }\end{array}$} \\
\hline \multicolumn{2}{|c|}{$\begin{array}{l}\text { USE: } \\
\text { Used for loosening and tightening jumper heads in pits. }\end{array}$} \\
\hline $\begin{array}{l}\text { APPLICABLE CONTROL NOT MET: } \\
\text { ICS } 2 \# 2\end{array}$ & $\begin{array}{l}\text { WHEN CONTROL NOT MET: } \\
\text { FG } 1 \text { EX Tank }\end{array}$ \\
\hline \multicolumn{2}{|c|}{$\begin{array}{l}\text { DISCIJSSION OF STANDING ORDER APPLICABILITY: } \\
\text { The impact wrench is a large, } 480 \text { VAC electrical induction motor and socket. It is not designed to meet the ICS } \\
\text { controls. The unit is used in tank farms for making jumper changes. }\end{array}$} \\
\hline \multicolumn{2}{|c|}{$\begin{array}{l}\text { RISK ACCEPIANCE: } \\
\text { See risk acceptance writeup starting on next page. }\end{array}$} \\
\hline \multicolumn{2}{|c|}{$\begin{array}{l}\text { IMPACT OF NOT ACCEPIING RISK OF CONTINUED USE: } \\
\text { Facility Group } 1 \text { Ianks-Will shut down most pit work until an alternate wrench, administrative controls or means } \\
\text { of isolating the pit from the tank vapor space can be derived. } \\
\text { Facility Group } 2 \text { Tanks-No impact. } \\
\text { Facility Group } 3 \text { or other Tanks-No impact. }\end{array}$} \\
\hline $\begin{array}{l}\text { REQUESTED APPROVAL FROM DOE: } \\
\text { Cont inued use when performin } \\
\text { 1) FG } 1 \text { EX Tank regions }\end{array}$ & rol $[F]$ for the electric impact wrench: \\
\hline
\end{tabular}


Risk Acceptance for Electric Impact Wrench.

The electrical impact wrench is both an electrical spark source and a mechanical spark source. It is used for tightening and loosening horizontal and vertical jumper heads in pump pits, diversion boxes, valve pits and any location where the old design Hanford or newer PUREX jumper heads are present. No equipnent is known t:o exist which can meet the standing order controls from both electrical and mechanical spark source standpoints. Manual wrenches are not practical for the majority of the high torques required and would result in high personnel exposures.

Concern is when a spark occurs coincident with a flamable gas mixture > $100 \%$ lower flamability limit (LFL). Per Appendix A of WHC-SD-LM-JCO-007, Rev OA (Draft), vapor space sample results for single-shelt tanks indicate that approximately $70-90 \%$ of the tanks show negligible or nondetectable flamable gas levels during non waste intrusive work. The remaining $10-30 \%$ of the tanks average $1.2-1.5 \%$ of the LFL. The highes t: CGM measurement ( $7 \%$ ) recorded to date using the organic vapor monitor (OVM) samples equated to approximately $3.5 \%$ of the LFL. The highest vapor sample results obtained via Type B/Type 4 vapor sampl ing correlates to $2.51 \%$ of the LFL. One IMUST tank sampled showed no flammable gas present. The highest recorded organic concentration, $3.8 \%$ of the LFL, was found in $241-\mathrm{C}-103.241-\mathrm{C}-103$ is the only waste tank known to have a significant floating organic layer. Since July 1996, one tank has shown a $10 \%$ of the LFL CGM reading ( $5 \%$ of the LFL), and one showed a 13\% LFL CGM reading (6.5\% LFL) prior to intrusive activities. Activeliy ventilated tanks would be expected to have low flammable gas levels because of the constant dilution air passing through the tanks. No actively ventilated single-shell tanks have shown flammable gas levels above minimum detectible levels in either the Type 3 or 4 vapors samples or in the special ovM samples taken in these tanks.

The foll lowing can be sumarized concerning the risk associated with using the impact wrench:

$$
\text { Its use is required to make jumper changes or repairs. }
$$

Flammable gas levels have not been seen in excess of the LFL in the tank dome space for any tank except in pre-mitigated 241-sY-101 during one or more GREs. In about $80 \%$ of the single-shell tanks that have been sampled the LFL is below detectable. In the remaining $20 \%$ of the single-shell tanks the LFL is less than $2 \%$, except for $2-3$ specific readings which have ranged up to $6.5 \%$. The presence of flammable gases in actively ventilated single-shell and double-shell tanks would be expected to be low most of the time because of the constant dilution air. Therefore, although the presence of $f$ lammable gas concentrations in Dome Intrusive areas above the LFL cannot be positively ruled out, they can be expected to be a rare occurrence. The presence of flammable gases at concentrations $>25 \%$ of the LFL in an Ex Iank area is expected to be even less likely.

Based upon the following, continued use of the impact wrench in Iank Farms poses a low risk of causing a $f$ lammable gas ignition event; a) the requirement to use the wrench if some transfers are to continue and b) the small percent of the time that flamable gas levels might be above the LFL in the Ex Tank pit area.

The risk associated with continuing use of the impact wrench is further reduced by performing $f($ anmable gas monitoring of the work area prior to and during use. This will include monitoring per method [F], which will require monitoring of both the tank dome space and the pit. See definition of monitoring methods at the end of this section. This monitoring is in compliance with the monitoring requirements referenced by RL letter 96-WSD-283.

When $\mathrm{fl}$, ammable gas levels reach $25 \%$ of the LFL, work ceases as required per the monitoring requirements referenced in section 8.0 of the standing orders. The National Fire Protection Association (NFPA 30, 1988) recommends that processes be controlled so that $\mathrm{flammable}$ gas concentrations are <25 percent of the lower flamability limit (LFL), when relying upon vapor space flamability levels to preclude the possibility of an ignition. DOE Order 5480.4 requires Hanford waste tanks to be operated within NFPA guidelines. Thus, a contral: of $525 \%$ of the LFL has been establ ished for performing activities in and around Tank Farm

facilities. Because of the unpredictable nature of GREs, it is currently not possible to ensure that $25 \%$ of the LFL. is never exceeded. Procedures and controls are thus in place to minimize the potential for a tank to exceed $25 \%$ of the LFL, and to cease work in areas common with the tank vapor space when the flammable gas concentration exceeds this value. This $25 \%$ limit is far below the actual limit at which flammability can occur, and is conservatively chosen to allow for potential measurement errors.

Monitoring is normally performed with a portable CGM. The CGM is calibrated with pentane and reads high by $100 \%$ when monitoring for hydrogen in air. For conservatism, no correction factor is applied in the field to the CGM reading when used for monitoring for personnel protection. Thus a $25 \%$ of the LFL reading on a CGM is actually $12.5 \%$ of the LFL for hydrogen in air, but is treated as if it were $25 \%$. Depending upon the concent:ration of the flammable gas constituent and oxidants (ammonia, methane, carbon monoxide, nitrous oxide) a $25 \%$ LFL CGM reading will be indicative of $12.5 \%$ to approximately $20 \%$ of the LFL. The response time of a CciM to an increase in flammable gas concentration is not instantaneous. The CGM starts responding to an increase in flammable gas concentrations almost immediately upon the gas reaching the CGM internals. The internal response $t$ ime for a CGM to reach a $10 \%$ of the LFL indication (5\% LFL actual for hydrogen in air) when exposed to a $23 \%$ of the LFL pentane mixture (equivalent to a $11.5 \%$ of the LFL hydrogen in air mixture) ranged from 7-12 seconds in a number of informal tests. Time to reach the full $23 \%$ test gas indication took $20-40$ seconds. 
If the CGM is drawing a sample out of a tank dome space, the time for the tank vapors to reach the CGM is approximately 26 seconds, based upon the $500 \mathrm{~cm}^{3} / \mathrm{min} \mathrm{CGM} \mathrm{flow} \mathrm{and} \mathrm{the} \mathrm{tubing} \mathrm{currently} \mathrm{used} \mathrm{for} \mathrm{flammable}$ gas monitoring. Thus an instantaneous change from 0 to $12.5 \%$ of the LFL for hydrogen in air in a tank vapor space (an indicated $25 \%$ of the LFL) would not indicate any change at al $L$ on a CGM for about 26 seconds. At 26 secionds, the indicated LFL would begin to rise and 33-36 seconds after the step change the CEM would indicate about $10 \%$ of the LFL. The CGM would indicate $25 \%$ of the LFL approximately $45-65$ seconds af ter the step change.

If the CGM was being used to sample the immediate work area where an impact wrench was used the 26 second delay would not apply, the CGM would start to rise immediately and a reading of $10 \%$ of the LFL would be noted 7-12 seconds after sensing a $25 \%$ step increase in the LFL.

A CGM is an acceptable instrument to use for flamable gas monitoring in Dome Intrusive or Ex Tank regions as long as work is halted upon significant increase in the indicated flammable gas levels. An instantaneous step increase in an entire tank dome vapor space concentration from 0 to $100 \%$ of the LFL is not realistic due to the large volume of gas which would be required to be released, although localized spots near the waste surface could show a quick step change to $>100 \%$ of the LFL from relatively small releases of gases from below the waste surface. The risk is very low that a gas stream would be released from the waste surface of a 75 foot diameter tank and enter a 4 inch diameter pit drain directly above without the gas being partially diffused by tank vapors. Since monitoring for flammable gases is done both in the tank done space and the pit while using the wrench, the current response time for CGMs is not a significant concern.

There does not appear to be a suitable substitute for an electric impact wrench which could adequately tighten and loosen jumper heads and, at the same time, create no potential for mechanical sparking. In its tank farm applications, the impact wrench is judged to present a low risk for ignition of flammable gas due to the combination of the location of its use and the relatively short duration of its use. Therefore, the benefits derived from the use of the impact wrench (e.g. enabling waste transfers and repairing jumper leaks) must be balanced with the low risk introduced by its potential for mechanical sparking. 


\section{ITEM CLASSIFICATION: NON-DE MINIMUS}

ITEM NUMBER: 6

EQUIPMENT: Type 4 Vapor Sampl ing Cart

CATEGORY: Electrical Spark Potential

USE :

Used for monitoring flows and providing suction for gas drawn through sampling tubes inserted in the tank.

APPL: CABLE CONTROL NOT MET:

ICS $2 \# 2$
WHEN CONTROL NOT MET:

FG 1,2 Dome Intrusive

DISCUSSION OF STAND ING ORDER APPLICABILITY:

The electronic equipment on the Type 4 sampling cart consists of four mass flowmeters, four electronic

total izers, and a vacuum pump. The Type 4 vapor sampl ing cart establishes the vacuum, and monitors the $f$ low of

tank vapors from the Type 4 vapor sampling head. The information is not yet available to show whether the $i$ tems

on the cart meet the controls for dome intrusive electrical equipment for Facility Group 1 and 2 Tanks. Although the definitions in the standing order would imply the equipment is not required to meet Dome Intrusive criteria, a conseryative assumption is that it should meet the requirements as filtered tank gases pass through the equipment and any flammable mixtures would be exposed to the electrical equipment internals. Type 4 vapor sampling is currently only performed on FG 2 and FG 3 tanks, plans are to sample at least one FG 1 tank in the future.

\section{RISK ACCEPTANCE:}

See risk acceptance writeup starting on next page.

IMPAIT OF NOT ACCEPTING RISK OF CONT INUED USE:

Facility Group 1 Tanks-No impact unless sample FG 1 tanks. If FG 1 tanks are sampled, the impact would be the same as for FG 2 tanks.

Facility Group 2 Tanks-If the risk of continuing to use the current equipment is not accepted, all in situ vapor sampling (Type 4) vapor sampling activities will be shutdown until different equipment is available or the existing equipment can be shown to meet the standing order criteria.

Facility Group 3 or other Tanks-No Impact.

REQUIESTED APPROVAL FROM DOE:

Continued use when performing flamable gas monitoring control [E] for the current Type 4 vapor sampling cart:

1) FG 1,2 Dome Intrusive regions 
HNF-SD-TWR-TI-003, REV. 3

Risk Acceptance for Type 4 vapor sampling cart.

The scope of this discussion is limited to potential electrical spark ignition events from the Type 4 sampling cart. See Item 4 regarding on static spark caused ignition events from the Type 4 vapor sampling head and tubing.

The Type 4 vapor sampling cart was developed to sample tank vapors to support resolution of tank safety issues. It replaces Type 3 vapor sarpling which is more expensive and time consuming, and did not provide in situ sampling.

Concern is when a spark occurs coincident with a flamable gas mixture $>100 \%$ lower flamability Limit (LFL). Per Appendix A of WHC-SD-WM-JCO-007, Rev OA (Draft), vapor space sample results for single-shell tanks indicate that approximately $70-90 \%$ of the tanks show negligible or nondetectable flammable gas levels during non waste intrusive work. The remaining $10-30 \%$ of the tanks average $1.2-1.5 \%$ of the LFL. The highest CGM measurement ( $7 \%$ ) recorded to date using the organic vapor monitor (VM) samples equated to approximately $3.5 \%$ of the LFL. The highest vapor sample results obtained via Type B/Type 4 vapor sampling correliates to $2.51 \%$ of the LFL. One IMUST tank sampled showed no flamable gas present. The highest recorded organic concentration, $3.8 \%$ of the LFL, was found in 241-C-103. 241-C-103 is the only waste tank known to have a significant floating organic layer. Since July 1996, one tank has shown a $10 \%$ of the LFL CGM reading ( $5 \%$ of the $L F L$ ), and one showed a $13 \%$ LFL CGM reading ( $6.5 \%$ LFL) prior to intrusive activities. Actively vent ilated tanks would be expected to have low flammable gas levels because of the constant dilution air passing through the tanks. No actively ventilated single-shell tanks have shown flammable gas levels above minimum detectible levels in either the Type 3 or 4 vapors samples or in the special ovM sample:s taken in these tanks.

The following can be summarized concerning the actual risk from using the Type 4 vapor sampling cart:

Analytical data from Type 4 vapor sampling is used to support waste tank safety issue resolution.

Flammable gas levels have not been seen in excess of the LFL in the tank dome space for any tank except in 241-sY-101 during one or more GREs. In about $80 \%$ of the single-shell tanks that have been sampled the LFL is below detectable. In the remaining $20 \%$ of the single-shell tanks the LFL is less than $2 \%$, except for $2-3$ specific readings which have ranged up to $6.5 \%$. The presence of flammable gases in actively ventilated single-shell and double-shell tanks would be expected to be low most of the time because of the constant dilution air. Therefore, although the presence of flammable gas concentrations in Dome Intrusive areas above the LFL cannot be positively ruled out, they can be expected to be a rare occurrence.

Based upon the need for Type 4 vapor sampling and the small percent of the time that flammable gas levels might be above the LFL, continued use of the Type 4 vapor sampling cart poses a low risk of causing a flamalole gas ignition event.

The risk associated with continued use of the Type 4 vapor sampling cart is further reduced by performing $f$ lammalo gas monitoring of the work area and dome space prior to and during use. This will include monitoring per method [E]. See definition of monitoring methods at the end of this section. This monitoring is in compliance with the monitoring requirements referenced by RL letter 96-WSD-283.

When $\mathrm{f}$ lammable gas levels reach $25 \%$ of the $\mathrm{LFL}$, work ceases as required per the monitoring requirements referenced in section 8.0 of the standing orders. The National Fire Protection Association (NFPA 30, 1988) recommends that processes be controlled so that $f$ lamable gas concentrations are <25 percent of the lower flarmability limit ( $L F L$ ), when relying upon vapor space flammability levels to prectude the possibility of an ignition. DOE Order 5480.4 requires Hanford waste tanks to be operated with in NFPA guidel ines. Thus, a control of $<25 \%$ of the LFL has been established for performing activities in and around Tank Farm facilities. Because of the unpredictable nature of GREs, it is currently not possible to ensure that $25 \%$ of the LFL is never exceeded. Procedures and controls are thus in place to minimize the potential for a tank to exceed $25 \%$ of the LFL, and to cease work in areas common with the tank vapor space when the $f$ lammable gas concentration exceeds this value. This $25 \%$ limit is far below the actual 1 imit at which flammability can occur, and is conservatively chosen to al low for potential measurenent errors.

Monitoring is normally performed with a portable CGM. The CGM is calibrated with pentane and reads high by $100 \%$ when monitoring for hydrogen in air. For conservatism, no correction factor is applied in the field to the CGM reading when used for monitoring for personnel protection. Thus a $25 \%$ of the LFL reading on a CGM is actually $12.5 \%$ of the LFL for hydrogen in air, but is treated as if it were $25 \%$. Depending upon the concentration of the flammable gas constituent and oxidants (ammonia, methane, carbon monoxide, nitrous oxide) a $25 \%$ LFL CGM reading will be indicative of $12.5 \%$ to approximately $20 \%$ of the LFL. The response time of a CGM to an increase in flammable gas concentration is not instantaneous. The cGM starts responding to an increase in $\mathrm{flammable} \mathrm{gas} \mathrm{concentrations} \mathrm{almost} \mathrm{immediately} \mathrm{upon} \mathrm{the} \mathrm{gas} \mathrm{reaching} \mathrm{the} \mathrm{CGM} \mathrm{internals.} \mathrm{The}$ internal response time for a CGM to reach a 10\% of the LFL indication ( $5 \%$ LFL actual for hydrogen in air) when exposed to a $23 \%$ of the LFL pentane mixture (equivalent to a $11.5 \%$ of the LFL hydrogen in air mixture) ranged from $7-12$ seconds in a number of informal tests. Time to reach the full $23 \%$ test gas indication took $20-40$ seconds. 
If the CGM is drawing a sample out of a tank dome space, the time for the tank vapors to reach the CGM is approximately 26 seconds, based upon the $500 \mathrm{~cm} / \mathrm{min}$ CGM flow and the tubing currently used for flammable gas monitoring. Thus an instantaneous change from 0 to $12.5 \%$ of the LFL for hydrogen in air in a tank vapor space (an indicated $25 \%$ of the LFL) would not indicate any change at all on a CGM for about 26 seconds. At 26 seconds, the indicated LFL would begin to rise and 33-36 seconds after the step change the CGM would indicate about $10 \%$ of the LFL. The CGM would indicate $25 \%$ of the LFL approximately $45-65$ seconds after the step change.

A CGM is an acceptable instrument to use for flammable gas monitoring in Dome Intrusive regions as long as work is halted upon significant increase in the indicated flammable gas levels. An instantaneous step increase in an entire tank dome vapor space concentration from 0 to $100 \%$ of the LFL is not real istic due to the large volume of gas which would be required to be released, although localized spots near the waste surface could show a quick step change to $>100 \%$ of the LFL from relatively small releases of gases from below the waste surface. The risk is very low that a gas stream would be released from the waste surface of a 75 foot diameter tank and enter the $2 \frac{1}{2}$ inch diameter sampling head directly above without the gas being partially diffused by tank vapors. The sampling head is not routinely used near the waste surface where there could be quick lacalized step changes in the flammable gas concentration. Were high gas

concentrations present for a few seconds until noted by the CGM, the CGM would indicate high flammable gas levels present before flamable gases approached the Type 4 vapor sampling cart, leaving adequate time for shutdown.

Cont inuous monitoring is performed during Type 4 vapor sampling using a cGM. Sampling is conducted through a tube within the flexible tube bundle that is lowered into the tank. Tank vapors flow faster through the tubing used for flammable gas monitoring than through the tubing used for sampling the tank gases. This is because the vapors are drawn through the flammable gas monitoring tube with the CGM while the tank vapors to be sampled are drawn through sampling tubes by the vacuum pump on the cart. The time for tank vapors to reach the CISM is approximately 26 seconds. Tank vapors being sampled by the cart take approximately 65 seconds to reach the in situ vapor sampling instrumentation on the cart. Therefore, with the current flammable gas monitoring arrangement, a significant change in the tank $f$ lammable gas concentration would be noticed with in 33-38 seconds or less, assuming there were no other indications of a GRE. This stilL Leaves approximately 30 seconds before the instrumentation on the cart would see the gas, which allows adequate time for personnel response to shut off the vacuum pump. This monitoring is continuous during Type 4 vapor sampling white the vacuum pump is running. Shutdown of the electrical equipment on the Type 4 cart is manual upon receipt of a CGM atarm or indication.

Additionally, given that vapor sampling is non waste disturbing, the activity would not induce a GRE. 
HNF-SD-TWR-TI-003, REV. 3

\section{ITEM CLASSIFICATION: NON-DE MINIMUS}

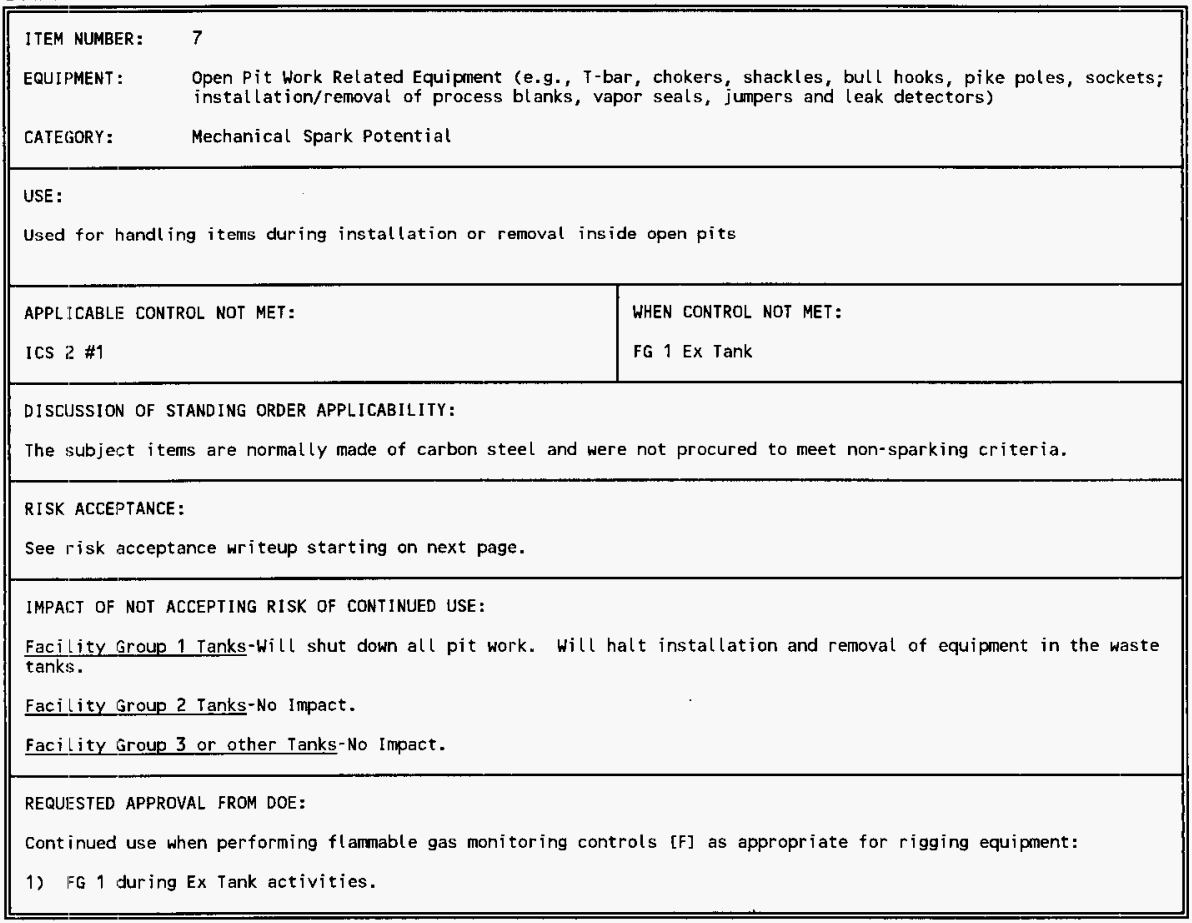


HNF-SD-TWR-TI-003, REV. 3

\section{Risk Acceptance for Open Pit Work Related Equipment.}

These items are potential mechanical spark sources. They are used for moving and adjusting equipment or sealing lines in various pits. Due to their size and weight, replacement equipment which meets the standing order requirements is not readily or economically available. Control is provided through the use of proper rigging controls and procedures. Tools and equipment in this exception request are either not readily or economically available in a spark resistant version or are only rarely used in areas which require the standing order controls.

Concern is when a spark occurs coincident with a $\mathrm{flammable} \mathrm{gas} \mathrm{mixture}>100 \%$ lower $\mathrm{flammabil}$ ity limit (LFL). Per Appendix A of WHC-SD-WM-JCO-007, Rev OA (Draft), vapor space sample results for single-shel! tanks indicate that approximately $70-90 \%$ of the tanks show negligible or nondetectable flamable gas levels during non waste intrusive work. The remaining 10-30\% of the tanks average $1.2-1.5 \%$ of the LFL. The highest CGM measurement (7\%) recorded to date using the organic vapor monitor (OVM) samples equated to approximately $3.5 \%$ of the LFL. The highest vapor sample results obtained via Type B/Type 4 vapor sampling correlates to $2.51 \%$ of the LFL. One IMUST tank sampled showed no flamable gas present. The highest recorded organic concentration, $3.8 \%$ of the LFL, was found in 241-C-103. 241-c-103 is the only waste tank known to have a significant floating organic layer. Since July 1996, one tank has shown a $10 \%$ of the LFL CGM reading ( $5 \%$ of the $L F L$ ), and one showed a $13 \%$ LFL CGM reading ( $6.5 \% L F L)$ prior to intrusive activities. Actively ventilated tanks would be expected to have low flammable gas levels because of the constant dilution air passing through the tanks. No actively ventilated single-shell tanks have shown flammable gas levels above minimum detectible levels in either the Type 3 or 4 vapors samples or in the special ovm samples taken in these tanks.

The following can be sumarized concerning the risk associated with using these tools and equipment: This equipment is required to accomplish pit work and to install and remove equipment in waste tanks.

$\mathrm{Fl}$ ammable gas levels have not been seen in excess of the LFL in the tank dome space for any tank except in 241-5Y-101 during one or more GREs. In about $80 \%$ of the single-shell tanks that have been sampled the LFL is below detectable. In the remaining $20 \%$ of the single-shell tanks the LFL is less than $2 \%$, except for $2-3$ specific readings which have ranged up to $6.5 \%$. The presence of flamable gases in actively ventilated single-shell and double-shell tanks would be expected to be low most of the time because of the constant dilution air. Therefore, although the presence of flamable gas concentrations in Dome Intrusive areas above the LFL cannot be positively ruled out, they can be expected to be a rare ofcurrence. The presence of $f$ lamable gases at concentrations $>25 \%$ of the LFL in an EX Tank area is therefore expected to be even less likely.

Based upon the following, cont inued use of these tools and equipment in Tank Farms poses a low risk of causing a flammable gas ignition event; a) the use of the tools and equipment is required if transfers are to continue: and $b$ ) the small percent of the time that flammable gas levels might be above the LFL in the Ex Tank pit area.

The risk associated with continuing use of the tools and equipment is further reduced by performing flamable gas monitoring of the work area prior to and during use. This will include monitoring per method [F]. See definition of monitoring methods at the end of this section. This monitoring is in compliance with the monitoring requirements referenced by RL letter 96-WSD-283.

When $f$ lammable gas levels reach $25 \%$ of the $L F L$, work ceases as required per the monitoring requirements referenced in section 8.0 of the standing orders. The National Fire Protection Association (NFPA 30, 1988) recommends that processes be controlled so that $\mathrm{flammable}$ gas concentrations are < 25 percent of the lower flamability limit (LFL), when relying upon vapor space flammability levels to preclude the possibility of an igrition. DOE Order 5480.4 requires Hanford waste tanks to be operated within NFPA guidel ines. Thus, a contral of $<25 \%$ of the LFL has been establ ished for performing activities in and around Jank Farm

facilities. Because of the unpredictable nature of GREs, it is currently not possible to ensure that $25 \%$ of the LFL is never exceeded. Procedures and controls are thus in place to minimize the potentiat for a tank to exceed $2.5 \%$ of the LFL, and to cease work in areas common with the tank vapor space when the flammable gas concertration exceeds this value. This $25 \%$ limit is far below the actual $t$ imit at which flammability can occur, and is conservatively chosen to allow for potential measurement errors.

Monitoring is normally performed with a portable CGM. The CGM is calibrated with pentane and reads high by $100 \%$ when monitoring for hydrogen in air. For conservatism, no correction factor is applied in the field to the CGiM reading when used for monitoring for personnel protection. Thus a $25 \%$ of the LFL reading on a CGM is actually $12.5 \%$ of the LFL for hydrogen in air, but is treated as if it were $25 \%$. Depending upon the conceritration of the $\mathrm{flammable} \mathrm{gas} \mathrm{constituent} \mathrm{and} \mathrm{oxidants} \mathrm{(ammoni} \mathrm{a,} \mathrm{methane,} \mathrm{carbon} \mathrm{monoxide,} \mathrm{nitrous}$ oxide; a $25 \%$ LFL CGM reading will be indicative of $12.5 \%$ to approximately $20 \%$ of the LFL. The response time of a CGM to an increase in flamable gas concentration is not instantaneous. The CGM starts responding to an increase in $\mathrm{flammable} \mathrm{gas} \mathrm{concentrations} \mathrm{almost} \mathrm{immediately} \mathrm{upon} \mathrm{the} \mathrm{gas} \mathrm{reaching} \mathrm{the} \mathrm{CGM} \mathrm{internals.} \mathrm{The}$ internal response time for a CGM to reach a $10 \%$ of the LFL. indication ( $5 \%$ LFL actual for hydrogen in air) when exposed to a $23 \%$ of the LFL pentane mixture (equivalent to a $11.5 \%$ of the LFL hydrogen in air mixture) ranged from $7-12$ seconds in a number of informal tests. Time to reach the full $23 \%$ test gas indication took $20-40$ seconds. 
If the CGM is drawing a sample out of a tank dope space, the time for the tank vapors to reach the CGM is approximately 26 seconds, based upon the $500 \mathrm{~cm}^{3} / \mathrm{min} \mathrm{CGM}$ flow and the tubing currently used for $\mathrm{flammable}$ gas monitoring. Thus an instantaneous change from 0 to $12.5 \%$ of the LFL for hydrogen in air in a tank vapor space (an indicated $25 \%$ of the $L F L$ ) would not indicate any change at all on a CGM for about 26 seconds. At 26 secionds, the indicated LFL would begin to rise and 33-36 seconds after the step change the CGM would indicate about $10 \%$ of the LFL. The CGM would indicate $25 \%$ of the LFL approximately $45-65$ seconds after the step clnange.

If the CGM was being used to sample the Ex Tank area where these tools are used the 26 second delay would not apply, the CGM would start to rise immediately and a reading of $10 \%$ of the LFL would be noted $7-12$ seconds after sensing a $25 \%$ step increase in the LFL.

A CGM is an acceptable instrument to use for $f($ ammable gas monitoring in Ex Tank and Dome Intrusive regions as long as work is halted upon significant increase in the indicated flammable gas levels. An instantaneous step increase in an entire tank dome vapor space concentration from 0 to $100 \%$ of the LFL is not realistic due to the large volume of gas which would be required to be released, al though localized spots near the waste surface could show a quick step change to $>100 \%$ of the LFL from relatively small releases of gases from below the waste surface. The risk is very low that a gas stream would be released from the waste surface of a 75 foot diameter tank and enter a 4 inch diameter pit drain directly above without the gas being partially diffused by tank vapors. Since monitoring for flamable gases is done in the pit while using the tools and equipment, the current response time for CGMs is not a significant concern. 


\section{ITEM CLASSIFICATION: NON-DE MINIMUS}

ITEM NUMBER: 8

EQUIPMENT: Closed Pit Work including the Installation and Removal of Valve Handles

CATEGORY: Mechanical Spark Potential

USE:

Used for operating valves in pits.

APPLICABLE CONTROL NOT MET:

WHEN CONTROL NOT MET:

ICS $2 \# 1$

FG 1 Ex Tank

DISCUSSION OF STANDING ORDER APPLICABILITY:

Valve handles are made of carbon steel. They were not procured to meet non-sparking criteria. The valve handles are bulky and are a potential spark source during installation and removal. valve operation is covered as a de minimus item.

RISK ACCEPTANCE:

See risk acceptance writeup starting on next page.

IMPACT OF NOT ACCEPTING RISK OF CONTINUED USE:

Facility Group 1 Tanks-Will shut down transfers.

Facility Group 2 Tanks-No Impact.

Facility Group 3 or other Tanks-No impact.

REQUESTED APPROVAL FROM DOE:

Cont inued use when performing flammable gas monitoring control [B] for installation and removal of valve handles in:

1) FG 1 tank EX Tank regions. 
HNF-SD-TWR-TI-003, REV. 3

\section{Risk Acceptance for Closed Pit Work.}

Valvie handles are potential mechanical spark sources as they could be dropped during installation or removal due to their size and weight. Concern is wherı a spark occurs coincident with a flarmable gas mixture > $100 \%$ lower $f$ lamnability Limit (LFL). Per Appendix A of WHC-SD-WM-JCO-007, Rev OA (Oraft), vapor space sample results for single-shell tanks indicate that approximately $70-90 \%$ of the tanks show negligible or nondetectable flammable gas levels during non waste intrusive work. The remaining $10-30 \%$ af the tanks average $1.2-1.5 \%$ of the LFL. The highest CGM measurement (7\%) recorded to date using the organic vapor monitor (OVM) samples equated to approximately 3.5\% of the LFL. The highest vapor samole correlates to $2.51 \%$ of the LFL. One INUST tank sampled showed no flammable gas present. The highest recorded organic concentration, $3.8 \%$ of the LFL, was found in 241-c-103. 241-c-103 is the only waste tank known to have a significant floating organic layer. Since July 1996, one tank has shown a $10 \%$ of the LFL CGM reading (5\% of the $L F L)$, and one showed a $13 \%$ LFL CGM reading $(6.5 \% \mathrm{LFL})$ prior to intrusive activities. Actively ventilated tanks would be expected to have low flammable gas levels because of the constant dilution air passing through the tanks. No actively ventilated single-shell tanks have shown flammable gas levels above minimum detectible levels in either the Type 3 or 4 vapors samples or in the special ovM samples taken in these tanks.

The following can be sumarized concerning the risk associated with installing and renoving valve handles, Valve handles are required to perform transfers.

2) Flammable gas levels have not been seen in excess of the LFL in the tank done space for any tank except in pre-mitigated 241-ş-101 during one or more GREs. In about $80 \%$ of the single-shell tanks that have been sampled the LFL is below detectable. In the remaining $20 \%$ of the single-shell tanks the LFL is less than $2 \%$, except for $2-3$ specific readings which have ranged up to $6.5 \%$. The presence of $f$ tammable gases in actively vent $i$ lated single-shell and double-shell tanks would be expected to be low most of the time because of the constant dilution air. Therefore, although the presence of flammable gas concentrations in Dome Intrusive areas above the LFL cannot be positively ruled out, they can be expected to be a rare occurrence. The presence of $f$ lammable gases at concentrations $>25 \%$ of the LFL in an Ex Tank area is therefore expected to be even less of a probability.

Based upon the need to install and remove valve handles if some transfers are to continue and the small percent of the time that flamable gas levels might be above the LFL in the Ex Tank pit area, continued installation and removal of the valve handles poses a low risk of causing a flammable gas ignition event.

The risk associated with continuing installation and removal of valve handles is further reduced by performing flammable gas monitoring of the work area prior to and during the activity. This will include monitoring per method [B]. See definition of monitoring methods at the end of this section. This monitoring is in compliance with the monitoring requirements referenced by RL letter $96-$ WSD-283.

When flammable gas levels reach $25 \%$ of the $L F L$, work ceases as required per the monitoring requirements referenced in section 8.0 of the standing orders. The National Fire Protection Association (NFPA 30, 1988) recommends that processes be controlled so that flammable gas concentrations are <25 percent of the lower flamability limit (LFL), when relying upon vapor space flamability levels to preclude the possibility of an ignition. DOE Order 5480.4 requires Hanford waste tanks to be operated within NFPA guidelines. Thus, a contral of $<25 \%$ of the LFL has been established for performing activities in and around Tank Farm

facilities. Because of the unpredictable nature of GREs, it is currently not possible to ensure that $25 \%$ of the LFL is never exceeded. Procedures and controls are thus in place to minimize the potential for a tank to exceed $25 \%$ of the LFL, and to cease work in areas common with the tank vapor space when the flammable gas concentration exceeds this value. This $25 \%$ limit is far below the actual limit at which flammability can occur, and is conservatively chosen to allow for potential measurement errors.

Monitoring is normally performed with a portable CGM. The CGM is calibrated with pentane and reads high by $100 \%$ when monitoring for hydrogen in air. For conservatism, no correction factor is applied in the field to the CGM reading when used for monitoring for personnel protection. Thus a $25 \%$ of the LFL reading on a CGM is actually $12.5 \%$ of the LFL for hydrogen in air, but is treated as if it were $25 \%$. Depending upon the concentration of the $f$ lammable gas constituent and oxidants (ammonia, methane, carbon monoxide, nitrous oxide) a $25 \%$ LFL CGM reading will be indicative of $12.5 \%$ to approximately $20 \%$ of the LFL. The response time of a CGM to an increase in $\mathrm{flammable} \mathrm{gas} \mathrm{concentration} \mathrm{is} \mathrm{not} \mathrm{instantaneous.} \mathrm{The} \mathrm{CGM} \mathrm{starts} \mathrm{responding} \mathrm{to}$ an increase in flammable gas concentrations almost immediately upon the gas reaching the CGM internals. The internal response time for a CGM to reach a $10 \%$ of the LFL indication (5\% LFL actual for hydrogen in air) when exposed to a $23 \%$ of the LFL pentane mixture (equivalent to a $11.5 \%$ of the LFL hydrogen in air mixture) ranged from $7-12$ seconds in a number of informal tests. Time to reach the full $23 \%$ test gas indication took $20-40$ seconds.

If the CGM is drawing a sample out of a tank doge space, the time for the tank vapors to reach the CGM is approximately 26 seconds, based upon the $500 \mathrm{~cm}^{3} / \mathrm{min} \mathrm{CGM}$ flow and the tubing currently used for flammable gas monitoring. Thus an instantaneous change from 0 to $12.5 \%$ of the LFL for hydrogen in air in a tank vapor space (an indicated $25 \%$ of the LFL) would not indicate any change at all on a CGM for about 26 seconds. At 26 seconds, the indicated LFL would begin to rise and 33-36 seconds after the step change the CGM would indicate about $10 \%$ of the LFL. The CGM would indicate $25 \%$ of the LFL approximately $45-65$ seconds after the step change. 
If the CGM were being used to sample the pit where these tools are used, the 26 second delay would be reduced to 3.6 seconds (due to shorter sample tube lengths and, thus, shorter transport times), and a reading of $10 \%$ of the LFL would be noted $10-18$ seconds after sensing a $25 \%$ step increase in the LFL.

A CGM is an acceptable instrument to use for flammable gas monitoring in pits as long as work is halted upon significant increase in the indicated $f$ larmable gas levels. An instantaneous step increase in an entire tank dome vapor space concentration from 0 to $100 \%$ of the LFL is not realistic due to the large volume of gas which would be required to be released, although localized spots near the waste surface could show a quick step change to $>100 \%$ of the LFL from relatively small releases of gases from below the waste surface. The $r$ isk is very low that a gas stream would be released from the waste surface of a 75 foot diameter tank and enter a 4 inch diameter pit drain directly above without the gas being partially diffused by tank vapors. Since monitoring for $f$ lammable gases is done in the pit before installation and removal of the valve: handles, the current response time for CGMs is not a significant concern.

There is no readily available substitute for the valve handles. Therefore, the ability to instal! and remove the existing valve handles is essential for transferring of waste and other basic plant operations. The benefits of the ability to install and remove valve handles tnust be balanced against the small risk of igniting flammable gas via mechanical sparking. 


\section{ITEM CLASSIFICATION: NON-DE MINIMUS}

\section{ITEM NUMBER : 9}

EOUIPMENT: Cover blocks, riser flanges, shield plugs, and tank installed waste intrusive and non waste intrusive equipment items (e.g., thermocouple trees, siteel Lows, pumps, manual tapes, FICs, ENRAFs, radar gauges, heated vapor probes, MITs, corrosion probes, VDTTs, water lances, void fraction meter, core sampling drill string, saltwell screens, dip tubes, cameras, lights, viscometer, auger sampler)

CATEGORY: Mechanical Spark Potential

USE:

1 teris are used for various purposes in risers and pits, or are equipnent installed or removed in tanks to perform various functions.

APPLICABLE CONTROL NOT MET:

ICS $2 \# 1$

WHEN CONTROL NOT MET:

FG 1 Ex Tank

FG 1,2 Dome Intrusive

FG 3 Dome Intrusive (LWD)

FG 2 Ex Tank (GWD)

\section{DISCUSSION OF STANDING ORDER APPLICABILLTY:}

These are potential mechanical spark sources during installation or renoval. Many are made of carbon steel.

These items are inserted into or attached to the top of a riser or pit opening. Where required by the standing

orders, these items are also bonded. Installation and removal of these items are considered routine operations.

The risk of mechanical sparks is minimized fer long items by controlling rate of insertion or removal.

Monitoring is done during installation and movement is stopped if required by $\mathrm{flammable} \mathrm{gas} \mathrm{levels.}$

\section{RISK. ACCEPTANCE :}

See risk acceptance writeup starting on next page.

IMPACT OF NOT ACCEPTING RISK OF CONTINUED USE:

Facility Group 1 Tanks-Wilt shut down most pit or riser installation work and halt installation of equipment into tanks.

Facility Group 2 Tanks-Will shut down most pit or riser installation work and halt installation of equipment into tanks.

Facility Group 3 or other Tanks-Will restrict or shut down all waste intrusive installations and removals.

REQUESTED APPROVAL FROM DOE:

Installation and removal performing flammable gas monitoring controls [A], [B] or [C] as appropriate for the above tank or pit installed equipment in:

1) FG 1 tanks during Ex Tank activities

2) FG 1,2 tanks during Dome Intrusive activities

3) FG 3 tanks during Dome Intrusive local waste disturbing activities

4) FG 2 EX Tank regions during global waste disturbing activities 
HNF-SD-TWR-TI-003, REV. 3

Risk Acceptance for Cover Blocks, Flanges, Shield Plugs, Waste Intrusive and Non Waste Disturbing Equipment.

These $i$ tems are potential mechanical spark sources due their material. Fabrication of the $i$ tems from nonsparking materials is not practical or cost effective.

Concern is when a spark occurs coincident with a flammable gas mixture $>100 \%$ lower flammability limit ( $L F L$ ). Per Appendix A of WHC-SD-WM-JCO-007, Rev OA (Draft), vapor space sample results for single-shell tanks indicate that approximately $70-90 \%$ of the tanks show negligible or nondetectable flammable gas levels during non waste intrusive work. The remaining $10-30 \%$ of the tanks average $1.2-1.5 \%$ of the LFL. The highest CGM measurement ( $7 \%$ recorded to date using the organic vapor monitor (OVM) samples equated to approximately $3.5 \%$ of the LFL. The highest vapor sample correlates to $2.51 \%$ of the LFL. One IMUST tank sampled showed no flammable gas present. The highest recorded organic concentration, $3.8 \%$ of the LFL, was found in $241-c-103.241-c-103$ is the only waste tank known to have a significant floating organic layer. since July 1996 , one tank has shown a $10 \%$ of the LFL CGM reading ( $5 \%$ of the LFL), and one showed a $13 \%$ LFL CGM reading $(6.5 \%$ LFL) prior to intrusive activities. Actively ventilated tanks would be expected to have low flamiable gas levels because of the constant dilution air passing through the tanks. No actively ventilated single-shell tanks have shown flamable gas levels above minimum detectible levels in either the Type 3 or 4 vapors samples or in the special OVM samples taken in these tanks.

The following can be summarized concerning the risk with using the tools and equipment:

The use of this equipment is required to perform much of the work in Tank Farms. This includes temperature, pressure and level monitoring, transfers, sampling, and installation of equipment.

These items often warrant critical lift procedures which involve controlled insertion/removal speed, drop precautions, and movement restrictions which collectively provide mechanical spark control.

Flammable gas levels have not been seen in excess of the LFL in the tank dome for any tank except in pre-mitigated 241-s\%-101 during one or more GREs. In approximately $80 \%$ of the single-shell tanks that have been sampled the flammable gas is below detectable levels. In the remaining $20 \%$ of the single-shell tanks the flammable gas is less than $2 \%$ of the LFL, except for $2-3$ specific readings which have ranged up to $6.5 \%$ of the L.FL. The presence of flammable gases in actively ventilated single-shell and double-shell tanks would be expected to be low because of the constant dilution air. Although the presence of $f$ lammable gas concentrations in Ex Tank and Dome Intrusive areas above the LFL cannot be positively ruled out, they can be expected to be a rare occurrence.

Based upon the following, continued use of the tools and equipment in Tank Farms poses a low risk of causing a flammable gas ignition event; a) the need to use the tools and equipment to operate tank farms, b) many of the items are installed using critical (ift procedures, and c) the small percent of the time that flammable gas levels might be above the LFL in a Dome Intrusive region.

The risk associated with continuing use of the tools and equipment is further reduced by performing $f$ larmable gas monitoring of the work area prior to and during use. This will include monitoring per method [A], [B] or in certain instances [C] where items are being lowered into or removed from the waste. See definition of monitoring methods at the end of this section. This monitoring is in compliance with the monitoring requirements referenced by RL letter $96-W S D-283$.

When flammable gas levels reach $25 \%$ of the $L F L$, work ceases as required per the monitoring requirements referenced in section 8.0 of the standing orders. The National Fire Protection Association (NFPA 30, 1988) recomends that processes be controlled so that flammale gas concentrations are <25 percent of the $i$ ower flammability limit (LFL), when relying upon vapor space flammability levels to preclude the possibility of an ignition. DOE order 5480.4 requires Hanford waste tanks to be operated within NFPA guidelines. Thus, a control of $<25 \%$ of the LFL has been establ ished for performing activities in and around Tank Farm

facilities. Because of the unpredictable nature of GREs, it is not possible to ensure that $25 \%$ of the LFL is nevier exceeded. Procedures and controls are thus in place to minimize the potential for a tank to exceed $25 \%$ of the LFL, and to cease work in areas common with the tank vapor space when the flammable gas concentration exceeds this value. This $25 \%$ limit is far below the actual limit at which flammability can occur, and is conservatively chosen to allow for potential measurement.

Monitoring is normally performed with a portable CGM. The CGM is calibrated with pentane and reads high by $100 \%$ when monitoring for hydrogen in air. For conservatism, no correction factor is applied in the field to the CGM reading when used for monitoring for personnel protection. Thus a $25 \%$ of the LFL reading on a CGM is actually $12.5 \%$ of the LFL for hydrogen in air, but is treated as if it were $25 \%$. Depending upon the concentration of the flammable gas constituent and oxidants (ammonia, methane, carbon monoxide, nitrous oxide) a $25 \%$ LFL CGM reading will be indicative of $12.5 \%$ to approximately $20 \%$ flammable gas mixture. The response time of a CGM to an increase in flamable gas concentration is not instantaneous. The CGM starts responding to an increase in flammable gas concentrations almost immediately upon the gas reaching the cGM internals. The internal response time for a CGM to reach a $10 \%$ of the LFL indication ( $5 \%$ LFL actual for hydrogen in air) when exposed to a $23 \%$ of the LFL pentane mixture (equivalent to a $11.5 \%$ of the LFL hydrogen in air mixture) ranged from 7-12 seconds in a number of informal tests. Time to reach the full $23 \%$ test gas indication took $20-40$ seconds. 
If the CGM is drawing a sample out of a tank dope space, the time for the tank vapors to reach the CGM is approximately 26 seconds, based upon the $500 \mathrm{~cm}^{3} / \mathrm{min} \mathrm{CGM} \mathrm{flow}$ and the tubing currently used for flammable gas monitoring. Thus an instantaneous change from 0 to $12.5 \%$ of the LFL for hydrogen in air in a tank vapor space (an indicated $25 \%$ of the LFL) would not indicate any change at all on a CGM for about 26 seconds. At 26 seconds, the indicated LFL would begin to rise and 33-36 seconds after the step change the cGM would indicate about $10 \%$ of the LFL. The CGM would indicate $25 \%$ of the LFL approximately $45-65$ seconds after the step change.

If the CGM was being used to sample the immediate work area, the 26 second delay would not apply, the CGM woutd start to rise immediately and a reading of $10 \%$ of the LFL would be noted $7-12$ seconds after sensing a $25 \%$ step increase in the LFL.

It is not real istic to have an instantaneous step change from $0 \%$ of the LFL to $100 \%$ of the LFL in an Ex Tank area. Therefore, a CGM is an acceptable instrument to use for flamable gas monitoring in these areas as long as work is halted upon significant increase in the indicated flammable gas levels. An instantaneous step increase in an entire tank dome vapor space concentration from 0 to $100 \%$ of the LFL also is not real istic due to the large volume of gas which would be required to be released. However, localized spots near the waste surface could show a quick step change to $>100 \%$ of the LFL from relatively small releases of gases from below the waste surface. The risk is very low that a gas stream would be released from the waste surface of a 75 foot diameter tank and enter a 4 inch diameter riser directly above without the gas being partially diffused by tank vapors. The response time for cGls is not a concern when monitoring prior to or during use of this equipment.

It is necessary to balance the minimal time at risk and the $r i s k$ of a mechanical sparking with the environmental and nuclear safety compliance enabled by the use of this equipment. 


\section{ITEM CLASSIFICATION: NON-DE MINIMIS}

ITEM NUMBER: 10,11

EQUIPMENT: Pressure switches, limit switches and leak detector for saltwell pumping 241-T-104 and 241-BY-109

CATEGORY: Electrical Spark Potential

USE:

Used to detect leaks, ensure proper valve positioning and provide pump pressure detection during saltwell pumping.

APPLICABLE CONTROL NOT MET:

ICS 2 \#2
WHEN CONIROL NOT MET:

FG 3 Dome Intrusive (GWD)

\section{DISCUSSION OF STANDING ORDER APPLICABILITY:}

The above equipment are items that are currently installed for saltwelt pumping Tanks 241-T-104 and 241-BY-109. These items are located in the saltwell pump pit and although potential spark sources, they would only do so under the following conditions; 1) if the pump or jumper were to develop a (eak, 2) a valve were to leak through or not seat proper(y, 3) high or (ow pressures were detected in the pump assembly, and 4) if valving were realigned during pumping. The exercising of these instruments results in a low time at risk for sparking. The Standing Order ICS \#2 requirements are only applicable for these pieces of equipment during saltwell pumping or any global waste disturbing activity.

Tank 241-BY-109 is listed as a Facility Group 2 tank in the standing orders. This tank will be moved to Facility Group 3 in the near future pending approval by RL. Pumping of Facility Group 2 tanks is not allowed by the standing orders. Pumping of 241-BY-109 will not commence without its transfer to Facility Group 3, and approval of the requested exception by $R L$.

\section{RISK ACCEPTANCE:}

See risk acceptance writeup starting on next page.

IMPACT OF NOT ACCEPTING RISK OF CONTINUED USE:

Facility Group 1 Tanks-N/A

Facility Group 2 Tanks-N/A

Facility Group 3 or other Tanks-Will delay interim stabilization of 241-T-104, potential impact to Iri-Party Agreement milestones and increased radialogical exposure to personnel.

REQUESTED APPROVAL FROM DOE:

Cont inued use of the above equipment with pit monitoring with installed flammable gas monitor and monitoring per method [C] in:

1) Tank 241-T-104 glabal waste disturbing activities.

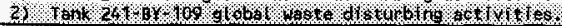


The scope of this discussion is limited to potential electrical spark ignition events from the listed equipment in the 241-T-104 and 241-BY-109 pump pits. The pressure switches, limit switches and leak detector are installed.

Tank 241-T-104 has been pumped for 7 months prior to its shutdown. Continuous flammable gas monitoring of the pump pit has consistently indicated less than detectible levels of $f(a m m a b l e ~ g a s e s(<3 \% L F L)$. It is estimated that pumping of this tank will be completed within three months of restart.

Tank 241-BY-109 has been pumped intermittently over the past several years. The highest flammable gas levels seen in the pump pit during the six weeks of purnping commencing September 10,1996 was $<10 \%$ of the LFL. During the previous pumping campaign in September 1995 the highest concentration shown in the tank dome space on the installed SHMS cabinet was $12 \%$ of the LFL for a two-hour period. The pump pit flamable gas monitor was installed after September 1995. The pump pit flamable gas monitor in 241-BY-109 deenergizes equipment in the pit at $10 \%$ of the LFL. It is estimated that pumping of this tank will be completed with in three months of restart.

Concern is when a spark occurs coincident with a flamable gas mixture $>100 \%$ lower flammability limit (LFL). Per Appendix A of WHC-SD-WM-JCO-007, Rev DA (Draft), vapor space sample results for single-shell tanks indicate that approximately $70-90 \%$ of the tanks show negligible or nondetectable flammable gas levels during non waste intrusive work. The remaining $10-30 \%$ of the tanks average $1.2-1.5 \%$ of the LFL. The highest CGM measurement $(7 \%$ ) recorded using the organic vapor monitor (OVM) samples equated to approximately $3.5 \%$ of the LFL. The highest vapor sample results obtained via Type B/Type 4 vapor sampling correlates to $2.51 \%$ of the LFL. One 1MUST tank sampled showed no flammable gas present. The highest recorded organic concentration, $3.8 \%$ of the LFL, was found in $249-C-103.241-C-103$ is the only waste tank known to have a significant floating organic layer. Since July 1996, one tank has shown a $10 \%$ of the LFL CGM reading $(5 \%$ of the $L F L$ ), and one showed a $13 \%$ LFL CGM reading ( $6.5 \%$ LFL) prior to intrusive activities. Actively ventilated tanks would be expected to have low flamable gas levels because of the constant dilution air passing through the tanks. No actively ventilated single-shell tanks have shown flammable gas levels above minimum detectible levels in either the Type 3 or 4 vapors samples or in the special OVM samples taken in these tanks.

The following can be sumarized concerning the risk with using the listed equipment:

1) The equipment is essentiat to the most cost effective and expeditious interim stabilization of ranks $241-\mathrm{T}-104$ and $241-\mathrm{BY}-109$.

2) No $f$ lammable gas has been detected in the pump pit throughout the 241-T-104 saltwell pumping campaign.

3) Tank 241-T-104 has pumped for 7 months atready, with three-months pumping estimated to remain. Flammable gas has been detected at $12 \%$ of the LFL in the 241-BY-109 vapor space for a very short period in September 1995.

Flammable gas has not been detected above the 10\% deenergizing setpoint in the pump pit. since the pump pit flammable gas monitor was installed.

5) Tank 241-BY-109 has been pumped intermittently for several years, with one month pumping estimated to remain.

The risk associated with continuing use of the equipment is further reduced by continuous flammable gas monitoring of the pit area with the installed pit flamable gas monitor during pumping. In addition, this includes monitoring per method [C]. See definition of monitoring methods at the end of this section. This monitoring is in compliance with the monitoring requirements referenced by RL Letter 96-WSO-283.

The design and configuration of the saltwell purning equipment in 241-T-104 and 241-BY-109 measures $\mathrm{flammable}$ gas levels in the pit area and deenergizes all electrical equipment in the pit upon detection of $10 \%$ LFL.

Stabilization of 241-T-104 and 241-BY-109 reduces the chance of an environmental release and is an M-41 TriParty Agreenent milestone. These benefits must be balanced against the minimal risks of a $f($ ammable gas ignition event due to a spark from the pit equipment. The increased risk of using this existing equipment is judged to be minimal if not equivalent due to the short pumping time remaining (approximately three months for 241-T-104 and one month for 241-BY-1(19) and the use of the continuous flammable gas monitor with automatic deenergization of equipment on detection of $10 \% \mathrm{LFL}$. Additionally, modification of this equipment would increase the potential for radiological exposure to the maintenance and operation crews and the potential for a spread of contamination to the environment. It will rake an estimated 20 man REM to modify equipment in the 241-BY-109 pump pit to meet the standing orders if this exception is not approved. 


\section{ITEM CLASSIFICATION: NON-DE MINIMUS}

ITEM NUMBER: 12

EQUIPMENT: Core Sampl ing Equipment-Remote Latch Unit (RLU), H-2-91665 Truck 1

CATEGORY: Electrical Spark Potential

USE:

Used for raising and lowering sampler in drill string.

APPLICABLE CONTROL NOT MET:

ICS 1 \#5
WHEN CONTROL NOT MET:

FG 2,3 waste Intruding Equipment

DISCUSSION OF STANDING ORDER APPLICABILITY:

The Truck 1 RLU is a sealed electrical unit which cannot demonstrate equivalency with the standing orders urder all applied conditions. The FGEAB has deternined that the RLU for Trucks 2 and 3 meet equivalence with the standing order, with monitoring of the nitrogen pressure and shutdown upon loss.

RISK ACCEPTANCE:

See risk acceptance writeup starting on next page.

IMPACT OF NOT ACCEPTING RISK OF CONTINUED USE:

Facility Group 1 Tanks-No impact.

Facility Group 2 Tanks-will stop all push mode core sampling (PMCS) and retained gas sampling (RGS) with Truck 1 unt il a different RLU is fabricated and installed.

Facility Group 3 or other Tanks-Will stop all PMCS and RGS with Truck 1 until a different RLU is fabricated and installed.

REQUESTED APPROVAL FROM DOE:

Continued use when performing flammable gas monitoring control [D] for the current RLU with Truck 1 in:

1) FG 2,3 waste intruding equipment. 


\section{Risk Acceptance for Electrical RLU.}

The electrical RLU consists of a DC motor sealed inside of a steel housing. There is a potential spark source only when the RLU is energized. There is an 0-ring seal in the RLU that isolates the electrical motor from the potentially flammable gas environment in the drill string. No RLUs have been known to fail due to liquid leaking past the 0-ring seals into the motor housing, but there is no study that qualifies the seal as a vapor tight barrier.

The RLU is used to retrieve and deposit the sampler at the bottom of the drill string. The motor is energized for about 130 seconds each time the RLU performs this function. The electrical RLU is considered to be a controlled ignition source for Iruck 1 , and its design does not meet verbatim compliance with lcs \#1 which calls for dual barrier protection. The RLU cannot demonstrate equivalency under all of these applied conditions because continuous water immersion cannot be guaranteed.

WHC-SD-WM-TRP-269, REV 0, REPORT ON IGNITABILITY TESTING OF FLAMMABLE GASES IN A CORE SAMPLING DRILL STRING, gives the results of testing done at the Bureau of Mines on the effects of ignition of "worst case" $\mathrm{flammable}$ gas mixtures in a drill string. This testing demonstrated that with a minimum of 28 inches water in the drill string and the drill string vented to the spray wash assembly, an ignition event in the drill

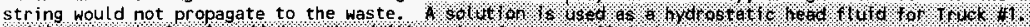

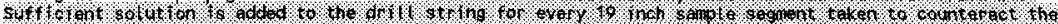

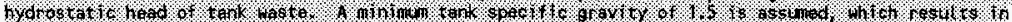

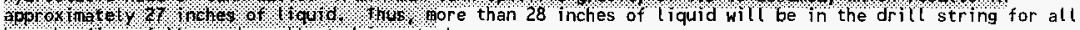
but the first futt sample collected in a tank.

The following can be sumarized concerning the risk with using the electrical RLU:

1) The RLU will not cause an ignition event when submerged.

2) The RLU is normally energized when submerged or when not in communication with the tank vapor space. However, it can be energized in the vapor space.

The DC motor has an 0-ring seal that keeps water out of the RLU and has not failed to date.

4) Testing has shown that an ignition in the drill string will not propagate to the waste if more than 28 inches of liquid is in the drill string. More than $28 \mathrm{in.}$ of liquid will be in the drill string for all but the first one to two segmerits collected from a tank.

The RLU was evaluated and accepted as a Low risk item by the FGEAB for the above reasons even though it does not meet equivalence to the Ignition controls in the standing orders under all applied conditions.

The risk associated with continued use of the existing RLU is further reduced by performing flammable gas monitoring per method $D$. See definition of monitoring methods at the end of this section. This monitoring is in compliance with the monitoring requirements referenced by RL letter 96-WSD-283.

When $\mathrm{flammable}$ gas levels reach $25 \%$ of the $L F L$, work ceases as required per the monitoring requirements referenced in section 8.0 of the standing orders. The National Fire Protection Association (NFPA 30, 1988) recommends that processes be controlled so that $\mathrm{flammable} \mathrm{gas} \mathrm{concentrations} \mathrm{are}<25$ percent of the lower flamability limit (LFL), when relying upon vapor space flamability levels to preclude the possibility of an ignition. DOE Order 5480.4 requires Hanford waste tanks to be operated within NFPA guidelines. Thus, a control of $<25 \%$ of the LFL has been established for performing activities in and around Tank Farm

facilities. Because of the unpredictable nature of GREs, it is not possible to ensure that $25 \%$ of the LFL is never exceeded. Procedures and controls are thus in place to minimize the potential for a tank to exceed 25\% of the LFL, and to cease work in areas common with the tank vapor space when the flammable gas concentration exceeds this value. This $25 \%$ limit is far below the actual limit at which flammability can occur, and is conservatively chosen to allow for potential measurement.

Monitoring is normally performed with a portable CGM. The CGM is calibrated with pentane and reads high by $100 \%$ when monitoring for hydrogen in air. For conservatism, no correction factor is applied in the field to the CGM reading when used for monitoring for personnel protection. Thus a $25 \%$ of the LFL reading on a CGM is actually $12.5 \%$ of the LFL for hydrogen in air, but is treated as if it were $25 \%$. Depending upon the concentration of the $\mathrm{ftammable}$ gas constituent and oxidants (ammonia, methane, carbon monoxide, nitrous oxide) a $25 \%$ LFL CGM reading will be indicative of $12.5 \%$ to approximately $20 \%$ of the LFL. The response time of a CGM to an increase in flammable gas concentration is not instantaneous. The CGM starts responding to an increase in flammable gas concentrations almost immediately upon the gas reaching the CGM internals. The internat response time for a CGM to reach a $10 \%$ of the LFL indication ( $5 \%$ LFL actual for hydrogen in air) when exposed to a $23 \%$ of the LFL pentane mixture (equivalent to a $11.5 \%$ of the LFL hydrogen in air mixture) ranged from 7-12 seconds in a number of informal tests. Time to reach the full $23 \%$ test gas indication took 20-40 seconds.

If the CGM is drawing a sample out of a tank dope space, the time for the tank vapors to reach the CGM is approximately 26 seconds, based upon the $500 \mathrm{~cm}^{3} / \mathrm{min}$ CGM flow and the tubing currently used for flamrnable gas monitoring. Thus an instantaneous change from 0 to $12.5 \%$ of the LFL for hydrogen in air in a tank vapor space (an indicated $25 \%$ of the LFL) would not indicate any change at all on a CGM for about 26 seconds. At 26 seconds, the indicated LFL. would begin to $r$ ise and 33-36 seconds after the step change the CGM would indicate about $10 \%$ of the LFL. The CGM would indicate $25 \%$ of the LFL approximately $45-65$ seconds after the step change. 
If the CGM was being used to sample the drill string, the 26 second delay would not apply, the CGM would start to rise immediately and a reading of $10 \%$ of the LFL would be noted $7-12$ seconds after sensing a $25 \%$ step increase in the LFL.

A CGM is an acceptable instrument to use for flammable gas monitoring in Dome Intrusive and waste Intruding Equipment regions as long as work is halted upon significant increase in the indicated flammable gas levels. An instantaneous step increase in an entire tank dome vapor space concentration from 0 to $100 \%$ of the $L \mathrm{FL}$ also is not realistic due to the large volume of gas which would be required to be released, although localized spots near the waste surface could show a quick step change to >100\% of the LFL from relatively small releases of gases from below the waste surface. The risk is very low that a gas stream would be released from the waste surface of a 75 foot diameter tank and enter a one inch diameter drill bit opening directly above without the gas being partially diffused by tank vapors. High flanmable gas concentrations in a drill string can, and have, occurred during times the drill string is classified as a waste Intruding Equipment region. Monitoring is performed continually during the sampler removal process and movement halted when high levels appear. The RLU would not be energized at this time.

The use of the existing RLU until a non-electric unit can be installed will permit PMCS and RGS to continue. The benefits to safety issue resolution and environmental compliance enabled by PMCS and RGS must be balanced against the minimal time at risk associated with the RLU motor when not fully submerged.

Truck \#1 is currently deployed on 241-U-103. The first core in this tank was partially completed when all sampling operations were halted October 1996. The next five tenks scheduled to be sampled with Truck \#1 are al! Facility Group 2 tanks, and include 241-5-106, 241-BY-101, 241-BY-109, 241-A-103, 241-5X-106, and 241-S-112. Core sampling with Truck \#1 bevond February 15, 1997 will be performed with a fully compliant RLU design. 


\section{ITEM CLASSIFICATION: NON-DE MINIMUS}

\begin{tabular}{|c|c|}
\hline \multicolumn{2}{|c|}{$\begin{array}{l}\text { ITEM NUMBER: } 13 \\
\text { EQUIPMENT: Core Sampl ing Equipment-Sh } \\
\text { CATEGORY: Electrical Spark Potential }\end{array}$} \\
\hline \multicolumn{2}{|l|}{$\begin{array}{l}\text { USE : } \\
\text { Used for sensing force on RLU. }\end{array}$} \\
\hline $\begin{array}{l}\text { APPLICABLE CONTROL NOT MET: } \\
\text { ICS } 1 \text { \#5 }\end{array}$ & $\begin{array}{l}\text { WHEN CONTROL NOT MET: } \\
\text { FG } 2,3 \text { Waste Intruding Equipment }\end{array}$ \\
\hline \multicolumn{2}{|c|}{ 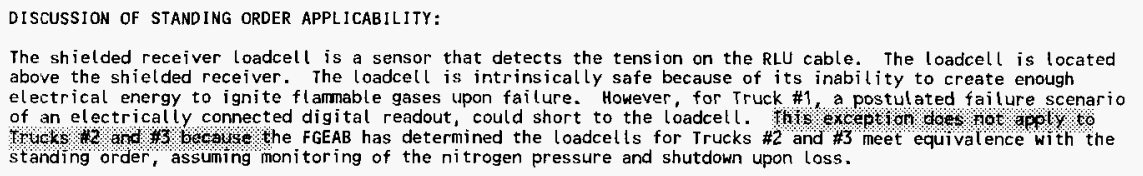 } \\
\hline \multicolumn{2}{|c|}{$\begin{array}{l}\text { RISK ACCEPIANCE: } \\
\text { See risk acceptance writeup starting on next page. }\end{array}$} \\
\hline \multicolumn{2}{|c|}{$\begin{array}{l}\text { IMPACT OF NOT ACCEPTING RISK OF CONIINUED USE: } \\
\text { Facility Group } 1 \text { Tanks-No impact. } \\
\text { Facility Group } 2 \text { Tanks-Will stop all PMCS and RGS with Truck } 1 \text { until an intrinsic safety barrier for the loadcell } \\
\text { is fabricated and installed. } \\
\text { Facility Group } 3 \text { or other Tanks-Will stop all PMCS and RGS with Truck } 1 \text { until an intrinsic safety barrier for the } \\
\text { loadcell is fabricated and installed. }\end{array}$} \\
\hline $\begin{array}{l}\text { REQUESTED APPROVAL FROM DOE: } \\
\text { Continued use when performin } \\
\text { 1) FG } 2,3 \text { waste intruding e }\end{array}$ & rol [D] and [G] for the RLU loadcell with Truck 1 in: \\
\hline
\end{tabular}


Risk Acceptance for shielded receiver loadcell and assembly, Truck \#1, H-2-91653.

The shielded receiver loadcell senses the weight/downforce on the RLU cable to enable personnel to detect when a sampler is attached to the loadcell, and whether a sampler is seated in the core barrel. This loadcell is not capable of causing an ignition event by itself, but postulated failure of an associated digital readout could send a $110 \mathrm{~V}$ signal to the loadcell. This voltage could destroy the loadcell, but it may be conservatively assumed that the voltage will cause the loadcell to spark.

The design does not meet equivalency with ICS \#1 which calls for a dual barrier protection. ICS \#1 controls are required since the drill string and shielded receiver are waste intruding equipment at times during core sampling. High flammable gas levels have occurred in the drill string during Truck 1 operations in the past. The presence of high flammable gas levels in the drill string has been minimized by procedural changes. The presence of high flamable gas levels cannot be eliminated so administrative controls are in place to deenergize the loadcell when high flammable gas levels occur in the drill string.

WHC-SD-WM-TRP-269, REV 0, REPORT ON IGNITABILITY TESTING OF FLAMMABLE GASES IN A CORE SAMPLING DRILL STRING, gives the results of testing done at the Bureaw of Mines on the effects of ignition of "worst case"

flammable gas mixtures in a drill string. This testing demonstrated that with a minimum of 28 inches water in the drill string and the drill string vented to the spray wash assembly, an ignition event in the drill string would not propagate to the waste. More than 28 inches of liquid will be in the drill string for all but the first full sample taken in a tank.

The following can be summarized concerning the risk with using the RLU loadcell:

1) The loadcell itself will not cause an ignition event.

2) Failure of a connected component could cause voltage to the loadcell that could result in a spark.

3) Flamable gas levels above $25 \%$ of the L.FL have occurred in the drill string. Procedure steps have been changed to minimize this from reoccurring.

4) Testing has shown that an ignition in the drill string will not propagate to the waste if more than 28 inches of liquid is in the drill string. More than 28 inches of liquid will be in the drill string for all but the first one to two segments taken from a tank.

The risk associated with continued use of the existing loadcell is further reduced by performing flarmable gas monitoring inside the drill string when it is a waste intruding equipment region. This includes monitoring per methods $D$ and $G$. This monitoring will include a 5 minute pause, with electrical equipment exposed to the drill string vapors deenergized, following breaking of the seal between the sampler and the drill string. A similar deenergized pause is made when the sampler has cleared the calculated hydrostatic head level in the drill string. See definition of monitoring methods at the end of this section. This monitoring is in compliance with the monitoring requirements referenced by RL Letter 96-WSD-283.

When $\mathrm{flammable}$ gas levels reach $25 \%$ of the $\mathrm{LLL}$, work ceases as required per the monitoring requirements referenced in section 8.0 of the standing orders. The National Fire Protection Association (NFPA 30, 1988) recommends that processes be controlled so that $f$ lammable gas concentrations are < 25 percent of the lower flarmability Limit (LFL), when relying upon vapor space flammability levels to preclude the possibility of an ignition. DOE Order 5480.4 requires Hanford waste tanks to be operated within NFPA guidel ines. Thus, a control of $<25 \%$ of the LFL has been established for performing activities in and around Tank Farm facitities. Because of the unpredictable nature of GREs, it is not possible to ensure that $25 \%$ of the LFL is never exceeded. Procedures and controls are thus in place to minimize the potential for a tank to exceed $25 \%$ of the LFL, and to cease work in areas common with the tank vapor space when the flamnable gas concentration exceeds this value. This $25 \%$ timit is far below the actual limit at which flammability can occur, and is conservatively chosen to allow for potential measurement.

Monitoring is normally performed with a portable CGM. The CGM is calibrated with pentane and reads high by $100 \%$ when monitoring for hydrogen in air. For conservatism, no correction factor is applied in the field to the CGM reading when used for monitoring for personnel protection. Thus a $25 \%$ of the LF $L$ reading on a CGM is actually $12.5 \%$ of the LFL for hydrogen in air, but is treated as if it were $25 \%$. Depending upon the concentration of the flammable gas constituent and oxidants (ammonia, methane, carbon monoxide, nitrous oxide) a $25 \%$ LFL CGM reading will be indicative of $12.5 \%$ to approximately $20 \%$ of the LFL. The response time of a CGM to an increase in $\mathrm{flammable} \mathrm{gas} \mathrm{concentration} \mathrm{is} \mathrm{not} \mathrm{instantaneous.} \mathrm{The} \mathrm{CGM} \mathrm{starts} \mathrm{responding} \mathrm{to}$ an increase in $\mathrm{flammable} \mathrm{gas} \mathrm{concentrations} \mathrm{almost} \mathrm{immediately} \mathrm{upon} \mathrm{the} \mathrm{gas} \mathrm{reaching} \mathrm{the} \mathrm{CGM} \mathrm{internals.} \mathrm{The}$ internal response $t$ ime for a CGM to reach a $10 \%$ of the LFL indication ( $5 \%$ LFL actual for hydrogen in air) when exposed to a $23 \%$ of the LFL pentane mixture (equivalent to a $11.5 \%$ of the LFL hydrogen in air mixture) ranged from 7-12 seconds in a number of informal tests. Time to reach the full $23 \%$ test gas indication took $20-40$ seconds.

If the CGM is drawing a sample out of a tank dope space, the time for the tank vapors to reach the CGM is approximately 26 seconds, based upon the $500 \mathrm{~cm}^{3} / \mathrm{min} \mathrm{CGM} f \mathrm{fl}$ and the tubing currently used for flammable gas monitoring. Thus an instantaneous change from 0 to $12.5 \%$ of the LFL for hydrogen in air in a tank vapor space (an indicated $25 \%$ of the LFL) would not indicate any change at all on a CGM for about 26 seconds. At 26 seconds, the indicated LFL would begin to rise and 33-36 seconds after the step change the CGM would indicate about $10 \%$ of the LFL. The CGM would indicate $25 \%$ of the LFL approximately $45-65$ seconds after the step change. 
If the CGM was being used to sample the drill string, the 26 second delay would not apply, the CGM would start to rise immediately and a reading of $10 \%$ of the LFL would be noted 7-12 seconds after sensing a $25 \%$ step increase in the LFL.

A CGM is an acceptable instrument to use for flamable gas monitoring in Dome Intrusive and waste Intruding Equipment regions as long as work is hatted upon significant increase in the indicated flammable gas levels. An instantaneous step increase in an entire tank dome vapor space concentration from 0 to $100 \%$ of the LFL also is not realistic due to the large volume of gas which would be required to be released, although localized spots near the waste surface could show a quick step change to $>100 \%$ of the LFL from relatively small releases of gases from below the waste surface. The risk is very low that a gas stream would be released from the waste surface of a 75 foot diameter tank and enter a one inch diameter drill bit opening directly above without the gas being partially diffused by tank vapors. High flammable gas concentrations in a drill string can, and have, occurred during times the drill string is classified as a Waste intruding Equipment region. Monitoring is performed continuously during the samplec removal process and movement is halted and equipment is deenergized when high levels appear.

The use of the existing loadcell until an intrinsic safety barrier fan be installed will permit PMCS and RGS to continue. The benefits to safety issue resolution and environnental compliance enabled by PMCS and RGS must be balanced against the minimal time at risk associated with the existing loadcell.

Truck \#1 is currently deployed on 241-U-103. The first core in this tank was partially completed when all sampling operations were halted October 1996. The next five tanks scheduled to be sampled with Iruck $\# 1$ are all Facility Group 2 tanks, and include 241-S-106, 241-BY-101, 241-BY-109, 241-A-103, 241-5K-106 and 241-\$-112. Core sampling with Truck \#1 beyond April 15, 1997 will be performed with an intrinsic safety barrier for the loadcell. 
HNF-SD-TWR-TI-003, REV. 3

\section{ITEM CLASSIFICATION: NON-DE MINIMUS}

ITEM NUMBER: 14

EGUIPMENT: Core Sampling Equipment-Shielded Receiver Weathercover - hoist, limit switches Iruck \#1 H-2-9165?, $H-2-91653$

CATEGORY: Electrical Spark Potential

USE:

Used for raising the remote latch unit (RLU) and samoler.

APPLICABLE CONTROL NOT MET:

WHEN CONTROL NOT MET:

ICS 1 \#5

FG 2,3 Waste Intruding Equipment

DISCUSSION OF STANDING ORDER APPLICABILITY:

The barrier separating the potentially flamable gas environment in the shielded receiver from the weathercover vapor space is not vapor tight. The shielded receiver hoist motor and limit switches are located in the

weathercover vapor space. Therefore, the design for Truck \#1 does not meet ICS 1 control \#5. The weathercover for Irucks \#2 and \#3 meet the standing order due to the purged and pressurized enclosure.

RISK ACCEPIANCE :

See risk acceptance writeup starting on next page.

IMPACT OF NOT ACCEPTING RISK OF CONTINUED USE:

Facility Group 1 Tanks-No impact.

Facility Group? Ianks-will stop all PMCS and RGS with Iruck 1 until a compliant design is installed for the weathercover.

Facility Group 3 or other Ianks-Will stop all PMCS and RGS with Truck 1 until a compliant design is installed for the weathercover.

REQUESTED APPROVAL FROM DOE:

Continued use when performing flammable gas monitoring control [D] and [G] for the weathercover for Iruck 1 in:

1) FG 2,3 waste intruding equipment. 
Risk Acceptance for eguipment common with shielded receiver weathercover vapor space.

The drill string vents to the shielded receiver via a small opening. The shielded receiver is vented to its weathercover via a small filtered opening. Flammable gases in the drill string could migrate to the weathercover vapor space where ignition by sparks from the hoist motor or limit switches could occur.

The design does not meet verbatim compliance with ICS \#1 which calls for dual barrier protection. ICS \#1 controls are required since the drill string and shielded receiver are waste intruding equipment at $t$ imes during core sampling. High flammable gas levels have occurred in the drill string during Truck 1 operations in the past. The presence of high flammable gas levels in the drill string has been minimized by procedural changes. The presence of high flammable gas levels cannot be eliminated therefore, administrative controls are in place to deenergize the hoist motor and limit switches when high flammable gas levels occur in the drill string.

WHC-SD-WM-TRP-269, REV 0, REPORT ON IGNITABILITY TESTING OF FLAMMABLE GASES IN A CORE SAMPLING DRILL STRING, gives the results of testing done at the Bureau of Mines on the effects of ignition of "worst case" $\mathrm{flam}$ able gas mixtures in a drill string. This testing demonstrated that with a minimum of 28 inches water in the drill string and the drill string vented to the spray wash assembly, an ignition event in the drill string would not propagate to the waste. More than 28 inches of liquid will be in the drill string for all but the first full sample taken in a tank.

The following can be summarized concerning the risk with using the hoist motor and limit switches:

The drill string vents via a small opening to the shielded receiver. The shielded receiver vents to the weathercover through a small opening. An ignition event in the weathercover is postulated to propagate back to the drill string, but this is judged to be unlikely.

Flammable gas levels above $25 \%$ of the LFL have occurred in the drill string before. Procedure steps have been changed to minimize this from occurring in the future, but the possibility cannot be el iminated.

Testing has shown that an ignition in the drill string will not propagate to the waste if more than about 28 inches of liquid are in the drill string. More than this amount of tiquid will be in the drill string for all but the first 1-2 segments taken from a tank.

The risk associated with continued use of the existing weathercover is further reduced by performing flamable gas monitoring inside the drill string when it is a waste intruding equipment region. This includes monitoring per methods $D$ and $G$. This monitoring will include a 5 minute pause, with electrical equipment exposed to the drill string vapors deenergized, following breaking of the seal between the sampler and the drill string. A similar deenergized paluse is made when the sampler has cleared the calculated hydrostatic head level in the drill string. See definition of monitoring methods at the end of this section. This monitoring is in compliance with the monitoring requirements referenced by RL Letter $96-w S 0$ 283 .

When 4 lammable gas levels reach $25 \%$ of the $L F L$, work ceases as required per the monitoring requirements referenced in section 8.0 of the standing orders. The National Fire Protection Association (NFPA 30, 1988) recommends that processes be controlled so that flamable gas concentrations are < 25 percent of the lower flamability limit (LFL), when relying upon vapor space flamability levels to preclude the possibility of an ignition. DOE order 5480.4 requires Hanford waste tanks to be operated within NFPA guidel ines. Thus, a control of $<25 \%$ of the LFL has been established for performing activities in and around Tank farm

facilities. Because of the unpredictable nature of GREs, it is not possible to ensure that $25 \%$ of the LFL is never exceeded. Procedures and controls are thus in place to minimize the potential for a tank to exceed $25 \%$ of the LFL, and to cease work in areas common with the tank vapor space when the flammable gas concentration exceeds this value. This $25 \%$ limit is far below the actual limit at which flammability can occur, and is conservatively chosen to allow for potential measurement.

Monitoring is normally performed with a portable CGM. The CGM is calibrated with pentane and reads high by $100 \%$ when monitoring for hydrogen in air. For conservatism, no correction factor is applied in the field to the CGM reading when used for monitoring for personnel protection. Thus a $25 \%$ of the LFL reading on a CGM is actually $12.5 \%$ of the LFL for hydrogen in air, but is treated as if it were $25 \%$. Depending upon the concentration of the flammable gas constituent and oxidants cammonia, methane, carbon monoxide, nitrous oxide) a $25 \%$ LFL CGM reading will be indicative of $12.5 \%$ to approximately $20 \%$ of the LFL. The response time of a CGM to an increase in flammable gas concentration is not instantaneous. The CGM starts responding to an increase in flammable gas concentrations almost immediately upon the gas reaching the CGM internals. The internal response time for a CGM to reach a $10 \%$ of the LFL indication ( $5 \%$ LFL actual for hydrogen in air) when exposed to a $23 \%$ of the LFL pentane mixture (equivalent to a $11.5 \%$ of the LFL hydrogen in air mixture) ranged from 7-12 seconds in a number of informal tests. Time to reach the full $23 \%$ test gas indication took $20-40$ seconds.

If the CGM is drawing a sample out of a tank done space, the time for the tank vapors to reach the CGM is approximately 26 seconds, based upon the $500 \mathrm{~cm}^{3} / \mathrm{min}$ CGM $\mathrm{flow}$ and the tubing currently used for flammable gas monitoring. Thus an instantaneous change from 0 to $12.5 \%$ of the LFL for hydrogen in air in a tank vapor space (an indicated $25 \%$ of the $L F L$ ) would not indicate any change at all on a CGM for about 26 seconds. At 26 seconds, the indicated LFL would begin to rise and 33-36 seconds after the step change the CGM would indicate about $10 \%$ of the LFL. The CGM would indicate $25 \%$ of the LFL approximately $45-65$ seconds after the step change. 
If the CGM was being used to sample the dritl string, the 26 second delay would not apply, the CGM would start to rise immediately and a reading of $10 \%$ of the LFL would be noted $7-12$ seconds after sensing a $25 \%$ step increase in the LFL.

A CGM is an acceptable instrument to use for flammable gas monitoring in Dome lntrusive and Waste Intruding Equipment regions as long as work is halted upon significant increase in the indicated flammable gas levels. An instantaneous step increase in an ent ire tank dome vapor space concentration from 0 to $100 \%$ of the LFL also is not realistic due to the large volume of gas which would be required to be released, although localized spots near the waste surface could show a quick step change to $>100 \%$ of the LFL from relatively small releases of gases from below the waste surface. The risk is very low that a gas stream would be released from the waste surface of a 75 foot diameter tank and enter a one inch diameter drill bit opening directly above without the gas being partially diffused by tank vapors. High flamable gas concentrations in a drill string can, and have, occurred during times the drill string is classified as a Waste Intruding Equipment region. Monitoring is performed continually during the sampler removal process and movement is halted and equipment is deenergized when high levels appear.

The use of the existing weathercover design until a compliant design can be implemented will permit PMcs and RGS to continue. The benefits to safety issue resolution and environmental compl $i$ ance enabled by PMCS and RGS must be balanced against the minimal time at risk associated with the operation of equipment conmon with the shielded receiver weathercover.

Truck \#1 is currently deployed on 241-U-103. The first core in this tank was partially completed when all sampling operations were halted October 1996. The next five tanks scheduled to be sampled with Truck \#1 are all Facility Group 2 tanks, and include 241-S-106, 241-BY-101, 241-BY-109, 241-A-103, SX-106 and $241-\mathrm{S}-112$. Core sampling with Truck \#1 beyond April 15, 1997 will be performed with a compliant weathercover design. 
HNF-SD--TWR-TI-003, REV, 3

\section{ITEM CLASSIFICATION: NON-DE MINIMUS}

I TEM NUMBER : 15

EQUIPMENT: Installation, removal, or extended presence of Nonconductive Rubber Matting

CATEGORY: Static Spark Potential

USE:

Used for providing a working surface.

APPLICABLE CONTROL NOT MET:

ICS $2 \# 1$
WHEN CONTROL NOT MET:

FG 1 Ex Tank

FG 2 Ex Tank (GWD)

\section{DISCUSSION OF STANDING ORDER APPLICABILITY:}

Rubber matting is used routinely in Ex Tank regions. Rubber matting provides a safe working surface that minimizes tripping and slipping hazards, and permits ease of decontamination. The majority of this matting meets standing order requirements. Some matting in use may not meet the standing orders.

\section{RISK ACCEPTANCE:}

This is an item where worker safety must be balanced with negligible ignition source risk. The risk of not using rubber matting would lead to more personnel accidents, contamination spread, and environmental contamination. This would restrict some work in the above listed Ex Tank regions until noncompliant material is phased out. The resulting delay to tank intrusive work must be balanced with the small risk of a flamable gas ignition event due to a spark from the rubber matting.

Rubber matting is normally used in radiation zones where personnel also wear rubber boots. There will be a small potential for increased static buildup for personnel wearing rubber boots than for personnel with other

noneonductive shoes or shoe covering. Providing adequate contamination control is a more significant concern

than that of a static spark event from a person with rubber boots walking on rubber fmatting. The risk asso:iated with continuing its use is managed by performing flamable gas monitoring, with safe shutdown controls, prior to and during use. This will include monitoring per method [H] for the activity. See definition of monitoring methods at the end of this section. This monitoring is in compliance with the monitoring requirements referenced by RL letter $96-W S D-283$.

IMPACT OF NOT ACCEPIING RISK OF CONTINUED USE:

Facility Group 1 Tanks "Would stop the majority of Ex Tank and most dome intrusive work and waste intruding equipment work.

Facility Group 2 Tanks-Would stop some Ex Tank and most dome intrusive work and waste intruding equipment work during glabal waste disturbing activities.

Facility Group 3 or other Tanks-No Impact.

REQUESTED APPROVAL FROM DOE:

Continued use when performing flamable gas monitoring control [H] for nonconductive rubber matting in:

1) FG 1 EX Tank regions

2) FG 2 EX Tank regions during global waste disturbing activities 


\section{ITEM CLASSIFICATION: NON-DE MINIMUS}

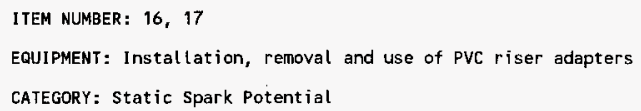

DISCUSSION OF STANDING ORDER APPLICABILITY:

The PVC adapter is an open ended spool piece added to a riser to bring it up to a more workable height, or is used as a specific tool adapter, or issued as an adapter for contamination control. It is in place for the duration of a grab sample, video, or vapor sample job. The PVC riser adapters are installed by removing the riser flange and bolting the adapter in its place. PVC adapters are judged to have a negligible potential for causing a flamable gas ignition under the applied conditions.

\section{RISK ACCEPTANCE :}

See risk acceptance writeup starting on next page.

\section{IMPACT OF NOT ACCEPTING RISK OF CONTINUED USE:}

Facility Group 1 Tanks-Medium impact. Use of carbon steel would result in the introduction of potential mechanical spark sources and an increase in worker safety concerns (i.e.. increased back injuries due to weight). Alternative materials would not be cost effective due to fabrication and disposal costs.

Facility Group 2 Tanks-Same as for FG 1 tanks.

Facility Group 3 or other Tanks-Same as above, but only for grab sampling.

\section{REQUESTED APPROVAL FRON DOE:}

Continued use when performing flammable gas monitoring control [B] for installation or removal of PVC $r i s e r$ adapters in:

1) FG 1 Ex Tank regions

2) FG 1,2 tanks during Dome Intrusive activities

3) FG 3 tanks Done Intrusive regions during local waste disturbing activities

Continued use when performing flamable gas monitoring control [I] when conducting activities through the Pvc riser adapters in:

1) FG 1 EX Tank regions

2) FG 1,2 tanks during Dome Intrusive activities

3) FG 3 tanks Dome Intrusive regions during local waste disturbing activities 


\section{$\forall t-O N$}

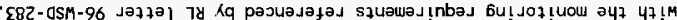

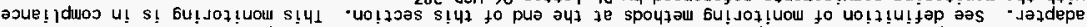

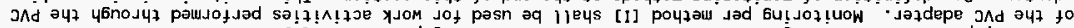

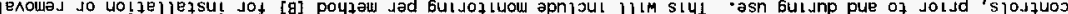

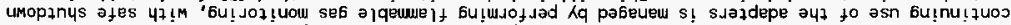

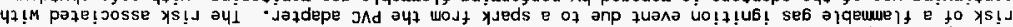

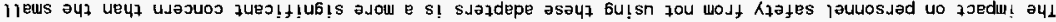

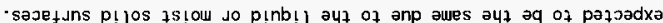

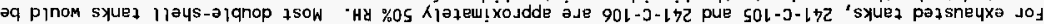

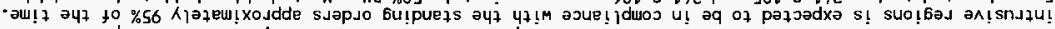

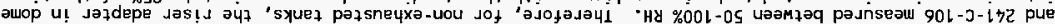

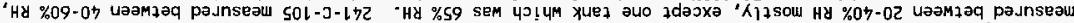

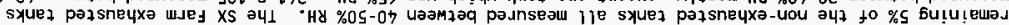

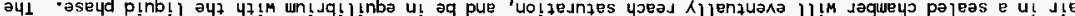

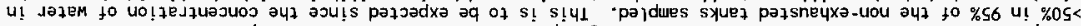

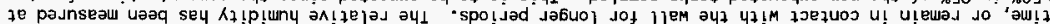

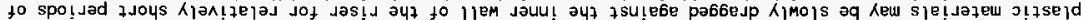

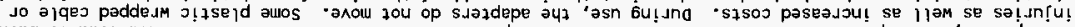

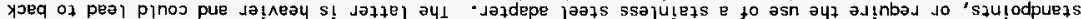

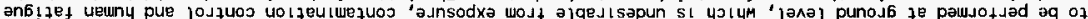

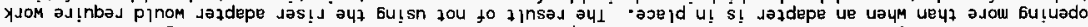

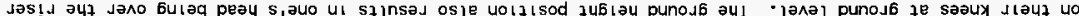

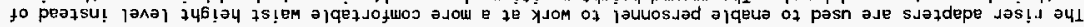




\title{
ITEM CLASSIFICATION: NON-DE MINIMUS
}

\author{
ITEM NUMBER: 18 \\ EQUIPMENT : Fiberglass and Tefzel LOWS \\ CATEGORY: Static Spark Potential
}

USE:

Used for determining interstitial liquid levels.

APPLICABLE CONTROL NOT MET:

WHEN CONTROL NOT MET:

ICS $2 \# 1$, ICS $1 \# 3$

FG 2,3 Dome Intrusive

FG 2,3 waste Intruding Equipment (Failed Lows only)

DISCUSSION OF SIANDING ORDER APPLICABILIIY:

Liquid observation wells are hollow pipes sealed at the bottom that are inserted into many single-shell tanks for measuring the interstitial liquid level. Measurement is done by lowering a neutron source to the bottom of the

LOW and measuring the observed neutron level as the probe is withdrawn. Fiberglass LoWs and Tefzel Lows are judged to have a negligible potential for causing $f$ lammable gas ignition under the applied conditions.

Failed LOWs are waste intruding equipment because of the potential to trap waste gases. A failed LOW is one that has broken or cracked inside the tank and can let waste enter the pipe. Any work inside a known failed Low requires flammable gas monitoring prior to the start.

RISK ACCEPIANCE:

See risk acceptance writeup starting on next page.

IMPACT OF NOT ACCEPTING RISK OF CONTINUED USE:

Facility Group 1 Tanks-No Impact.

Facility Group 2 Tanks -Removal of the LoWs would result in loss of leak detection capability and therefore cause environnental non-compliance. The risk of removing the LOWs is far greater from cost, ALARA, and lack of level monitoring standpoints, than the risk involved with leaving them in place.

Facility Group 3 or other Tanks-Same as for FG 2 tanks.

REQUESTED APPROVAL FROM DOE:

Continued presence and use of $f$ iberglass and Tefzel ${ }^{\circ}$ Lows in tanks without $f$ lammable gas monitoring:

1) FG 2,3 Dome Intrusive regions

Continued presence of failed fiberglass and Tefzel ${ }^{\circ}$ Lows without flammable gas monitoring, or work in a failed fiberglass or Jefzel LoW following flamable gas monitoring control [0] for:

2) FG 2,3 tanks Waste Intruding Equipment 
Risk Acceptance for Fiberglass and Tefzel LOWS.

This is an item where environmental compliance must be balanced against the minimal risk associated with flamable gas ignition due to the presence and use of fiberglass or Tefzel LOWs. The LOWs are already installed in the tanks. The cost in personnel, time, waste disposal, and personnel exposure to remove the LOWs must be balanced with the low risk of a flamable gas ignition event due to a spark from a Low. steel LOWs can be installed as new ones are needed, but these are not compatible for all proposed LOW monitoring methods.

The relative humidity $(\mathrm{RH})$ has been measured to be $>50 \%$ in $95 \%$ of the non-exhausted tanks sampled. This is to be expected since the concentration of water in air in a sealed chamber will eventually reach saturation, and be in equilibrium with the liquid phase. The remaining $5 \%$ of the non-exhausted tanks measured between 40-50\% RH. The SX Farm exhausted tanks measured between 20-40\% RH, except one tank which was $65 \%$ RH. 241-C:-105 measured between 40-60\% RH, and 241-C-106 measured between 50-100\% RH. Therefore, for nonexhausted tanks. plastics in dome intrusive regions are expected to be in compliance with the standing orders about $95 \%$ of the time. For exhausted tanks, 241-c-105 and 241-c-106 are approximately 50\% RH. For the inside of failed LoWs, any concentrated (i.e., non diluted by tank air) waste gases will be at $100 \%$ RH because the gases come from waste pockets surrounded by liquid waste. In such pockets the water vapor in the gas would be at equilibrium with the water in the liquid. The gas in failed Lows will Likely be partially mixed with tank vapors, but as most tank vapors have a high RH, the RH in the failed Lows shoutd be expected to be $>50 \%$. There is negligible air flow across LOWs in service to build up a static charge on them.

For use of intact LOWs, a swab is taken of each LOW prior to work inside the pipe; swabbing and monitoring is currently performed weekly. This is done by running a swab up and down the inside of the Low and monitoring the swab for radioactivity. This is a much more accurate means of detecting a leaking Low than using flamable gas monitoring. Work is rarely performed inside failed LOWs. The only activity in recent years was in confirming a failed LOW in 241-5x-104. When required, monitoring is conducted per method [D].

The presence and use of fiberglass and Tefzel ${ }^{\text {LOWls }}$ is of concern when the LOW has failed such that flammable gas may accumulate and be ignited due to static discharge upon removal of the nonconductive Low cap. The time at risk is reduced to that time which is required to remove a cap. This time is on the order of seconds. The existing LOW caps will be replaced by caps of a suitable material by January 1, 1998. Flamable gas monitoring is not an appropriate control for the routine presence of the LOWs in a tank" vapor space as no response actions are available. It is an acceptable risk based upon experience for the LoWs to remain installed in the tanks without monitoring for flammable gases: 
HNF-SD-TWR-TI-003, REV. 3

\title{
ITEM CLASSIFICATION: NON-DE MINIMUS
}

\author{
ITEM NUMBER: 19 \\ EQUIPMENT: Continuous Air Sampler (SAIC Model \#H-810 and H-809V1)
}

CATEGORY: Electrical Spark Potential

USE :

Used for monitoring for airborne radioactivity

APPLICABLE CONTROL NOT MET:

ICS 2 \#2
WHEN CONTROL NOT MET:

FG 1 Ex Jank

FG 2 Ex Tank (GWD)

DISCUSSION OF STANDING ORDER APPLICABILITY:

The Continuous Air sampler (CAS) uses a $110 \mathrm{v}$ sparking motor to drive the vacuum pump which draws the air sample.

The unit is not in compliance with the standing orders, as it does not meet the requirements of ICS 2 \#2. In

most applications, the sampler draws air from areas requiring ICS 2 controls. The unit will be located is

opening diameters or 15 feet from the tank opening, whichever is less. Plastic hoses will be used to connect the

sampler pump to the sampler head located in the worker's breathing space. Use of the plastic hoses is addressed

in Item 1. Additionally, continuous monitoring for flammable gas while the unit is operating will be employed.

If $\mathrm{flammable} g a s$ concentration in excess of $10 \%$ of the LFL is detected, the unit will be immediately shut off.

RISK ACCEPIANCE:

See risk acceptance writeup starting on next page.

IMPACT OF NOT ACCEPTING RISK OF CONTINUED USE:

Facility Group 1 Tanks-Failure to accept the risk of continued use will shut down all tank intrusive work. All manned activity in Ex Tank areas will be canceled until qualified air samplers which meet requirements can be identified and procured. Essential Ex Tank work may be performed only if workers are on breathing air.

Facility Group 2 Tanks-Failure to accept the risk of continued use will shut down all tank intrusive work during global waste disturbing operations. All manned activity in Ex Tank areas during globally waste disturbing activities will be canceled until qualified air samplers can be identified and procured. During global waste disturbing activities, essential Ex rank work may be performed only if workers are on breathing air.

Facility Group 3 or other Tanks-No Impact.

REQUESTED APPROVAL FROM DOE:

Continued use when performing flamable gas monitoring controls [B] for CASs in:

1) Ex Tank regions in FG 1 tanks.

2) Ex Tank regions in FG 2 tanks (GWD) 
HNF-SD-TWR-TI-003, REV. 3

Risk Acceptance for Continuous Air Sampler.

Use of continuous air samplers for personnel safety is standard in the nuclear industry. At Hanford, the HANFORD SITE RADIOLOGICAL CONTROL MANUAL, HSRC-1, requires air monitoring when appropriate as one of its basic tenets. Sections 125 and 136 both require evaluation of air spaces. Sections 551 and 555 give more specific requirements for this monitoring.

Concern is when a spark occurs coincident with a $f$ lamable gas mixture $>100 \%$ lower flammability limit (LFL). Per Appendix A of WHC-SD-WM-JCO-007, Rev OA (Draft), vapor space sample results for single-shell tanks indicate that approximately $70-90 \%$ of the tanks show negligible or nondetectable flamable gas levels during non waste intrusive work. The remaining $10-30 \%$ of the tanks average $1.2-1.5 \%$ of the $L F L$. The highest CGM measurement ( $7 \%$ ) recorded to date using organic vapor monitor (OVM) samples equated to approximately $3.5 \%$ of the LFL. The highest vapor sample results obtained via Type B/Iype 4 vapor sampling correlates to $2.51 \%$ of the LFL. One IMUST tank sampled showed no flammable gas present. The highest recorded organic concentration, 3.8\% of the $L F L$, was found in 241-C-103. 241-C-103 is the only waste tank knowr to have a significant floating organic layer. Since July 1996 , one tank has shown a $10 \%$ of the LFL CGM reading ( $5 \%$ of the LFL), and one showed a $13 \%$ LFL CGM reading (6.5\% LFL) prior to intrusive activities. Actively ventilated tanks would be expected to have low $f$ lammable gas levels because of the constant dilution air passing through the tanks. No actively ventilated single-shell tanks have shown flammable gas levels above minimum detectible levels in either the Type 3 or 4 vapors samples or in the special ovM samples taken in these tanks.

The following can be summarized concerning the actual risk with using the CAS:

1) Hanford site radiological controls require use of a CAS for many of the operations in tank farms.

Flammable gas levels have not been seen in excess of the LFL in the tank dome space for any tank except in pre-mitigated 241-sY-101 during one or more GREs. In about $80 \%$ of the single-shell tanks that have been sampled the LFL is below detectable. In the remaining $20 \%$ of the single-shell tanks the LFL is less than $2 \%$, except for 2.3 specific readings which have ranged up to $6.5 \%$. The presence of $f$ lammable gases in actively ventilated single-shell and double-shell tanks would be expected to be low most of the time because of the constant dilution air. Therefore, although the presence of flammable gas concentrations in Dome Intrusive areas above the LFL cannot be positively ruled out, they can be expected to be a rare occurrence. The presence of $f$ lammable gases at concentrations $>25 \%$ of the LFL in an Ex Tank area is therefore expected to be eyen less likely.

Based upon the requirement for remote placement of the CAS instrument during work in Ex Tank areas, continuous monitoring and shutdown if flammable gas concentration exceeds $10 \%$ of the LFL, and the iminimat potential for flammable gas concentrations above the LFL in the Ex-Tank area, the Use of the CAS, with the compensatory measures prescribed poses an acceptable risk. This is especially relevant when balanced with the competing safety requirements for the protection of workers during these activities.

When flammable gas levels reach $25 \%$ of the $L F L$, work ceases as required per the monitoring requirements referenced in section 8.0 of the standing orders. The National Fire Protection Association (NFPA 30, 1988) recommends that processes be controlled so that $\mathrm{flammable}$ gas concentrations are <25 percent of the lower flammability limit (LFL), when relying upon vapor space flammability levels to preclude the possibility of an ignition. DOE Order 5480.4 requires Hanford waste tanks to be operated within NFPA guidelines. Thus, a control of $<25 \%$ of the LFL has been established for performing activities in and around Tank Farm facilities. Because of the unpredictable nature of GREs, it is currently not possible to ensure that $25 \%$ of the LFL is never exceeded. Procedures and controls are thus in place to minimize the potential for a tank to exceed $25 \%$ of the LFL, and to cease work in areas common with the tank vapor space when the flammable gas concentration exceeds this value. This $25 \%$ limit is far below the actual limit at which flammability can occur, and is conservatively chosen to allow for potential measurement errors. For the cas the equipment shutdown limit is set more conservatively at $10 \%$ of the LFL.

Monitoring is normally performed with a portable CGM. The CGM is calibrated with pentane and reads high by $100 \%$ when monitoring for hydrogen in air. For conservatism, no correction factor is applied in the field to the LGM reading when used for monitoring for fersonnel protection. Thus a $25 \%$ of the LFL reading on a CGM is actually $12.5 \%$ of the LFL for hydrogen in air, but is treated as if it were $25 \%$. Depending upon the concentration of the flamable gas constituent and oxidants (ammonia, methane, carbon monoxide, nitrous oxide) a $25 \%$ LFL CGM reading will be indicative of $12.5 \%$ to approximately $20 \%$ of the LFL. The response time of a CGM to an increase in flammable gas concentration is not instantaneous. The CGM starts responding to an increase in flammable gas concentrations almost immediately upon the gas reaching the CGM internals. The internal response time for a CGM to reach a $10 \%$ of the LFL indication ( $5 \%$ LFL actual for hydrogen in air) when exposed to a $23 \%$ of the LFL pentane mixture (equivalent to a $11.5 \%$ of the LFL hydrogen in air mixture) ranged from $7-12$ seconds in a number of informal tests. Time to reach the full $23 \%$ test gas indication took $20-40$ seconds.

If the CGM is drawing a sample out of a tank dome space, the time for the tank vapors to reach the CGM is approximately 26 seconds, based upon the $500 \mathrm{~cm}^{3} / \mathrm{min} \mathrm{CGM}$ flow and the tubing currently used for flammable gas monitoring. Thus an instantaneous change from 0 to $12.5 \%$ of the LFL for hydrogen in air in a tank vapor space (an indicated $25 \%$ of the LFL) would not indicate any change at all on a CGM for about 26 seconds. At 26 seconds, the indicated LFL would begin to rise and 33-36 seconds after the step change the CGM would indicate about $10 \%$ of the LFL. The CGM would indicate $25 \%$ of the LFL approximately $45-65$ seconds after the step change. 
If the CGM was being used to sample the immediate work area where a continuous air sampler is being used the 26 second delay would not apply, the CGM would start to rise immediately and a reading of $10 \%$ of the LFL would be noted 7-12 seconds after sensing a $25 \%$ step increase in the LFL.

A CGM is an acceptable instrument to use for flammable gas monitoring in Dome Intrusive or Ex Tank regions as long as work is halted upon significant increase in the indicated flammable gas levels. An instantaneous step increase in an entire tank dome vapor space concentration from 0 to $100 \%$ of the LFL is not realistic due to the large volume of gas which would be required to be released, al though local ized spots near the waste surface could show a quick step change to $>100 \%$ of the LFL from relatively small releases of gases from below the waste surface. The risk is very low that a gas stream would be released from the waste surface of a 75 foot diameter tank and enter a 4 inch diameter riser directly above without the gas being partially diffused by tank vapors. Since monitoring for flamable gases is done in the immediate area when using the CAS, the current response time for CGMs is not a significant concern.

The risk to personnel of internal exposure due to unmonitored airborne radioactivity is a more significant risk than that of a flammable gas ignition event due to a spark from the CAS motor. This competing safety concern requires the monitoring to be performed or the job will be shut down. No site approved CASs are currently available that meet the requirements of the standing orders, and initial attempts to identify an intrinsicalty safe air particulate sampler have failed to identify a substitute. 
Monitoring definitions used in the previous sheets are:

[A] This includes a monitoring of the area for flammable gases prior to conducting the activity.

[B] For dome intrusive activities perform [A] above, plus the monitoring required in section 8.0 of standing orders $96-36$ (East) and 96-34 (West). For dome intrusive work in a riser or pit this includes monitoring for flamable gases a nominal three feet inside the opening. For dome intrusive work in a tank dome space this includes monitoring for flammable gases a noninal three feet below the bottom of the riser.

[C] For waste intrusive activities perform [A] and [B] above, plus the monitoring required in Section 8.0 of Standing orders $96-36$ (East) and 96-34 (West). This requires periodic sampling and recording of the tank dome space $f$ lammable gas levels.

[D] For a waste intruding equipment activity, perform [A] above, plus the monitoring required in Section 8.0 of Standing orders $96-36$ (East) and 96-34 (West). Sampling during waste intrusive activities associated with handling waste intruding equipment is as specified in [C] above. Monitoring associated with the waste intruding equipment shall include monitoring before any equipment item in the waste intruding equipment vapor space is energized, prior to (or during if necessary) connecting/disconnect ing equipment, or prior to working with nonconductive plastic materials. For push mode core sampling with Truck 1 this includes sampling the drill string or shielded receiver; 1) prior to connecting or disconnecting items of equipment from the drill string, 2) prior to energizing the RLU, unpurged electrical equipment or electrical equipment without intrinsic safety barriers, and 3) constantly when raising or towering a sampler in the drill string.

[E] For Type 4 vapor sampl ing perform [B] above, plus monitor the tank dome space for flammable gases continually while the Type 4 vapor sampling system is energized and drawing vapors from the tank dome space.

[F] Monitoring per [B] or [C] above as applicable to operations in the tank at the time, plus cont inuous monitoring of the pit vapor space.

[G] There will be continuous alarmed monitoring of the drill string vapor space during sampler removal. This will include a 5 minute pause, with shutdown of electrical equipment potentially exposed to the vapor space (hoist motor, limit switches, loadcel() located within the weathercover after; 1) the seal between the core sampler and the core barrel is broken, and 2) after the sampler has cleared the calculated liquid level in the drill string.

[H] Monitaring per [A] or [B] above with continuous monitoring of Ex Tank region while manned activity is occurring or non-compliant electrical equipment is operating in the Ex Tank region. Contimuous shall mean the instrument used for monitoring flammable gas levels shall be operable and in service.

[I] Monitoring per [B] or [C] above with continuous monitoring of the Dome Intrusive region while manned activity is occurring through the PVC adapter. Continuous shall mean the instrument used for monitoring flammable gas levels shall be operable and in service. 
DISTRIBUTION SHEET

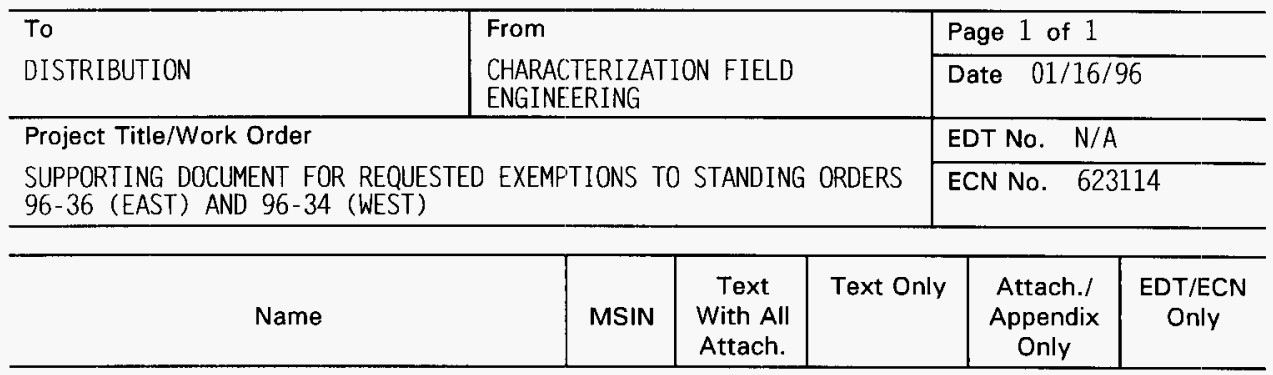

DE\&S Hanford. Inc.

R. J. Cash

W. M. Funderburke

T. C. Geer

C. E. Leach

0. M. Serrano

$57-14$

$\mathrm{R} 2-38$

$\mathrm{R} 2-38$

R1 -49

R2-38

$x$
$x$
$x$
$x$
$x$

Lockheed Martin Hanford Corporation

S. D. Brumley

C. B. Bryan

J. G. Burton

M. P. DeLozier

L. R. Dunbar

M. D. Ebben

L. E. Hal1

M. A. Payne

R. S. Popielarczyk

J. L. Rhoades

W. E. Ross

C. C. Scaief

R. L. Schlosser

D. B. Smet

A. M. Umek

J. H. Wicks

$57-74$

S7-01

T4- 07

S7.85

H5- 24

H5-24

S7-85

S7-84

R2 - 38

$57-84$

S5-07

R1-56

R1 -56

N1-46

S7-81

R2-50

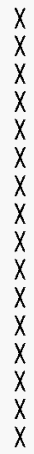

Numatec Hanford Corporation

R. E. Raymond

J. S. Schofield

S7-12

S7 -12

$X$
$X$ 